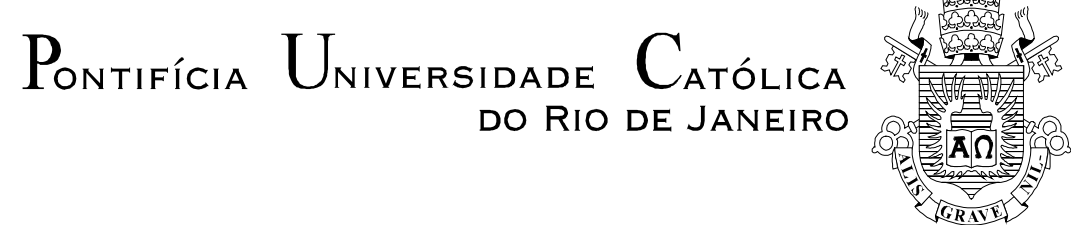

Izabela Machado Pureza

\title{
Dimensionamento da Reserva Técnica de Transformadores de Subestação de Distribuição Considerando Unidades Móveis
}

Dissertação apresentada como requisito parcial para obtenção do grau de Mestre pelo Programa de PósGraduação em Engenharia Elétrica da PUC-Rio.

Orientador: Prof. Armando Martins Leite da Silva Coorientador: Prof. João Guilherme de Carvalho Costa 


\section{Pontifícia Universidade Católica $_{\text {a }}$ \\ DO RIO DE JANEIRO}

Izabela Machado Pureza

\section{Dimensionamento de Reserva Técnica de Transformadores de Subestação de Distribuição Considerando Unidades Móveis}

Dissertação apresentada como requisito parcial para obtenção do grau de Mestre pelo Programa de Pós-Graduação em Engenharia Elétrica da PUC-Rio. Aprovada pela Comissão Examinadora abaixo assinada.

Prof. Armando Martins Leite da Silva

Orientador

Departamento de Engenharia Elétrica - PUC-Rio

Prof. João Guilherme de Carvalho Costa

Co-Orientador

UNIFEI

Prof. Airton Violin

UNIFEI

Prof. Delberis Araújo Lima

Departamento de Engenharia Elétrica - PUC-Rio

Prof. Márcio da Silveira Carvalho

Coordenador Setorial do Centro

Técnico Científico - PUC-Rio

Rio de Janeiro, 26 de abril de 2017 
Todos os direitos reservados. É proibida a reprodução total ou parcial do trabalho sem autorização da universidade, do autor e do orientador.

\section{Izabela Machado Pureza}

Graduou-se em Engenharia Elétrica pela Universidade Federal de Juiz de Fora em 2012. Atualmente trabalha como oficial do corpo de engenheiros da Marinha do Brasil.

Ficha Catalográfica

Pureza, Izabela Machado

Dimensionamento da reserva técnica de transformadores de subestação de distribuição considerando unidades móveis / Izabela Machado Pureza; orientador: Armando Martins Leite da Silva; coorientador: João Guilherme de Carvalho Costa. - 2017.

$91 \mathrm{f} .:$ il. color; $30 \mathrm{~cm}$

Dissertação (mestrado) - Pontifícia Universidade Católica do Rio de Janeiro, Departamento de Engenharia Elétrica, 2017.

Inclui bibliografia

1. Engenharia Elétrica - Teses. 2. Análise Probabilística de Custos. 3. Confiabilidade. 4. Número de Reservas. 5. Transformadores Reservas. I. Silva, Armando Martins Leite da. II. Costa, João Guilherme de Carvalho. III. Pontifícia Universidade Católica do Rio de Janeiro. Departamento de Engenharia Elétrica. IV. 


\section{Agradecimentos}

Agradeço a Deus por todas as minhas vitórias, vem d'Ele a força que me fez superar os obstáculos.

Aos meus pais, pelo carinho, esforço, companheirismo e paciência, sem o suporte e o incentivo deles dificilmente este trabalho seria concluído.

Ao mentor de uma vida, Dom José Carlos de Lima Vaz (in memoriam), por me fazer enxergar todo o mundo que o estudo poderia oferecer.

Ao orientador, professor Armando Martins Leite da Silva, pelo acolhimento, incentivo, apoio, paciência, dedicação, orientação e acompanhamento deste trabalho, permitindo meu crescimento não apenas estudantil, mas sobretudo profissional.

Ao professor João Guilherme de Carvalho Costa, pela dedicação, suporte, disposição, coorientação e conhecimentos transmitidos.

Aos professores Debora Rosana Ribeiro Penido Araujo e Leandro Ramos de Araujo por não permitirem que a paixão pela engenharia se extinguisse em mim.

Aos colegas de curso, em especial, José Filho, pelo apoio, ajuda e amizade.

Ao meu amor, cuja paciência inesgotável e apoio incondicional foram alento ao longo desta caminhada.

Aos companheiros de farda, aos mais antigos que permitiram o término dessa caminhada, e aos mais modernos que apoiaram e motivaram.

À CAPES e à PUC-Rio, pelo apoio financeiro. 


\section{Resumo}

Pureza, Izabela Machado; Leite da Silva, Armando Martins. Dimensionamento da Reserva Técnica de Transformadores de Subestação de Distribuição Considerando Unidades Móveis. Rio de Janeiro, 2017. 91p. Dissertação de Mestrado - Departamento de Engenharia Elétrica, Pontifícia Universidade Católica do Rio de Janeiro.

O dimensionamento de equipamentos sobressalentes se mostra como importante ferramenta de análise de investimento para o projeto e planejamento da operação e manutenção de qualquer sistema de grande porte. Não sendo diferente no que contempla o sistema de distribuição elétrica no cenário brasileiro. Os sistemas de distribuição, regulados pela Agência Nacional de Energia Elétrica, precisam fornecer energia de forma segura, estável e com índices de defeito extremamente baixos, tornando-se cabíveis punições monetárias no caso de descumprimento das normas estabelecidas. Um dos pontos de maior sensibilidade em um sistema de distribuição são as subestações existentes no mesmo, onde os defeitos impactam um número elevado de consumidores, além de possuir equipamentos de grande custo de aquisição. A redundância em sistemas desse porte poderia reduzir consideravelmente as falhas, mas demandaria um investimento inicial muito elevado. Sendo assim, a existência de estoque estratégico torna-se relevante, visando diminuir a duração das falhas com o menor investimento possível. Os transformadores apresentam grande relevância em uma subestação, sendo possível a análise de estoque de unidades fixas, que atenderiam apenas uma localidade ou região, e o estoque de unidades móveis, que poderiam atender, ainda que em caráter provisório, diferentes regiões atingidas. Esta dissertação apresenta uma metodologia probabilística para a definição da estratégia de dimensionamento dos estoques de equipamentos reservas ao longo do tempo, dando enfoque às unidades móveis, sendo possível avaliar a confiabilidade do sistema, comparar os investimentos e custos operacionais de diferentes cenários. Permite também que sejam consideradas questões importantes, como o envelhecimento dos equipamentos, o aumento da carga com características diferentes para cada unidade 
e a possibilidade de transferência de carga de uma unidade avariada para outra em funcionamento. Essas premissas proporcionam dados mais precisos para análise de investimentos, por considerar as condições individuais dos equipamentos. A ferramenta básica de análise será a simulação Monte Carlo cronológica, de modo a capturar precisamente todas as características do problema em questão. A metodologia acima proposta é aplicada a um grupo de transformadores da classe 138-13,8 kV, 25 MVA, visando demonstrar a capacidade da metodologia de encontrar as soluções condizentes do ponto de vista técnico e econômico.

\section{Palavras-chave}

Análise Probabilística de Custos; Confiabilidade; Número de Reservas; Transformadores Reservas. 


\section{Abstract}

Pureza, Izabela Machado; Leite da Silva, Armando Martins (Advisor). Assessment of Spare Transformer Requirements for Distribution Substations Considering Mobile Units. Rio de Janeiro, 2017. 91p. Dissertação de Mestrado - Departamento de Engenharia Elétrica, Pontifícia Universidade Católica do Rio de Janeiro.

The sizing of equipment spares is an important investment analysis for the design and planning of the operation and maintenance of any large system. These concepts can also be applied to electric distribution systems of the interconnected Brazilian network. Distribution systems, regulated by the Brazilian Electricity Regulatory Agency, need to supply energy in a secure, stable, and extremely low fault rate, making monetary penalties possible in case of non-compliance with established standards. One of the most sensitive points in a distribution system is its current substations, where failures impact a large number of consumers, besides having relatively high-cost equipment. Redundancy in systems of this type could considerably reduce failures, but would require a very high initial investment. Thus, the need of a strategic inventory becomes relevant, aiming to reduce the duration of the failures with the least possible investment. Transformers are of great importance in an electric power station, whose spare requirements are usually assessed, but would only serve a locality or region, while the stock of mobile units, although on a temporary basis, would serve to different affected regions. This dissertation presents a probabilistic methodology for assessing of spare transformer requirements and the associated inventory acquisition strategy over time, focusing on mobile units. It includes the evaluation of reliability indices and comparison of investment and operational costs for different scenarios. It also allows important issues to be considered, such as equipment aging, load increasing with different characteristics for each unit, and the possibility of load transfers from one faulty unit to another in operation. These assumptions provide more accurate input data for investment analysis, considering the individual conditions of equipment. The basic tool to be used is the chronological Monte Carlo simulation that accurately 
captures all characteristics of the problem being solved. The proposed methodology is applied to a group of transformers of the class $138-13.8 \mathrm{kV}, 25 \mathrm{MVA}$, aiming to demonstrate the ability of the proposed method to find the appropriate solutions from a technical and economic points of view.

\section{Keywords}

Number of Spares; Probabilistic Cost Analysis; Reliability; Spare Transformers; Substation Planning. 


\section{Sumário}

1 Introdução 15

1.1. Considerações Iniciais $\quad 15$

$\begin{array}{ll}\text { 1.2. Desenvolvimento Histórico } & 18\end{array}$

$\begin{array}{ll}\text { 1.3. Estrutura da Dissertação } & 19\end{array}$

2 Modelos Analíticos para Dimensionamento de Reserva Técnica 21

2.1. Introdução 21

2.2. Modelo de Poisson 21

2.2.1. Distribuição de Poisson 22

2.2.2. Sistemas com Equipamentos Reservas 23

2.2.2.1. Exemplo 1

2.3. Modelo de Markov 25

2.3.1. Montagem do Espaço de Estados 25

2.3.2.Cálculo das Probabilidades 28

$\begin{array}{ll}\text { 2.3.3. Probabilidades Estacionárias } & 29\end{array}$

2.3.3.1. Probabilidades Estacionárias - Resolução Tradicional 29

2.3.3.2. Probabilidades Estacionárias - Resolução Alternativa 30

2.3.4. Indicadores de Frequência e Duração 31

2.3.4.1. Exemplo 2

2.3.5. Aspectos Econômicos 33

2.3.6. Aplicação em um Sistema Real 34

2.6. Conclusões 36

3 Modelos de Simulação Monte Carlo para Determinação de Estoque 37

3.1. Introdução 37

3.2. Simulação Monte Carlo 37

3.2.1. Simulação Não Sequencial 38 
3.2.2. Sequencial 39

3.3. Simulação Monte Carlo Cronológica - Índices e Evoluções $\quad 40$

3.3.1. Índices de Confiabilidade 40

3.3.2. Aplicação em um Sistema Real 41

3.3.3. Evolução nas Análises 43

3.4. Conclusões 44

4 Metodologia de Simulação Cronológica Considerando

Unidades Móveis 46

4.1.Introdução 46

4.2.Subestações Móveis 46

4.3.Modelo Cronológico Básico 49

4.3.1.Processo de Simulação 49

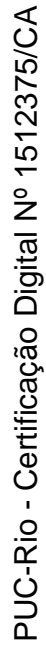

4.3.2.Estratégias Operativas 51

4.4.Resultados 53

4.4.1.Caso $1 \quad 54$

4.4.2.Caso $2 \quad 56$

4.4.3.Caso $3 \quad 58$

4.4.4.Caso $4 \quad 60$

4.4.5.Caso $5 \quad 62$

4.4.6.Caso $6 \quad 64$

$\begin{array}{ll}\text { 4.4.7.Caso } 7 & 67\end{array}$

$\begin{array}{ll}\text { 4.4.8.Caso } 8 & 69\end{array}$

4.5.Tempos de Simulação

$\begin{array}{ll}\text { 4.6.Conclusão } & 73\end{array}$

5 Conclusão $\quad 74$

6 Referências bibliográficas $\quad 77$ 
7 Apêndice

7.1. Caso 1: Resultados 81

7.2. Caso 2: Resultados 82

7.3. Caso 3: Resultados 83

7.4. Caso 4: Resultados 84

7.5. Caso 5: Resultados 86

7.6. Caso 6: Resultados 87

7.7. Caso 7: Resultados 88

7.8. Caso 8: Resultados 90 


\section{Lista de figuras}

Figura 2.1 - Modelo equivalente de um equipamento 26

Figura 2.2 - Espaço de estados 27

Figura 2.3 - Espaço de estados simplificado 28

Figura 2.4 - Espaço de estados 32

Figura 3.1 - llustração de uma SMC cronológica 39

Figura 4.1 - Fluxograma de decisões em caso de falha 52

Figura 4.2 - Comportamento EENS (MWh/p) com a inserção de subestações móveis $\quad 55$

Figura 4.3 - Comparação entre o Caso 1 e 2

Figura 4.4 - Índice EENS versus tempo máximo de utilização das móveis 59

Figura 4.5 - Índice EENS versus tempo máximo de utilização das móveis 61

Figura 4.6 - Índice EENS versus unidade móvel em um sistema degradado 63

Figura 4.7 - Índice EENS versus tempo de instalação de unidade móvel

em um sistema 66

Figura 4.8 - Índice EENS versus tempo de execução de transferência

de carga em um sistema 69

Figura 7.1 - Resultados completos do processo de simulação Caso 181

Figura 7.2 - Resultados completos do processo de simulação Caso $2 \quad 82$

Figura 7.3 - Resultados primeira metade do intervalo do Caso $3 \quad 83$

Figura 7.4 - Resultados segunda metade do intervalo do Caso $3 \quad 83$

Figura 7.5 - Resultados primeira metade do intervalo do Caso $4 \quad 85$

Figura 7.6 - Resultados segunda metade do intervalo do Caso $4 \quad 85$

Figura 7.7 - Resultados do Caso 5

Figura 7.8 - Resultados da primeira metade das simulações do Caso $6 \quad 87$

Figura 7.9 - Resultados da segunda metade das simulações do Caso $6 \quad 87$

Figura 7.10 - Resultados das simulações do Caso 6 sem unidades móveis 88

Figura 7.11 - Resultados da primeira metade das simulações do Caso $7 \quad 88$

Figura 7.12 - Resultados da segunda metade das simulações do Caso $7 \quad 89$

Figura 7.13 - Resultados do segundo teste do Caso $7 \quad 89$

Figura 7.14 - Resultados do Caso $8 \quad 90$ 
Figura 7.15 - Resultados do Caso 8

90

Figura 7.16 - Resultados do Caso 8 


\section{Lista de tabelas}

Tabela 2-1 - Efeito do Número de Reservas 25

Tabela 2-2 - Dados do Sistema da Seção 2.3.6 35

Tabela 2-3 - Resultados em $10^{6} \times \mathrm{R} \$$ /ano 35

Tabela 3-1 - Índices de Confiabilidade 42

Tabela 3-2 - Valores de Custos em R\$/ano 42

Tabela 4-1 - Caso 1: Índices de Confiabilidade 54

Tabela 4-2 - Caso 2: Índices de Confiabilidade 56

Tabela 4-3 - Caso 3: Índices de Confiabilidade 58

Tabela 4-4 - Caso 4: Índices de Confiabilidade 60

Tabela 4-5 - Caso 5: Índices de Confiabilidade 63

Tabela 4-6 - Caso 6: Índices de Confiabilidade 65

Tabela 4-7 - Caso 6: Índices de Confiabilidade - Sem Unidades Móveis 65

Tabela 4-8 - Caso 7: Índices de Confiabilidade 68

Tabela 4-9 - Inclusão de Unidades Convencionais 70

Tabela 4-10 - Análise de Custos anualizados de Inclusão de

$\begin{array}{ll}\text { Unidades Convencionais } & 71\end{array}$

Tabela 4-11 - Inclusão de Unidades Móveis 71

Tabela 4-12 - Análise de Custos anualizados de Inclusão de

$\begin{array}{ll}\text { Unidades Móveis } & 71\end{array}$ 


\section{Introdução}

\section{1.}

\section{Considerações Iniciais}

O planejamento de sistemas deve ter como um de seus principais objetivos eliminar ou minimizar falhas durante sua operação, levando em consideração a viabilidade econômica das soluções encontradas. Para isso, são feitas análises de confiabilidade dos sistemas em questão, buscando sempre que possível dimensionar redundâncias ou reservas técnicas. Em alguns sistemas, as redundâncias representam grande investimento de capital, e, portanto, estudos de dimensionamento de estoques de equipamentos que incluem os riscos de interrupção no suprimento e custos associados devem ser considerados. Esse é o caso do sistema elétrico de um modo geral.

O sistema elétrico apresenta considerável complexidade de análise por envolver uma longa rede interligada com grande diversidade de componentes, os quais necessitam operar de forma conectada e sincronizada visando fornecer continuamente energia dentro de valores pré-estabelecidos. De grande relevância, a distribuição de energia elétrica é responsável pelo atendimento ao consumidor final, sendo necessários estudos atentos aos projetos de subestações, onde a falha de qualquer equipamento pode interromper inúmeros usuários. Tendo o transformador como um dos mais relevantes equipamentos contemplados no projeto de uma subestação, devido não só ao seu impacto direto na confiabilidade das mesmas, por conseguinte, nos sistemas, como também pelo elevado custo de cada unidade e o longo tempo de reposição, não sendo equipamento de pronta entrega como transformadores de menor potência, há necessidade de encomenda com tempo estimado de entrega entre 12 e 18 meses [1].

A falha de um transformador de subestação é um problema que invariavelmente causa interrupção de abastecimento a um elevado número de consumidores finais, apresentando grande impacto no sistema, causando prejuízos 
pela energia não suprida, eventuais multas contratuais e indenizações judiciais. Esses equipamentos, sujeitos a falhas inesperadas de grande impacto global, usualmente são analisados pelo critério $\mathrm{N}-1$, geralmente adotando redundância de unidades que permitam que na falha de um equipamento a carga seja suprida no momento de maior valor da mesma sem a necessidade de interrupção de fornecimento a nenhum cliente. Apesar de estatisticamente muito confiável, e, consequentemente, reduzir de forma acentuada as perdas financeiras decorrentes de falhas do equipamento em questão, apresenta custos consideravelmente altos, empregando investimentos, que por muitas vezes, poderiam ser diversificados em outros projetos apresentando retornos mais atraentes [2].

Uma opção para melhorar a confiabilidade do sistema empregando menor investimento inicial seria a reserva técnica, que se constitui de equipamentos em estoque para substituição de unidades em caso de avarias, mitigando assim as falhas, proporcionando um tempo de reposição menor, por existir peça em disposição, melhorando os índices de confiabilidade, reduzindo, portanto, os impactos financeiros das falhas no período de operação do sistema. Um ponto de destaque é a possibilidade da reserva ser dimensionada tendo como objetivo atender subestações de uma mesma região geográfica que possuam unidades transformadoras similares.

As reservas técnicas de transformadores de subestações podem contar com unidades de reposição e unidades móveis. Unidades de reposição se assemelham às em operação que apresentaram avarias e serão instaladas no local das mesmas, visando substituí-las de forma definitiva. Unidades móveis podem substituir as unidades em falha sempre em caráter provisório. Essas opções apresentam características distintas, sendo o custo da segunda bem maior. Esta última opção se torna válida devido à sua diversidade de aplicações e tempo de resposta rápido, conseguindo reduzir ainda mais o tempo de falha e, portanto, os prejuízos decorrentes da mesma.

Dado o custo elevado das unidades em estoque, tanto móveis como convencionais, torna-se indispensável uma análise criteriosa da quantidade necessária para evitar superdimensionamento, com intuito de reduzir ao mínimo possível os valores de falhas. Evita-se assim um número excessivo de unidades que 
não impactam na melhora nos índices de desempenho, que poderiam ter o investimento correspondente aplicado em outros equipamentos. Além disso, existe a questão da alocação física, espaço destinado a guardar equipamentos que apresentam grande porte, e manutenção da reserva existente, visando monitoramento da mesma para assegurar capacidade operativa caso necessário, o que implica em despesas de forma direta, as quais devem ser consideradas nas análises de custos de operação e viabilidade de implantação da mesma.

Deve ser ressaltado o grande impacto sobre o sistema que o equipamento apresenta e seu elevado tempo para aquisição. Em caso de falha do mesmo e ausência de unidade de reposição em estoque ou unidade móvel capaz de substituilo, existiria um impacto de longa duração e escala no sistema, com grandes prejuízos, demonstrando a importância de dimensionar adequadamente as unidades necessárias para estoque.

O dimensionamento da reserva técnica necessária para atender uma subestação é determinado pelo nível de confiabilidade requerido e custos agregados à operação do sistema, como investimento na aquisição do estoque, armazenamento e manutenção dos equipamentos, interrupção do fornecimento de energia, além de compensações financeiras ou multas previstas nos Procedimentos de Distribuição de Energia Elétrica no Sistema Elétrico Nacional, PRODIST Módulo 8 [3].

A quantidade de equipamentos a serem disponibilizados nos estoques tem influência direta nos custos de investimento e operação das companhias de eletricidade, devendo-se então buscar, sempre que possível, um bom dimensionamento do estoque, onde não exista unidades em excesso e que esteja disponível na quantidade necessária para reduzir os impactos de uma eventual interrupção.

A metodologia proposta visa encontrar o ponto ideal entre unidades reservas e custos de investimento e operação. Ressalva-se que as análises utilizam os transformadores como exemplo por seu impacto direto no funcionamento dos sistemas elétricos, contudo, nada impede a generalização dos métodos aplicados a seguir para os demais equipamentos elétricos, ou mesmo para diferentes sistemas. 


\section{2. \\ Desenvolvimento Histórico}

A análise da reserva operativa industrial apresenta longo histórico, entretanto, seu enfoque em peças de reposição e sobressalentes é recente, oriundo da necessidade crescente de concorrência, onde os custos precisam ser minimizados e a qualidade do serviço maximizada. Tomando como base o setor elétrico nacional, que apresenta forte regulamentação da ANEEL (Agência Nacional de Energia Elétrica), torna-se fundamental um estoque bem dimensionado visando reduzir as falhas e interrupções, buscando alcançar as taxas e qualidade requisitadas pelo órgão regulador, evitando multas e reduzindo, sempre que possível, os custos operacionais.

Recentemente houve destaque para os estudos das condições operativas dentro do sistema elétrico de potência, sendo foco de muitos trabalhos sobre a confiabilidade do mesmo [4], [5]. Dentre os equipamentos de maior impacto nessa análise, destacam-se os transformadores [6], além de seu elevado custo de aquisição, possuem alto tempo de reposição, não sendo equipamento de fácil obtenção. Os localizados em subestações apresentam alto impacto no sistema em caso de falha, devendo ser estudado com cautela. As falhas do equipamento podem ser divididas entre reparáveis no campo, que apresentam pequeno impacto na análise de confiabilidade do sistema por ter sua duração em curto intervalo, e irreparáveis, que exigem unidades de reposição e tendem a ter maior impacto no sistema. Sendo o segundo tipo tema de maior destaque nos estudos por envolver maiores custos e perdas, será o abordado ao longo desse estudo.

Os transformadores, como outros equipamentos elétricos, apresentam característica de envelhecimento, resultando em progressivo aumento de sua taxa de falha. Entretanto, os modelos mais utilizados para essa análise desconsideram este efeito. Os modelos probabilísticos mais utilizados são o binomial, Poisson e o modelo de Markov. Segundo [7], todos os métodos consideram a taxa de falha constante ao longo do tempo. Modelos baseados em Poisson utilizam apenas a taxa de falha para calcular diferentes configurações, para um determinado período de tempo, enquanto que aqueles baseados em Markov utilizam as taxas de falha e reparo e o número de unidades para cálculo das probabilidades para o mesmo período de tempo. 
A distribuição de Poisson é usada classicamente considerando que a vida das unidades é exponencialmente distribuída, como em [2], [10], considerando para análise de custos a energia não suprida e o custo do investimento. Nos exemplos [7] e [8], a metodologia é baseada no processo de Markov para determinar a reserva necessária de unidades transformadoras fixas e unidades móveis para alcançar um nível de confiabilidade estabelecido. Em [9] o processo de Markov é utilizado visando encontrar o menor custo entre investimento em reserva operativa e custos de operação. Em todos os exemplos é descartada a capacidade de envelhecimento das unidades, além de fixar características iguais para as unidades do mesmo tipo.

Uma metodologia que contempla a análise dos fatores não analisados pelos métodos supracitados é a simulação Monte Carlo Cronológica (SMC). Métodos de análise que utilizam SMC apresentam capacidade de considerar diversos fatores desconsiderados anteriormente, como envelhecimento, análise das características individuais das unidades, impacto de defeitos transitórios na vida útil do equipamento, tempo de instalação, entre outras. Apesar de possibilitar estudos completos e mais realistas por permitir a modelagem minuciosa dos equipamentos, os métodos que utilizam SMC apresentam a desvantagem do custo computacional devido ao grande número de amostras necessárias para a determinação de resultados com precisão adequada. Entretanto, com a evolução rápida dos sistemas computacionais, esse problema tem reduzido seu impacto, possibilitando um aumento considerável na utilização da SMC. Existem diversos estudos que utilizam a SMC para obter resultados mais precisos e com maior proximidade com o comportamento das unidades reais, como [9], [11], [12], [13].

Os métodos citados anteriormente serão melhor detalhados ao longo do capítulo 2.

\section{3.}

\section{Estrutura da Dissertação}

Esta dissertação apresenta uma metodologia utilizando simulação Monte Carlo Cronológica para dimensionamento da reserva técnica de transformadores de subestações de distribuição, considerando unidades móveis e unidades 
convencionais. Está dividida em cinco capítulos que serão resumidamente descritos a seguir.

Este capítulo abordou o problema do dimensionamento de reserva técnica e delineou os aspectos que serão estudados ao longo da dissertação. Também foram abordadas as principais técnicas empregadas na solução do problema proposto e citadas referências para embasar esses métodos.

O Capítulo 2 apresenta os modelos mais utilizados para o dimensionamento de estoque: o modelo de Poisson e o de Markov. Serão utilizados exemplos com finalidade de comparação entre os métodos para melhor compreensão e ilustração.

O Capítulo 3 introduz e analisa os principais aspectos da simulação Monte Carlo e a evolução de seus modelos. Será apresentada a modelagem dos custos de investimento e operação e descritos os índices a serem calculados.

No Capítulo 4 é descrita a simulação cronológica e o sistema que servirá para caso de estudo. Ao longo deste capítulo serão retratadas as restrições e peculiaridades do estudo em questão e apresentados as principais considerações e resultados obtidos com o estudo em questão.

O Capítulo 5 apresenta as principais conclusões do estudo e sugere trabalhos para continuação do tema em desenvolvimentos futuros.

O Capítulo 6 apresenta as referências bibliográficas utilizadas ao longo deste trabalho.

Por último, os resultados detalhados oriundos do processo de simulação são mostrados em Apêndice. 


\section{2 \\ Modelos Analíticos para Dimensionamento de Reserva Técnica}

\section{1. \\ Introdução}

Este capítulo fará uma breve descrição dos dois modelos probabilísticos mais utilizados até então para a análise de reserva técnica: Poisson e Markov. Como apresentado anteriormente, esses modelos, e consequentemente os métodos que os utilizam, apresentam algumas limitações que serão tratadas e comparadas entre si através de exemplos numéricos.

A distribuição de Poisson parte da premissa da distribuição exponencial do período de vida de um equipamento, sendo comumente utilizado para avaliar a confiabilidade de cenários pré-definidos. $\mathrm{O}$ modelo anterior considera apenas as taxas de falha, porém o modelo de Markov possibilita o uso de uma taxa de reparo, que inclui na análise feita por espaço de estados a possibilidade de reparo de um equipamento e o tempo médio desse reparo.

A seguir, os métodos são apresentados com maior riqueza de detalhes.

\section{2.}

Modelo de Poisson

Equipamentos de sistemas elétricos como geradores, linhas de transmissão e disjuntores apresentam uma taxa de falha que varia ao longo de sua vida operativa. No entanto, na região de vida útil a taxa de falha pode ser considerada constante, o que implica tempos de funcionamento exponencialmente distribuídos [14]. 


\subsection{1 \\ Distribuição de Poisson}

Considerando que o equipamento a ser analisado passou pelo período de mortalidade infantil e se encontra na região de operação onde sua taxa de falha apresenta estabilidade, considera-se que a mesma pode ser representada por uma constante. Essa premissa torna possível a utilização da distribuição de Poisson, que permite calcular, para um intervalo de tempo definido, a probabilidade de um evento ocorrer um determinado número de vezes. Sendo a taxa de falha representada por $\lambda$, tem-se:

$$
R(t)=e^{-\lambda t}
$$

onde $R$ é a probabilidade de um equipamento estar funcionando em um instante $t$ futuro e pode ser definida como a confiabilidade do equipamento no instante $t$.

A equação acima é o primeiro termo da distribuição de probabilidade de Poisson, sendo muito utilizado para calcular a confiabilidade de um sistema elétrico, como em [2], [15], [10] e [16].

A probabilidade de um equipamento com taxa de falha $\lambda$ falhar $x$ vezes em um intervalo de tempo $(0, t)$ é dada pela distribuição de Poisson [14]:

$$
P_{x}(t)=\frac{e^{-\lambda t}(\lambda t)^{x}}{x !}
$$

Para avaliar a confiabilidade do sistema para o intervalo determinado, calcula-se as probabilidades de sucesso do mesmo e soma-se as mesmas. Por exemplo, uma subestação com dois transformadores funcionando em paralelo e capazes de suprir a carga individualmente, neste caso, para um intervalo de tempo $t$, a probabilidade de sucesso do sistema ocorre caso não ocorra avaria de nenhum transformador $(x=0)$ ou no caso de uma falha $(x=1)$, no caso dos dois transformadores falharem no intervalo de tempo determinado $(x=2)$, todo o sistema falharia, não sendo considerado estado de sucesso. Assim, a confiabilidade seria definida por:

$$
R(t)=P_{0}(t)+P_{1}(t)
$$




\subsection{2.}

\section{Sistemas com Equipamentos Reservas}

Visando um melhor funcionamento dos sistemas elétricos, é imprescindível que se planeje certas redundâncias com o intuito de reduzir os impactos causados pelas falhas a que todos os equipamentos elétricos são sujeitos. Em caso de inobservância desse planejamento, um dos exemplos mais claros é o de subestações de distribuição, onde uma falha em uma unidade transformadora pode ter um impacto imenso, por atingir diversos consumidores finais e ser de difícil reposição se a mesma não for planejada previamente.

De acordo com [14], há duas classificações para redundâncias: paralelo e "standby". Sistemas paralelos apresentam grande custo de investimento por utilizar dois componentes para exercer função equivalente a apenas um, entretanto em algumas aplicações específicas, torna-se uma excelente alternativa por sua confiabilidade elevada e a inexistência de interrupção em caso de falha em apenas um equipamento.

Os sistemas ditos "standby" são aqueles que possuem um ou mais equipamentos em reserva capazes de substituir o equipamento avariado imediatamente após a falha. Para caracterizar o sistema que possui estoque como "standby" é necessário que a substituição ocorra em um tempo relativamente pequeno quando comparado ao tempo médio de funcionamento do equipamento em questão.

Sendo assim, a confiabilidade do sistema para o intervalo de tempo $t$ com $N$ componentes principais e $n$ reservas, onde $N \lambda$ é a taxa de falha equivalente do sistema em questão, pode ser calculada por:

$$
R(t)=e^{-N \lambda t}\left[1+N \lambda t+\frac{(N \lambda t)^{2}}{2 !}+\frac{(N \lambda t)^{3}}{3 !}+\cdots+\frac{(N \lambda t)^{n}}{n !}\right]
$$

Reescrevendo a Eq. (2.4), tem-se:

$$
R(t)=e^{-N \lambda t} \sum_{k=0}^{n} \frac{(N \lambda t)^{k}}{k !}
$$


Através da observação da Eq. (2.4), é possível constatar que o acréscimo de unidades reservas gera um aumento de confiabilidade no sistema. Entretanto, de acordo com o aumento de unidades, o impacto da nova unidade sobre a confiabilidade é reduzido, chegando ao ponto em que mais uma unidade reserva produz muito pouca alteração no sistema. Contudo, o custo das unidades reservas são expressivos, demonstrando assim a importância de uma análise que busque o mínimo custo com a confiabilidade adequada, evitando a compra de unidades de estoque desnecessárias.

\subsubsection{1. Exemplo 1}

Considere uma subestação com quatro transformadores em operação e uma unidade reserva. Admita que a taxa de falha seja de 0,15 f/ano e o tempo médio para que um transformador que falhou seja reparado (ou substituído por um novo) e volte a compor o estoque seja de 12 meses. Assim, para $N=4, n=1, \lambda=0,15$ e $t$ $=1$, tem-se uma confiabilidade $\mathrm{R}(\mathrm{t})=0,8781$. O risco de falha do sistema no período de um ano é de aproximadamente $12 \%,(1-0,8781=0,1218)$.

Na Tabela 2-1 são apresentados os resultados da variação do número de unidades reservas. Observa-se o impacto da inclusão de uma unidade de estoque, melhorando a confiabilidade do sistema. Entretanto, quanto maior o número de unidades de estoque menor sua influência na confiabilidade do sistema, o que faz com que a melhora causada pela unidade extra não compense seu investimento.

Destaca-se que o cálculo da confiabilidade de um sistema não é suficiente para determinar o número ótimo de equipamentos a serem disponibilizados no estoque de um grupo de subestações, por não levar em consideração os custos envolvidos em todo o processo de operação do sistema.

Para o dimensionamento adequado é preciso considerar o custo de investimento da aquisição de unidades de estoque, custos provenientes da interrupção do fornecimento dos consumidores, como multas por interrupção e o valor da energia não fornecida. Para essa análise, indicadores de frequência e 
duração das falhas, e valores esperados de energia não suprida são fatores de grande importância no cálculo dos custos de operação do sistema.

Tabela 2-1 - Efeito do Número de Reservas

\begin{tabular}{|c|c|c|}
\hline $\boldsymbol{n}$ & $\mathbf{R}(\mathbf{t})$ & $\begin{array}{c}\text { Acréscimo na } \\
\text { Confiabilidade }\end{array}$ \\
\hline 0 & 0,5488 & - \\
\hline 1 & 0,8781 & 0,3293 \\
\hline 2 & 0,9769 & 0,0988 \\
\hline 3 & 0,9966 & 0,0197 \\
\hline 4 & 0,9996 & 0,003 \\
\hline
\end{tabular}

\section{3.}

\section{Modelo de Markov}

As cadeias de Markov são processos estocásticos e modelam evoluções aleatórias no tempo, onde o estado atual e as probabilidades de transição são as únicas variáveis que definem o comportamento futuro do sistema [14]. Ao longo dessa subseção será descrito o modelo de Markov, que resumidamente pode ser expresso como um sistema de transições de estados, onde a probabilidade do sistema estar em determinado estado futuro depende apenas do estado atual do sistema [17]-[20].

\subsection{1.}

\section{Montagem do Espaço de Estados}

A modelagem por espaço de estados via o modelo de Markov permite o cálculo das probabilidades instantâneas de funcionamento e falha de equipamentos [9]. Além disso, para obter as probabilidades de sucesso e falha do sistema, avaliamse primeiramente as probabilidades de cada estado. Tais probabilidades estão vinculadas com: as características do sistema; o número de equipamentos; a taxa de falha dos equipamentos existentes; os tempos de reparo dos equipamentos; o número de unidades em situação de defeito; o tamanho do estoque; e o tempo de instalação de cada unidade [8].

A Fig. 2.1 ilustra os dois estados possíveis de um equipamento: (1) Up, em operação e (2) Down, em reparo. Na figura, $\lambda$ ilustra a taxa de falha, que deverá representar apenas as falhas não reparáveis para o estudo do dimensionamento de 
estoque de transformadores. A taxa de reparo de um equipamento é representada por $\mu$, considerando a premissa anterior, podemos adotar seu valor como o inverso do tempo médio necessário para a aquisição de um transformador novo. Admite-se, por simplicidade, que os tempos de reposição de um transformador são distribuídos exponencialmente.

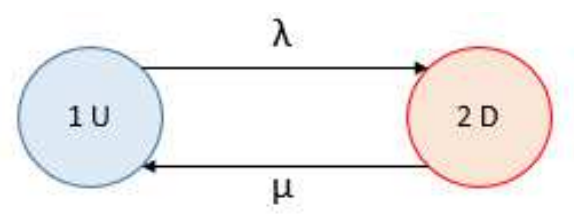

Figura 2.1 - Modelo equivalente de um equipamento

Um sistema de apenas um equipamento sem unidades reservas pode ser representado pela Fig. 2.1 Entretanto, para representar um sistema maior, com transformadores no campo e unidades reservas, deve-se montar o espaço de estados do sistema, obtido a partir dos espaços de estados individuais de seus componentes.

A Fig. 2.2 representa um sistema composto por dois transformadores principais e um sobressalente. Os estados são representados por círculos e as setas entre os mesmos indicam as taxas de falha e reparo entre os oito estados existentes. A classificação de um estado quanto ao sucesso ou falha depende das condições de operação estabelecidas para o sistema. No exemplo da Fig. 2.2, foi considerado que para estado de sucesso do sistema são necessários pelo menos dois transformadores em funcionamento. O sucesso é ilustrado então pelos estados em azul, onde no estado 1 as três unidades estão funcionando e nos estados 2,3 e 4 duas unidades estão em condições operativas. Nos estados em vermelho, apenas uma unidade (5, 6 e 7), ou nenhuma unidade (8) está em condição operativa, sendo, portanto, enquadrado como estado de falha do sistema.

Entretanto, pode-se considerar que apenas uma unidade em funcionamento consegue atender a carga e manter o sistema operando normalmente. Nesse caso os estados de sucesso e falha mudam, sendo apenas o estado 8 considerado estado de falha por todas as unidades se encontrarem em estado de falha. Pode-se concluir então, que apesar das mesmas taxas e dos mesmos estados, situações de operação distintas produzem análises diferentes. 


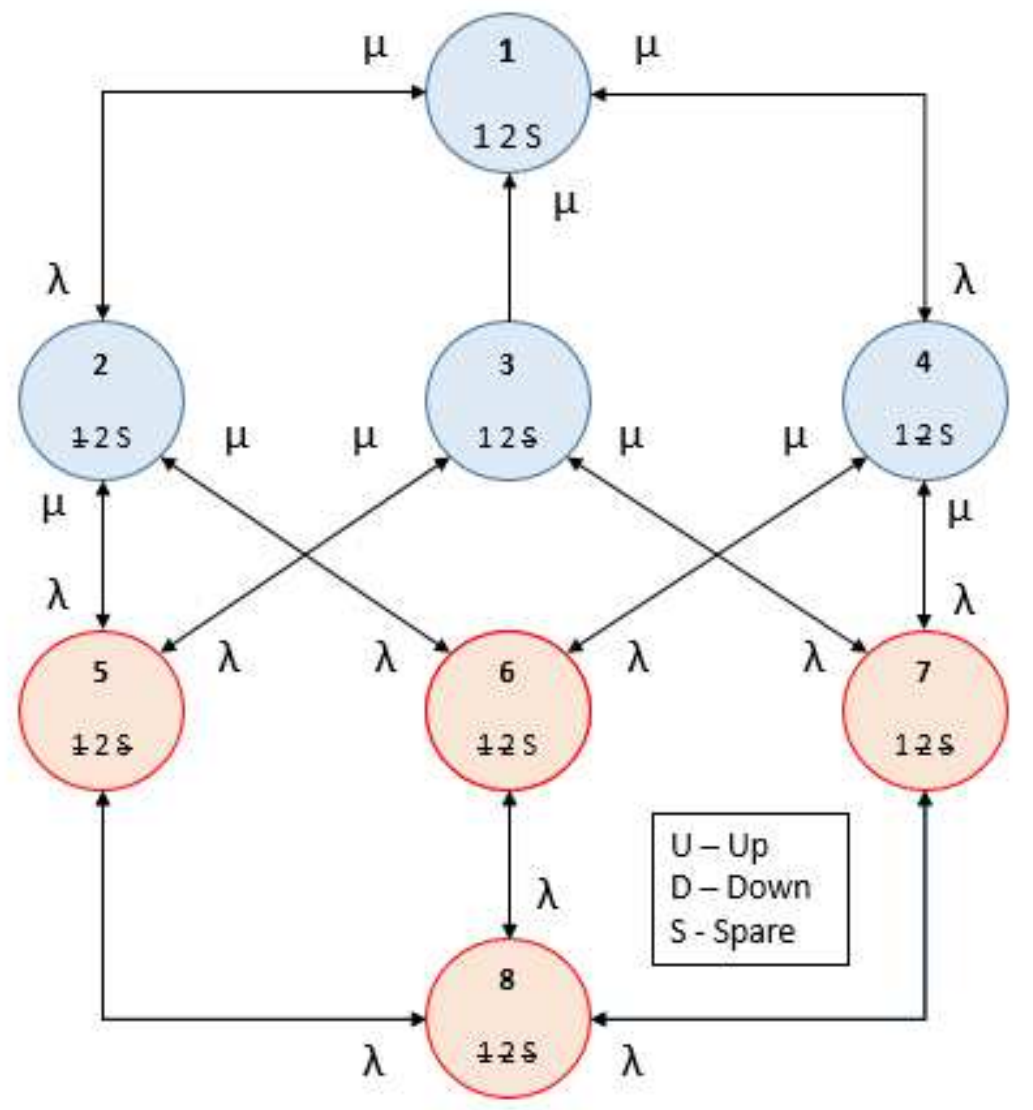

Figura 2.2 - Espaço de estados

O modelo da Figura 2.2 apresenta complexidade crescente de acordo com o número de unidades representadas, sendo o número de estados:

$$
N_{\text {estados }}=2^{n}
$$

Sendo $n$ o número de componentes no sistema a ser representado, um sistema com muitos componentes tornaria a análise pelos estados cansativa e complexa. Visando simplificar a análise, elabora-se um diagrama reduzido, em que estados com condições operativas similares são agregados em um único estado. Por exemplo, os estados 2, 3 e 4 da Fig. 2.2 apresentam dois transformadores em operação e um avariado, podendo ser ilustrados por um único estado, como o estado 2 da Fig. 2.3. Para que o modelo simplificado seja matematicamente equivalente ao original, as taxas de transição devem ser recalculadas, encontrando-se a equivalência entre os modelos [14]. 


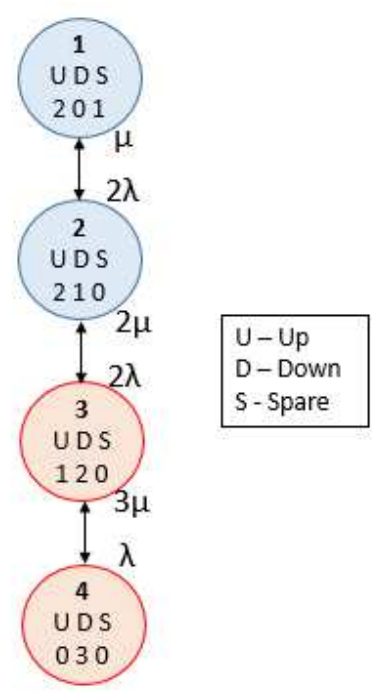

Figura 2.3 - Espaço de estados simplificado

\subsection{2.}

\section{Cálculo das Probabilidades}

As probabilidades dos estados, para qualquer instante $t$, podem ser calculadas mediante a solução do sistema de equações diferenciais [11].

$$
\dot{P}(t)=P(t) \times \Lambda
$$

onde $P(t)$ descreve o vetor $1 \times n_{e} \quad\left(n_{e}=N+n+1\right.$, sendo $N$ o número de transformadores no campo e $n$ a quantidade de transformadores em estoque) das probabilidades instantâneas dos estados e $\Lambda$ a matriz $n_{e} \times n_{e}$ das taxas de transição, construída conforme (2.8):

$$
\begin{aligned}
& \Lambda_{i j}=\lambda_{i j} \\
& \Lambda_{i i}=-\sum_{\substack{j=1 \\
j \neq i}}^{n_{e}} \lambda_{i j}
\end{aligned}
$$

A taxa de transição entre o estado $i$ e o estado $j$ é descrita por $\lambda_{i j}$. As probabilidades transitórias podem ser calculadas numericamente em tempo discreto (com $\Delta t$ suficientemente pequeno), a partir de um instante inicial $(t=0)$ onde as probabilidades são conhecidas, usando o seguinte processo iterativo:

$$
P(t+\Delta t)=P(t) \times P
$$


Considera-se como condição inicial o estado onde não há unidades avariadas, ou seja, onde existe $N$ transformadores em operação e $n$ transformadores reservas no estoque:

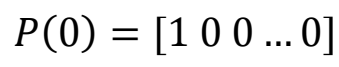

A matriz de probabilidades de transição é calculada em função da matriz de taxas por:

$$
P=\Delta t \times \Lambda+I
$$

onde $I$ é a matriz identidade com a mesma dimensão de $\Lambda$. Visando calcular as probabilidades transitórias, utiliza-se (2.9) de forma repetitiva, através de passos de tempo $\Delta t$, até o alcançar o instante $t$. A disponibilidade do sistema em $t, A(t)$, corresponde à soma das probabilidades dos estados de sucesso.

$$
A(t)=\sum_{k=1}^{n+1} P_{k}(t)
$$

\subsection{3. \\ Probabilidades Estacionárias}

\subsubsection{1.}

Probabilidades Estacionárias - Resolução Tradicional

As probabilidades tendem a ficar constantes na região estacionária, assim em (2.7) os elementos do vetor de derivadas tornam-se nulos, resultando em um sistema linear de equações algébricas:

$$
0=P S \times \Lambda
$$

Entretanto, a matriz de taxas é singular por construção, resultando em um sistema indeterminado. Visando encontrar o vetor de probabilidade estacionária, $P S$, e sabendo que a soma de todas as probabilidades tem de ser igual a 1 , deve-se substituir uma das equações por: 


$$
P S_{1}+P S_{2}+P S_{3}+\cdots+P S_{n_{e}}=1
$$

Resolvido o sistema, a disponibilidade do sistema é dada por:

$$
A=\sum_{i=1}^{n+1} P S_{i}
$$

A confiabilidade, neste caso, corresponde à probabilidade de o sistema ser encontrado em operação em qualquer instante de tempo futuro, assumindo que as condições sejam mantidas. A indisponibilidade, probabilidade de o sistema ser encontrado em situação de falha, é dada por:

$$
\bar{A}=1-A
$$

Outra forma de representar a indisponibilidade é em horas indisponíveis por ano, conversão mais facilmente interpretada:

$$
U=\bar{A} \times 8760
$$

\subsubsection{2.}

\section{Probabilidades Estacionárias - Resolução Alternativa}

As probabilidades estacionárias também podem ser determinadas sem necessidade de cálculos matriciais, utilizando-se de um processo de nascimento $e$ morte, que é um tipo especial de cadeia de Markov de tempo contínuo e bem conhecido na Teoria das Filas [19], [21]-[27]. Esta formulação é baseada no fato de que, em sistemas ergódicos, as frequências de entrada e saída de qualquer estado simples ou acumulado devem ser idênticas. Considerando a Fig. 2.3, tem-se, por exemplo:

$$
P S_{1} \times N \lambda=P S_{2} \times \mu
$$

A probabilidade do Estado 2 pode ser expressa em função da probabilidade do Estado 1:

$$
P S_{2}=\frac{N \lambda}{\mu} \times P S_{1}=N \lambda \tau \times P S_{1}
$$


Sendo $\tau$ o tempo médio necessário para aquisição de um novo transformador:

$$
\tau=\frac{1}{\mu}
$$

Genericamente, a probabilidade estacionária de cada estado de sucesso, para $k$ variando de 1 a $n$, é dada por:

$$
P S_{1+k}=\frac{(N \lambda \tau)^{k}}{k !} \times P S_{1}
$$

Pode-se mostrar [11] que a probabilidade estacionaria de cada estado de falha, para $j$ variando de 1 a $N$, é:

$$
P S_{n+1+j}=\frac{N !(\lambda \tau)^{j}(N \lambda \tau)^{n}}{(N-j) !(n+j) !} \times P S_{1}
$$

Note que a soma de todas as probabilidades deve ser igual a 1.

$$
P S_{1}+\sum_{k=1}^{n} P S_{1+k}+\sum_{k=1}^{N} P S_{n+1+j}=1
$$

A probabilidade do Estado 1 deve ser determinada pela combinação de 2.21 e 2.23, resultando [11]:

$$
P S_{1}=\left[1+\sum_{k=1}^{n} \frac{(N \lambda \tau)^{k}}{k !}+N !\left(N \lambda_{\tau}\right)^{n} \sum_{j=1}^{N} \frac{(\lambda \tau)^{j}}{(N-j) !(n+j) !}\right]^{-1}
$$

Após calcular a probabilidade do Estado 1, as probabilidades estacionárias de todos os outros estados podem ser determinadas através de 2.21 e 2.22.

\subsection{4.}

\section{Indicadores de Frequência e Duração}

A representação por espaço de estados permite calcular outros índices além das vistas anteriormente, como as frequências em que os estados são encontrados e os tempos de duração médios de cada um deles. A frequência média de falha de um sistema, [14], pode ser calculada por (2.25) e equivale ao número médio de falhas que ocorrem em um sistema por unidade de tempo, por exemplo, por ano.

$$
F_{\text {falha }}=P S_{n+1} \times N \lambda=P S_{n+2} \times(n+1) \mu
$$


Considere que uma falha ocorra no sistema quando não há mais unidades de estoque disponíveis e uma das unidades em operação apesenta avaria. Neste caso, o sistema opera em estado de falha, com um transformador a menos em campo, e pode restabelecer a condição operativa normal caso um novo transformador seja adquirido e instalado, e que nenhum outro apresente defeito no período de reposição. A duração de cada falha depende então do tempo necessário para adquirir um novo equipamento e da possibilidade de ocorrerem outras falhas no período. Matematicamente, a duração média das falhas do sistema é expressa por:

$$
D_{\text {falha }}=\frac{P_{\text {falha }}}{F_{\text {falha }}}=\frac{\bar{A}}{F_{\text {falha }}}
$$

E o tempo médio entre as falhas (MTBF):

$$
M T B F=\frac{1}{F_{\text {falha }}}
$$

\subsubsection{1.}

\section{Exemplo 2}

Com a finalidade de ilustrar o cálculo dos indicadores, o exemplo 1 com quatro transformadores no campo e um transformador reserva, onde $\lambda=0,15$ falhas/ano é novamente resolvido. Sendo $\mu=1$ tem-se o espaço de estados simplificado ilustrado na Fig. 2.4:

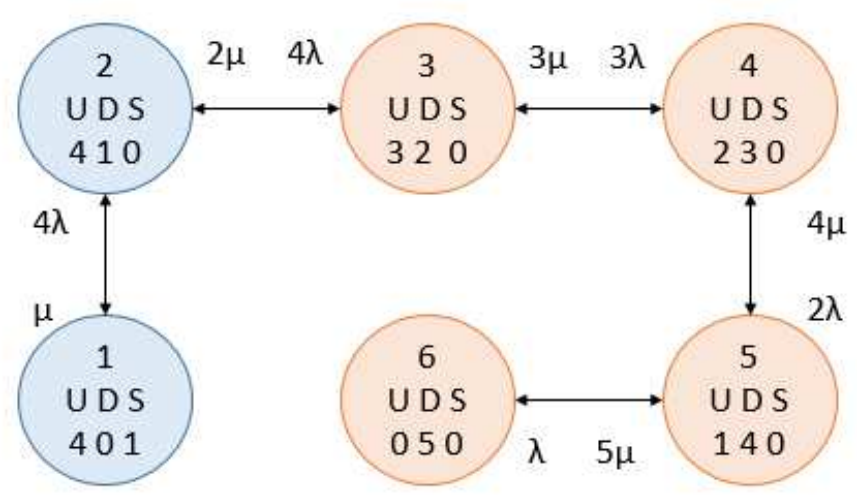

Figura 2.4 - Espaço de estados 
Considerando os estados 1 e 2 como estados de sucesso, tem-se uma confiabilidade $\mathrm{R}(\mathrm{t})=0,9446$. O risco de falha do sistema no período de um ano é de $5,5 \%(1-0,9446=0,0554)$.

Nota-se uma melhora na confiabilidade do sistema, que se deve ao fato de ser considerada a possibilidade de reparo ou obtenção de nova unidade no período de análise na modelagem Markoviana. Como no exemplo acima considerou-se $\mu=1$ o sistema apresentou melhoras no resultado, contudo, se o mesmo sistema for resolvido por Markov considerando $\mu=0$ o resultado será $\mathrm{R}(\mathrm{t})=0,87806$ de onde pode-se observar que o sistema volta para o estado calculado em Poisson, concluindo assim que a modelagem de Poisson pode ser tratada como um caso particular do modelo de Markov onde $\mu=0$.

\subsection{5.}

\section{Aspectos Econômicos}

O dimensionamento ótimo de estoque visa minimizar a soma entre custos de investimento e operação do sistema, que inclui custos de não faturamento, interrupção de energia, penalidades previstas em lei [3], perdas técnicas, reposição de equipamentos avariados e quaisquer outras parcelas que se deseje representar. Neste estudo, serão considerados os custos de interrupção, não faturamento e investimento. Como parcela de análise, o custo anual de operação será estimado a partir do cálculo da energia média não suprida (EENS):

$$
\text { Custo }_{o p}=\left(C_{E}+C_{I}\right) \times \text { EENS }
$$

onde $C_{E}$ é o valor da energia em $\$ / \mathrm{MWh}, C I$ é o valor médio do custo unitário de interrupção [38] de cada consumidor em \$/MWh e EENS = EPNS $\times$ 8760h.

A EPNS corresponde à média ponderada da potência que deixa de ser suprida, levando em conta as falhas, em cada estado do diagrama de estados, onde os pesos são as probabilidades estacionárias de cada estado, dada por:

$$
E P N S=\sum_{i=1}^{n_{e}} P N S_{i} \times P S_{i}
$$


Considerando o estado $i$, a potência não suprida aos consumidores pode ser estimada por:

$$
P N S_{i}=N A_{i} \times S_{N} \times F P \times F C
$$

onde $N A_{i}$ é a quantidade de transformadores em falha no campo no estado $i, S_{N}$ é a potência nominal dos transformadores em MVA, FP é o fator de potência da carga e $F C$ é o fator de carregamento médio dos transformadores.

O custo anual de investimento no estoque pode ser calculado por:

$$
\text { Custo }_{\text {inv }}=n \times C_{T} \times F V A
$$

em que $n$ é o número de transformadores reservas, $C_{T}$ é custo de aquisição de um transformador novo em $\$$ (unidade monetária), e $F V A$ é o fator para conversão de valor presente em valor anual, utilizando uma taxa anual $j$ e um período de $n_{p}$ anos.

$$
F V A=\frac{(1+j)^{n_{p}}-1}{j \times(1+j)^{n_{p}}}
$$

O aumento no número de transformadores reservas aumentará o custo de investimento e tornará o sistema mais confiável, resultando, consequentemente, em menores custos de interrupção e não faturamento. O número ótimo de estoque pode ser obtido comparando os custos do sistema em diversas alternativas de configuração do estoque, optando-se pela alternativa que apresentar a menor soma entre os custos de investimento e operação, desde que os indicadores de confiabilidade resultantes estejam dentro dos padrões exigidos.

\subsection{6.}

\section{Aplicação em um Sistema Real}

Considerando um sistema de 176 transformadores de $138-13,8 \mathrm{kV}$, com potência de 25 MVA e com os parâmetros descritos na Tabela 2-2, foi aplicada a solução do modelo proposto visando obter o comportamento do sistema ao acréscimo de unidades de estoque e comparar o comportamento dos custos em relação ao conjunto como um todo. 
Tabela 2-2 - Dados do Sistema da Seção 2.3.6

\begin{tabular}{|c|c|c|c|}
\hline Parâmetro & Símbolo & Valor & Unidade \\
\hline $\begin{array}{c}\text { Número de transformadores no } \\
\text { campo }\end{array}$ & $N$ & 176 & - \\
\hline Potência do transformador & $S$ & 25 & $\mathrm{MVA}$ \\
\hline Fator de carregamento médio & $F C$ & 0,508 & - \\
\hline Taxa de falha do transformador & $\lambda$ & 0,0135 & Falhas/ano \\
\hline $\begin{array}{c}\text { Taxa de aquisição (reposição do } \\
\text { estoque) }\end{array}$ & $\mu$ & 1 & Reposições/ano \\
\hline Vida útil do transformador & $V U$ & 40 & Anos \\
\hline Preço de venda da energia & $C_{E}$ & 204,6 & $\mathrm{R} \$ / \mathrm{MWh}$ \\
\hline $\begin{array}{c}\text { Custo de interrupção } \\
\text { Preço de um transformador novo }\end{array}$ & $C T$ & $1,70 \times 10^{6}$ & $\mathrm{R} \$ / \mathrm{MWh}$ \\
\hline $\begin{array}{c}\text { Taxa anual de desconto da } \\
\text { empresa }\end{array}$ & $j$ & $12 \%$ & - \\
\hline
\end{tabular}

A Tabela 2-3 apresentam os custos obtidos, para o número de reservas variando de uma a dez unidades.

Tabela 2-3 - Resultados em $10^{6} \times \mathrm{R} \$ /$ ano

\begin{tabular}{|c|c|c|c|}
\hline Reservas & Investimento & Operacional & Soma \\
\hline 1 & 0,20622 & 274,96733 & 275,17354 \\
\hline 2 & 0,41243 & 146,67375 & 147,08618 \\
\hline 3 & 0,61865 & 67,3173 & 67,93595 \\
\hline 4 & 0,82486 & 26,76269 & 27,58755 \\
\hline 5 & 1,03108 & 9,31198 & 10,34306 \\
\hline 6 & 1,23729 & 2,86713 & 4,10443 \\
\hline 7 & 1,44351 & 0,78937 & 2,23288 \\
\hline 8 & 1,64972 & 0,19616 & 1,84589 \\
\hline 9 & 1,85594 & 0,04436 & 1,90031 \\
\hline 10 & 2,06216 & 0,00919 & 2,07136 \\
\hline
\end{tabular}

Nota-se que os custos foram divididos entre custo de investimento e os custos operacionais, que englobam “interrupção" e "não faturamento". Pode-se observar 
que a partir da unidade 9 de estoque, seu impacto no sistema não causa melhora suficiente para pagar o seu investimento. Desse modo, o menor custo global será o de 8 unidades de estoque, pois até esse ponto o acréscimo de uma unidade apresenta impacto suficiente nos custos operacionais para viabilizar sua aquisição.

\section{6. \\ Conclusões}

Este capítulo apresentou um pequeno detalhamento dos dois modelos probabilísticos mais utilizados para abordar o problema proposto nesta dissertação, que são os modelos de Poisson e Markov.

O modelo de Poisson, apesar de ainda muito utilizado para determinar o nível de estoque ótimo, apresenta uma aplicação muito limitada, com a geração de poucos índices de comparação de funcionamento para os sistemas em estudo. Ademais, não permite a reposição do estoque durante o período de análise, além de não considerar envelhecimento dos equipamentos e não contemplar a modelagem dos componentes individualmente.

O modelo de Markov permite estimar indicadores de confiabilidade como indisponibilidade, frequência e duração média das falhas, tempo médio entre falhas, além dos valores esperados de potência e energia não supridas. Contudo algumas limitações existem, como a obrigatoriedade dos tempos envolvidos seguirem distribuições exponenciais, da necessidade de ter uma taxa de falha constante e igual para todos os transformadores do sistema, não retratando, assim, um sistema real. Tal modelo também não consegue modelar o envelhecimento dos equipamentos e suas peculiaridades individuais. No próximo capítulo será abordada a modelagem capaz de dimensionar de forma mais real os equipamentos dos sistemas elétricos. 


\section{3 Modelos de Simulação Monte Carlo para Determinação de Estoque}

\section{1. Introdução}

Este capítulo apresenta o modelo de simulação Monte Carlo (SMC) com suas principais considerações e evoluções. O método em questão baseia-se na análise de um grande número de anos, onde é simulado o comportamento de operação do sistema ao longo do período e contabilizadas os índices para o estudo. São utilizadas as taxas de falha e reparo dos equipamentos, sendo possível a discretização de dados por unidade, possibilitando assim a análise de equipamentos com mesma função, porém com características distintas.

A SMC apresenta dois modelos: não sequencial e cronológica. A SMC não sequencial não considera a cronologia dos eventos, perdendo a capacidade de analisar com precisão o envelhecimento dos equipamentos envolvidos no sistema, desconsiderando assim dados relevantes para alguns comparativos, como o desgaste por falhas, por uso em sobrecarga ou envelhecimento dos equipamentos. A simulação cronológica comtempla o envelhecimento dos seus equipamentos, refletindo da forma mais fiel possível, as condições de operação e o histórico de impactos sofridos pelos mesmos ao longo de sua vida operativa.

\section{2.}

\section{Simulação Monte Carlo}

A simulação Monte Carlo é uma metodologia estatística que se baseia em uma grande quantidade de amostragens aleatórias, visando calcular as probabilidades heuristicamente. $\mathrm{O}$ método tem ampla utilização, em diferentes áreas, visando obter uma aproximação numérica da solução de problemas de alta complexidade. 


\subsection{1.}

\section{Simulação Não Sequencial}

A SMC não sequencial utiliza a metodologia baseada na representação de espaço de estados, onde pode-se usar o modelo de Markov para os equipamentos e para a carga simultaneamente. Os estágios de operação são sorteados de acordo com as distribuições associadas, sem contemplar nenhum critério cronológico, utilizando-se apenas da probabilidade de ocorrência dos eventos.

A simulação do método não cronológico consiste basicamente em cinco passos [28]:

1) Modelar o sistema, considerando as taxas de falha e reparo, de cada equipamento e as possibilidades de variação da carga. Definir o que será considerado falha e o que será estado de sucesso;

2) Sortear valores aleatórios entre 0 e 1 para todos os equipamentos do sistema e compará-los com os valores de operação para definição do estágio do equipamento e condição da carga;

3) Armazenar os dados obtidos nos itens anteriores e calcular a variação nos valores que são encontrados para os índices calculados ao longo das simulações, que tem por finalidade observar o andamento dos valores dos índices para a convergência das mesmas;

4) Analisar a convergência dos índices de desempenho do sistema através de um coeficiente de variação. Uma vez satisfeita tal tolerância seguir para passo 5, caso contrário, voltar ao passo 3;

5) Estimar os índices relacionados à confiabilidade do sistema, considerando todas as amostras obtidas ao longo das simulações.

A simulação não sequencial é preferível em relação aos métodos analíticos anteriormente descritos quando se lida com sistemas maiores e mais complexos. Ademais, a SMC não sequencial apresenta uma implementação bem simples e um custo computacional menor se comparado ao modelo cronológico. Entretanto, esse tipo de simulação não consegue capturar sequências de eventos cronológicos (e.g., efeitos do envelhecimento e desgaste dos equipamentos, tempos não exponenciais, etc.) e, diante de um sistema pode apresentar um desempenho computacional inferior aos métodos analíticos. 


\subsection{2.}

\section{Sequencial}

A simulação Monte Carlo sequencial ou cronológica representa uma ferramenta ideal para análise de eventos que dependem do transcorrer do tempo. A simulação sequencial basicamente segue os mesmos princípios iniciais da não cronológica, contudo, leva em consideração o estado atual de cada componente, da carga e do sistema como um todo para definir os próximos estados. Com essas características, o modelo permite modelar uma gama de fatores que são relacionados ao envelhecimento e a inter-relação de eventos.

Pode-se tomar como exemplo a Figura 3.1, onde tem-se a ilustração do funcionamento da SMC cronológica ao problema de dimensionamento de estoque, considerando três equipamentos iguais:

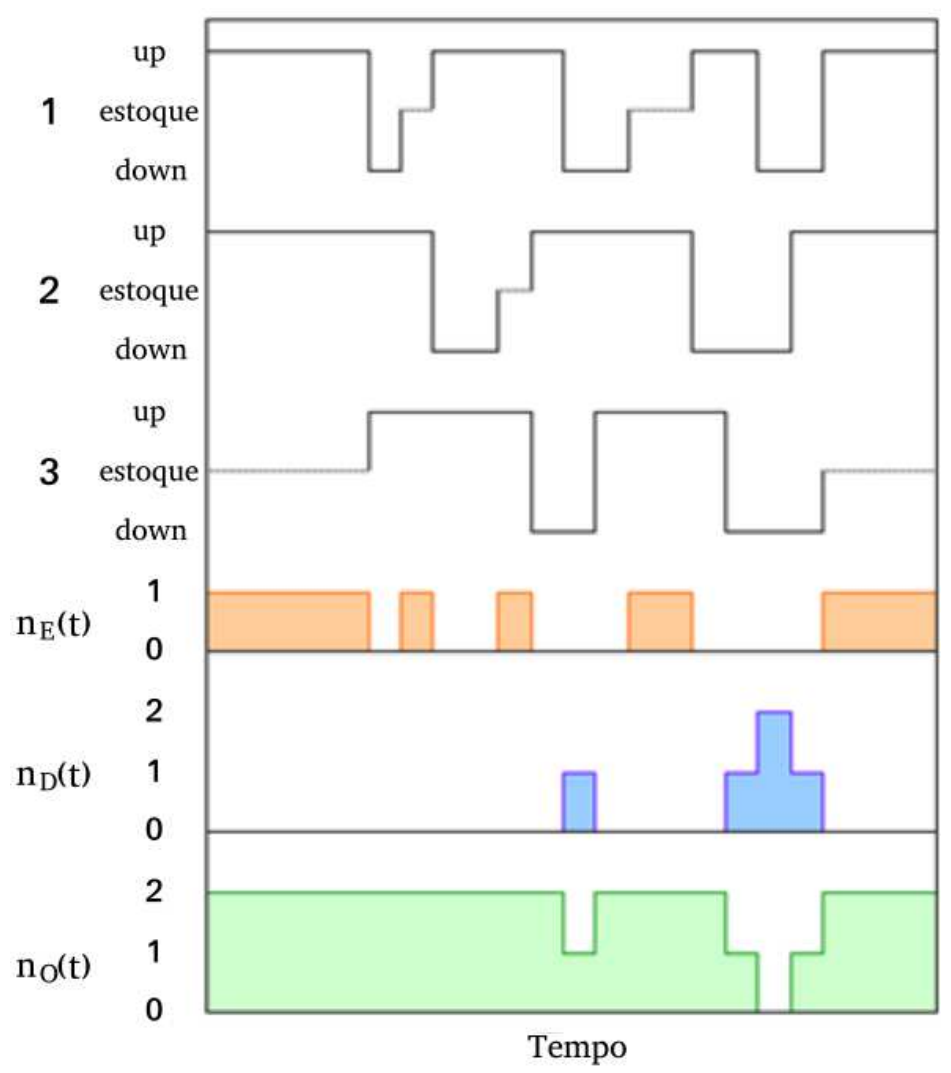

Figura 3.1 - llustração de uma SMC cronológica

Observa-se que o sistema inicialmente apresenta duas unidades operando e uma unidade em estoque, no momento em que a unidade 1 sofre um defeito e é substituída pela unidade 3. Destaca-se que o tempo de substituição de um equipamento pelo reserva é desconsiderado, por apresentar valor muito pequeno se comparado ao tempo de operação total. 
Com o decorrer do tempo os equipamentos são repostos e passam a compor o estoque caso não tenha ocorrido nenhuma outra falha até o momento de reposição, caso a segunda opção ocorra, ele entrará diretamente em operação.

A análise temporal, como feita acima, permite detectar a cada momento selecionado o número de unidades em operação $\left(n_{O}\right)$, as unidades disponíveis no estoque $\left(n_{E}\right)$ e o déficit de equipamentos no campo $\left(n_{D}\right)$.

Considerando uma distribuição exponencial, os tempos de funcionamento de cada equipamento são sorteados por:

$$
t_{f}=-\frac{1}{\lambda} \times \ln (U)
$$

onde $\lambda$ é a taxa de falha do equipamento e $U$ é um número pseudoaleatório com distribuição uniforme entre 0 e 1 . Pode-se obter uma expressão análoga para os tempos de aquisição, bastando substituir $\lambda$ pela taxa de reposição $\mu$ :

$$
t_{r}=-\frac{1}{\mu} \times \ln (U)
$$

As Equações 3.1 e 3.2 utilizam distribuições exponenciais, válidas no período de vida útil do equipamento [14], frequentemente admitida para tempos de reposição, quando se utilizam processos Markovianos. Entretanto, o modelo não se restringe a essa modelagem, possibilitando a representação de diferentes distribuições estatísticas como a Gaussiana, etc., como também outras quaisquer cujos dados de entrada podem ser lidos através de histogramas, por exemplo.

\section{3. \\ Simulação Monte Carlo Cronológica - Índices e Evoluções}

\subsection{1.}

\section{Índices de Confiabilidade}

Entre os índices de confiabilidade que a simulação cronológica permite calcular, destacam-se:

- Disponibilidade: probabilidade de um sistema apresentar, em qualquer instante de tempo futuro, todos os seus transformadores de campo em operação normal.

$$
P=\frac{\text { Tempo total de funcionamento }}{\text { Tempo total de simulação }}
$$


- Frequência média das falhas: número esperado de falhas do sistema por unidade de tempo. Sendo considerado falha apenas quando em caso de falha de um equipamento não houver equipamento em estoque para substituição, causando interrupção de fornecimento.

$$
f=\frac{\text { Número de falhas do sistema }}{\text { Tempo total de simulação }}
$$

- Duração média das falhas: tempo médio durante o qual o sistema terá uma interrupção de alimentação, parcial ou total, a cada vez que ocorrer uma falha.

$$
D=\frac{\text { Tempo total de falha }}{\text { Número de falhas do sistema }}
$$

- Tempo médio entre falhas (MTBF - Mean Time Between Failures): representa o tempo médio decorrido entre duas falhas consecutivas no sistema.

$$
M T B F=\frac{\text { Tempo total de simulação }}{\text { Número de falhas do sistema }}
$$

- $\quad$ Potência Média Não Suprida (EPNS - Expected Power Not Supplied): valor médio da potência não suprida, a potência equivalente que o sistema deixa de suprir à sua carga em decorrência de suas falhas.

$$
E P N S=\frac{\text { Energia total não fornecida }}{\text { Tempo total de simulação }}
$$

\subsection{2.}

\section{Aplicação em um Sistema Real}

Para fins de comparação, será utilizado o mesmo sistema resolvido por Markov, discriminado na Tabela 2-2, com 176 transformadores de 138-13,8 kV e potência de 25 MVA. Os dados foram analisados através do programa computacional desenvolvido neste trabalho, e foram considerados tempos com distribuição exponencial para viabilizar a comparação entre métodos. As tabelas 31 e 3-2 ilustram os resultados obtidos pela SMC. 
Tabela 3-1 - Índices de Confiabilidade

\begin{tabular}{|c|c|c|c|c|}
\hline $\begin{array}{c}\text { Número de } \\
\text { Reservas }\end{array}$ & $\begin{array}{c}\text { Indisponibilidade } \\
\text { (horas/ano) }\end{array}$ & $\begin{array}{c}\text { Frequência } \\
\text { (falhas/ano) }\end{array}$ & $\begin{array}{c}\text { Duração } \\
\text { (dias) }\end{array}$ & EENS (MWh/ano) \\
\hline 1 & 6039,27 & 0,5337 & 471,55 & $162.909,50$ \\
\hline 2 & 3646,32 & 0,6232 & 243,8 & $85.554,77$ \\
\hline 3 & 1900,45 & 0,4992 & 158,6 & $39.931,36$ \\
\hline 4 & 820,33 & 0,2972 & 115 & $15.766,87$ \\
\hline 5 & 296,82 & 0,1393 & 88,8 & 5400,95 \\
\hline 6 & 95,12 & 0,0547 & 72,4 & 1654,64 \\
\hline 7 & 27,68 & 0,0188 & 61,3 & 465,23 \\
\hline 8 & 6,95 & 0,0055 & 52,2 & 113,73 \\
\hline 9 & 1,62 & 0,0015 & 46,3 & 25,99 \\
\hline 10 & 0,34 & 0,0003 & 41,1 & 5,38 \\
\hline
\end{tabular}

Tabela 3-2 - Valores de Custos em R $\$$ /ano

\begin{tabular}{|c|c|c|c|}
\hline Número de Reservas & Investimento & $\begin{array}{c}\text { Interrupção e Não } \\
\text { Faturamento }\end{array}$ & Total \\
\hline 1 & $206.216,16$ & $277.695 .530,99$ & $277.901 .747,16$ \\
\hline 2 & $412.432,33$ & $145.836 .659,56$ & $146.249 .091,89$ \\
\hline 3 & $618.648,49$ & $68.049 .953,10$ & $68.668 .601,59$ \\
\hline 4 & $824.864,65$ & $26.876 .211,25$ & $27.701 .075,90$ \\
\hline 5 & $1.031 .080,82$ & $9.206 .454,77$ & $10.237 .535,59$ \\
\hline 6 & $1.237 .296,98$ & $2.820 .499,92$ & $4.057 .796,90$ \\
\hline 7 & $1.443 .513,14$ & $793.035,55$ & $2.236 .548,69$ \\
\hline 8 & $1.649 .729,31$ & $193.872,44$ & $1.843 .601,74$ \\
\hline 9 & $1.855 .945,47$ & $44.309,02$ & $1.900 .254,49$ \\
\hline 10 & $2.062 .161,63$ & 9176,07 & $2.071 .337,71$ \\
\hline
\end{tabular}

A simulação cronológica chegou a resultados próximos dos encontrados por Markov na Tabela 2-3, onde o menor custo de operação anual seria com oito unidades reservas. Isso demonstra que para distribuições exponenciais a SMC apresenta comportamento dentro do esperado por Markov. 


\subsection{3. Evolução nas Análises}

O modelo Cronológico possibilita uma maior proximidade das características reais dos sistemas. Como citado anteriormente, a capacidade de considerar taxas de falhas distintas para cada componente e analisar as mesmas no decorrer do tempo consegue inserir na simulação dados mais realistas e ignoradas pelos outros métodos por impossibilidade de incluir o modelo na análise.

Fator amplamente discutido e desprezado por outros métodos de simulação, o envelhecimento das unidades transformadoras apresenta grande impacto no ciclo final de vida dos mesmos. Uma modelagem que pode ser empregada pela simulação cronológica, a Teoria de Arrhenius [29], [31] modela o impacto de sobrecargas e faltas transitórias sobre a vida útil do equipamento, mostrando de forma efetiva a variação na taxa de falha do mesmo com o decorrer do tempo.

A flexibilização da modelagem cronológica permite ainda considerar componentes e situações até então pouco tratados ou analisados de forma superficial, como a transferência de carga [30] para circuitos em paralelo ou subestações próximas. Com isso, torna-se possível analisar o impacto das mesmas, dimensionar um tempo máximo não prejudicial para essas transferências, e considerar também a possibilidade de transferência de carga para o período de substituição de unidades, visando mitigar o tempo de interrupção de energia aos clientes.

O problema proposto das unidades móveis também toma uma análise distinta das feitas até então [34]-[37], onde os métodos propostos se baseiam principalmente no modelo de Markov. Na modelagem proposta nestas referências, as unidades móveis são consideradas da mesma forma que as convencionais, não sendo possível modelar tempos de instalação, que são diferentes entre os dois tipos de equipamento, ficando assim as unidades móveis limitadas em suas vantagens operacionais. Nas análises anteriores, a utilização da unidade móvel fica restrita a situações de manutenção programada, não sendo considerada como uma ferramenta capaz de intervir em diferentes configurações, limitando assim seu poder de atuação, o que acaba por reduzir seu impacto durante a operação de um sistema. 
Como mencionado no Capítulo 2, os modelos Markovianos utilizados em [34]-[37] se caracterizam por taxas de transição constantes (i.e., exponenciais), e fornecem resultados de índices (e.g., indisponibilidade, etc) estacionários. Tais índices geralmente são interpretados em bases anuais, caracterizados por médias. No modelo aqui proposto, será analisado um período de operação qualque, onde se consegue analisar processos de falha e reparo cujas durações podem ser caracterizadas por distribuições exponenciais ou não.

O modelo proposto nesta dissertação possibilita a análise da vantagem operacional do tempo de instalação inferior que a unidade móvel apresenta em relação a unidade convencional. Considera também a possibilidade de utilização da unidade móvel em todas as localidades do sistema, permitindo ainda combinar a transferência de carga com o uso de unidades móveis e ilustrar os benefícios alcançados com a utilização dessas ferramentas. Uma unidade móvel é modelada de forma a cada unidade possuir o seu próprio tempo de instalação, permitindo levar em consideração as diferenças de distância ou dificuldades de acesso de uma determinada unidade, o que tornaria a utilização da unidade móvel menos atrativa. Com uma modelagem mais realista, é possível analisar o real impacto em termos de confiabilidade e custos para o sistema de diferentes estratégias de uso dos estoques e de seus componentes.

Outro fator positivo da resolução por SMC é a consideração da renovação dos componentes, que poderão se apresentar com características distintas daqueles que irão substituir, sendo possível analisar uma expansão do parque de transformadores e também a evolução da carga com o passar dos anos.

\section{4. Conclusões}

A simulação Monte Carlo apesar do esforço computacional exigido, apresenta grande variedade de recursos, o que torna sua utilização interessante em sistemas de modelagem complexa e com comportamentos que fogem aos modelados por Markov, como o envelhecimento progressivo de equipamentos ou tempos de instalação relevantes. 
A diferenciação de cada unidade, com suas taxas e tempos de utilização distintos permite uma análise mais coerente quanto a real necessidade de estoque, apresentando um cenário mais realístico do que é encontrado em campo.

Destaca-se ainda, que apesar do foco em transformadores, a SMC permite modelar diferentes equipamentos elétricos, com suas peculiaridades e características de funcionamento. 


\section{4 \\ Metodologia de Simulação Cronológica Considerando Unidades Móveis}

\section{1. Introdução}

Este capítulo tem por objetivo detalhar a metodologia proposta, descrevendo seu processo de simulação e as hipóteses consideradas ao longo do mesmo. Conforme mencionado no Capítulo 2, os modelos analíticos apresentam limitações, o que leva a considerações e premissas de funcionamento do sistema analisado por esses métodos que distanciam do comportamento real de um sistema elétrico.

A metodologia de simulação Monte Carlo Cronológica foi escolhida por melhor representar o comportamento dos equipamentos a serem analisados, podendo considerar o efeito do envelhecimento dos transformadores, a distribuição de carga não homogênea, o impacto da substituição de uma unidade antiga por uma nova. De um modo geral, é possível modelar diferentes comportamentos de equipamentos e considerá-los individualmente, o que não era possível nas metodologias do Capítulo 2.

As subestações móveis e seu comportamento também serão descritos ao longo deste capítulo, mostrando a evolução de sua modelagem e seu impacto em um sistema elétrico real.

\section{2.}

\section{Subestações Móveis}

Uma subestação móvel é uma subestação elétrica completamente equipada que pode facilmente ser movimentada por estar montada em um protótipo de trailer [33]. 
As subestações móveis são equipamentos de grande flexibilidade operacional, dentro de suas características elétricas, como tensão e potência, podendo substituir temporariamente uma unidade avariada, sendo capaz de se deslocar por longas áreas para atender falhas em diferentes locais [32]. Uma grande vantagem, modelada no Modelo Monte Carlo Cronológico a seguir, é a possibilidade de deslocamento de uma unidade móvel em caso de falha, visando mitigar o tempo com a unidade em estado de defeito. Neste caso, a móvel é instalada temporariamente até que a instalação de uma nova unidade convencional seja concluída. Como seu tempo de instalação (1 a 3 dias) é inferior ao tempo de instalação de uma unidade convencional (11 a 13 dias), devido à necessidade de obras civis e ajustes para a instalação de um transformador novo, mesmo se existir estoque disponível a móvel se torna atrativa, pois diminui a duração da falha, estando disponível e capaz de suprir o sistema em menos da metade do tempo de uma unidade convencional. No caso da inexistência de estoque, a móvel pode ser utilizada para suprir a carga até a chegada de uma nova unidade.

Um ponto relevante é que concluída a instalação do transformador convencional, a subestação móvel poderá ser desligada e atender a uma nova falha em outra subestação, sendo necessário apenas seu tempo de deslocamento até o novo ponto de falha, se tornando assim um interessante instrumento para redução dos impactos decorrentes de falhas em transformadores de subestações de distribuição.

Outra utilização da subestação móvel citada na literatura [32] é seu emprego na situação de uma subestação convencional não acompanhar o crescimento da demanda. Como por exemplo a implantação de uma nova planta industrial que não poderia ser energizada por exigir obras ou expansões em uma subestação que ainda não foram concluídas. Nessa situação, uma unidade móvel pode ser utilizada até a conclusão das obras e após isso, pode ser deslocada para atender pontos em falha novamente.

Sua utilização para fins de manutenção de unidades visando não interromper o fornecimento de energia em períodos de manutenção preventiva e preditiva é citada na literatura [32], [33]. A carga destinada ao transformador que entrará em manutenção é previamente direcionada para uma subestação móvel que fará a alimentação da carga pelo período necessário para a manutenção, aumentado a flexibilidade da operação ao planejar trocas de equipamentos ou manutenções sem 
impacto para o sistema. Outra aplicação da subestação móvel é sua utilização para alimentação de áreas isoladas ou como reservas em áreas de conflitos e regiões atingidas frequentemente por impactos naturais.

Apesar de não modelar as aplicações mencionadas nos dois últimos parágrafos, essas opções de operação são importantes para salientar a flexibilidade e diversidade de utilização de unidades móveis, o que as torna mais interessantes e atrativas para as concessionárias, por aumentar sua flexibilidade operacional e consequentemente reduzir seus custos operativos.

Estudos recentes mostram como unidades móveis podem impactar positivamente nos custos em sistemas de distribuição. Em [34] é apresentado dados do sistema elétrico canadense, simulando os custos financeiros da utilização de subestações móveis aplicadas a redução dos tempos de falha em subestações de distribuição. Em seu modelo inicial, foi considerada a necessidade que sua distribuidora estava passando, de substituição de equipamentos programados e da possibilidade de falha no transformador redundante durante a substituição das mesmas, passando então a alocar unidades móveis disponíveis para suprir essas falhas locais. Através de sua análise, torna-se possível visualizar o impacto positivo na redução dos custos de interrupção.

Em [35] a análise de [34] é expandida sendo apresentado o novo modelo utilizado. O sistema de [35] foi desenvolvido seguindo um modelo de Markov, que implica algumas aproximações já citadas em seções anteriores. Contudo, ressaltase que por esse modelo a unidade móvel passa a ser vista como uma unidade de estoque, entrando em operação assim que a unidade em operação falhar sendo considerada apta a substituir qualquer unidade que falhe no sistema. O modelo de Markov apresenta comportamento mais realista que o utilizado em [34], onde uma unidade móvel só podia atender a uma determinada situação de manutenção, agora é possível uma unidade móvel atender a uma emergência em um grupo maior de unidades, desde que apresentem as mesmas características elétricas. Entretanto, o modelo ainda apresenta limitações, por não permitir a modelagem do tempo de instalação de unidades móveis diferente das unidades convencionais.

Em [36] é aperfeiçoado o modelo de custos em relação à [35] e em [37] o modelo utilizando Markov passa a possibilitar a utilização de unidades móveis de forma temporária, atrelando o seu tempo de uso ao tempo de reparo ou compra de uma nova unidade. Com essas atualizações, o modelo [37] atende às necessidades 
apresentadas para análise de custo de operação do modelo proposto, as subestações de distribuição, com unidades redundantes, passando por períodos programados de manutenção. Contudo, o modelo Markov apresenta limitações que impedem uma análise mais aproximada da realidade operativa.

No modelo proposto em [37] todas as unidades são vistas de forma semelhante, desprezando o envelhecimento individual de cada unidade, problema descrito ao longo de [34], visto que as unidades estão em período de troca por estarem alcançando o tempo máximo de operação. Além disso, não é possível modelar as diferenças de tempo entre instalação de uma unidade convencional, uma unidade móvel e a execução de uma transferência de carga, parâmetros esses que são de fundamental importância para mitigar o tempo decorrido entre a falha e sua extinção. Considerando a instalação de uma unidade móvel ou unidade convencional como instantânea, deixa-se de contabilizar o período de falha e a transferência de carga se torna um recurso completamente desnecessário.

A modelagem proposta nesta dissertação cobre todos as limitações do modelo Markoviano citadas acima, tornando possível e mais próxima da realidade comparações de estratégias para minimizar os tempos de falha e comparações reais sobre custos operacionais e de investimento.

\section{3. \\ Modelo Cronológico Básico}

\subsection{1.}

\section{Processo de Simulação}

O modelo de simulação Monte Carlo (SMC) cronológica, é uma ferramenta matemática baseada na seleção e análise de uma grande quantidade de amostras dos estados dos componentes de um sistema, obtidos através das variáveis aleatórias correspondentes. A representação cronológica dos eventos permite analisar situações de operação geralmente não suportadas pelo método analítico.

Formulações seguindo Poisson e Markov utilizam distribuição exponencial do tempo e equipamentos com taxas de falha idênticas. Entretanto, na prática, de acordo com o processo de envelhecimento dos transformadores, a expansão do 
sistema com a entrada de novas subestações e a substituição de equipamentos avariados por novos, implica na necessidade de análise individual de cada equipamento, que terá idade e características de operação distintas, o que vai contra as premissas iniciais desses modelos.

O algoritmo proposto neste trabalho foi desenvolvido para permitir o cálculo dos índices de confiabilidade e os custos associados a um grupo de transformadores, possibilitando analisar a viabilidade e a estratégia econômica para composição de estoque para o período considerado. Os dados de entrada deste problema são: período de análise; número de transformadores em operação; número de unidades reservas e de subestações móveis; carga de cada transformador; previsão de inclusão de novas subestações e aumento de carga; e dados com a data e número de unidades sobressalentes a serem incluídos.

O tempo de vida restante dos transformadores é modelado individualmente, portanto, se necessário, cada transformador no sistema pode ter sua própria distribuição de probabilidades, Parâmetros relacionados ao tempo de reposição de estoque, tempo para transferência de carga, para instalação de subestação móvel ou substituição de unidade avariada por uma do estoque também são modelados por distribuições de probabilidades específicas.

O algoritmo cronológico gera uma grande quantidade de simulações do período analisado, baseado nas distribuições de probabilidade de tempo definidas e das estratégias de composição do sistema e de estoque estabelecidas para o período. Baseado nessas simulações, os índices de confiabilidade, já explicados na Seção 3.3.1, são calculados.

Além dos índices de confiabilidade, os custos médios de operação podem ser calculados. Esses custos são estimados através da energia esperada não suprida (EENS), que quantifica a energia que a concessionária deixou de vender e também aos custos pagos por interrupção do fornecimento de energia ao cliente durante as mesmas. Considerando $C_{E}$ a tarifa de venda da energia e $C_{I}$ o custo de interrupção, ambos em \$/MWh, tem-se:

$$
\text { Custo }_{\text {Operação }}=\left(C_{E}+C_{I}\right) \times \text { EENS }
$$


É importante destacar que os índices e custos estimados pelo modelo cronológico são dependentes dos parâmetros fornecidos como dados de entrada. Diferentes estratégias de operação implicam em diferentes índices de confiabilidade e custos de operação, tornando o modelo atrativo para comparação entre configurações de estoque e alternativas de investimento, visando otimizar os mesmos.

O algoritmo de simulação Monte Carlo proposto neste trabalho está resumido nos seguintes passos:

1. Ler os dados de entrada, o período de análise e a estratégia de composição de estoque.

2. Inicializar o processo de simulação $N_{S}=0$;

3. Incrementar o número de simulações, $N_{S}=N_{S}+1$;

4. Simular um período completo de análise, amostrando os tempos de operação dos transformadores, de reposição de estoque, transferência de carga, instalação de unidades móveis e unidades reservas;

5. Monitorar e acumular, nas variáveis correspondentes, o tempo de falha do sistema, o número de falhas ocorridas e a energia não suprida, para o cálculo dos índices de confiabilidade e os custos;

6. Verificar a convergência (via um coeficiente de variação $\beta$ [38]), caso necessário, retornar para o passo 3;

Após a convergência, calcular os índices de confiabilidade, os custos de operação e apresentar os resultados.

\subsection{2.}

\section{Estratégias Operativas}

O item 4 do algoritmo representa todos os passos necessários e a sequência operacional adotada no processo.

A Figura 4.1 ilustra através de um fluxograma as principais medidas adotadas para o sistema em caso de falha em um transformador. A primeira medida é dar início ao processo de aquisição de um novo transformador, onde será determinado o tempo para aquisição através de uma distribuição uniforme de probabilidades, o intervalo adotado foi entre 11 e 13 meses. 


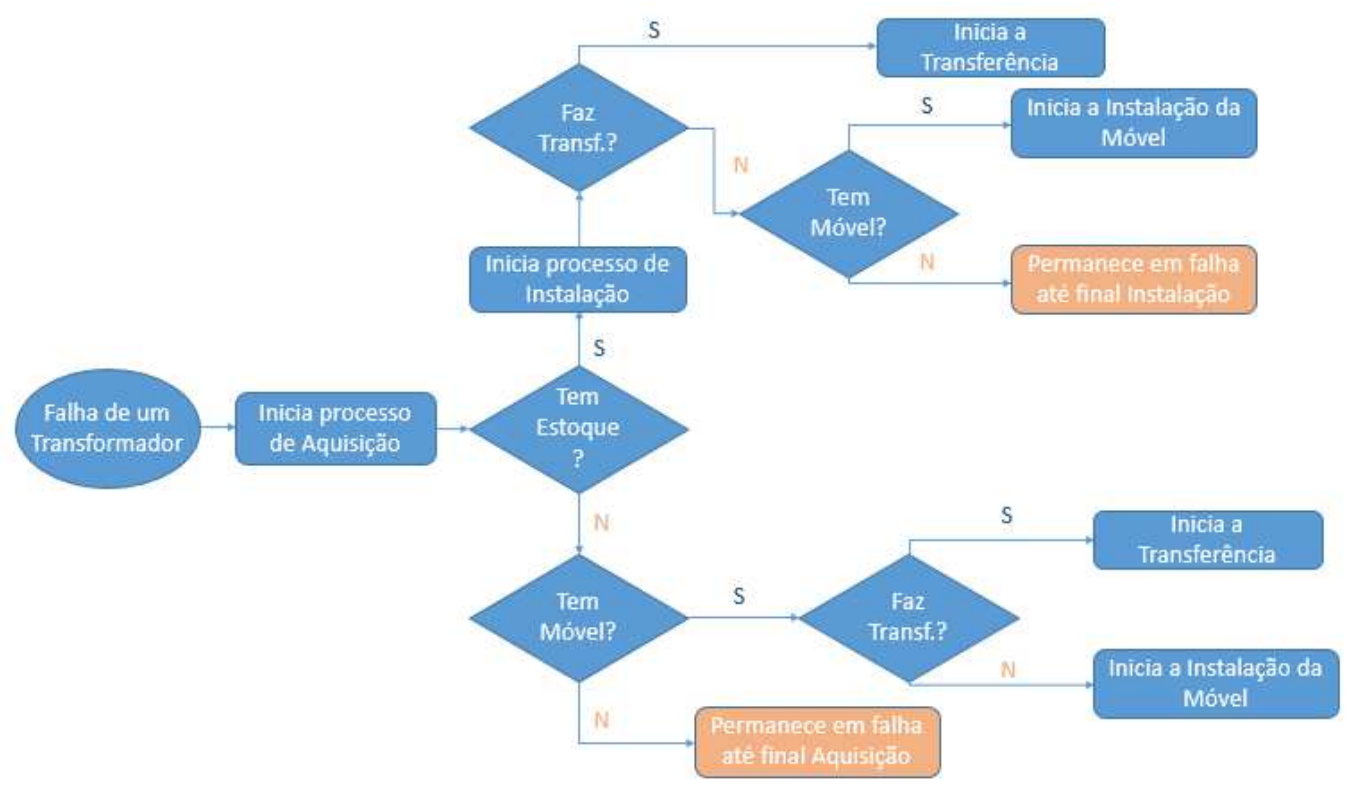

Figura 4.1 - Fluxograma de decisões em caso de falha

Em seguida, é avaliada a existência ou não de unidade disponível em estoque. Caso exista unidade de estoque disponível, uma unidade é retirada do estoque e seu tempo de instalação é determinado através de uma distribuição uniforme de probabilidades com intervalo entre 9 e 11 dias. A instalação fica programada e então são analisadas as outras opções. Inicialmente, verifica-se a possibilidade de a unidade avariada ter sua carga transferida para outra subestação. Caso seja possível, será realizada a transferência de carga, mitigando a falha em um tempo entre 2 e 4 horas, e será finalizada assim que a instalação for concluída. Caso a transferência não seja viável, será verificada a disponibilidade de unidades móveis. Se estiver disponível, uma será direcionada para a falha, passando a alimentar a carga em um intervalo entre 1 e 3 dias. A móvel será desligada e novamente disponibilizada para o sistema assim que a instalação da unidade de estoque for concluída. Caso não seja possível efetuar a transferência e não exista móveis disponíveis, o sistema estará em estado de falha até a instalação da unidade de estoque ser concluída. A transferência é considerada primeiro por apresentar um tempo de reação menor e não diminuir a disponibilidade de equipamentos para outras falhas.

Caso não exista estoque disponível, será analisada apenas a existência ou não de unidades móveis, pois não é recomendado a utilização de transferência de carga 
por longos períodos de tempo devido ao impacto que a mesma pode causar em outras unidades como sobrecargas, podendo levar a falha de outro equipamento. Caso haja disponibilidade de uma unidade móvel, a mesma será direcionada para o local de falha, eliminando a interrupção no intervalo de 1 a 3 dias, ficando alocada no ponto de interrupção até a chegada de uma nova unidade ou o término do seu tempo máximo de utilização, definido inicialmente em 180 dias. Caso seja possível a transferência de carga da unidade avariada e exista disponibilidade de unidade móvel, pode ser feita a transferência para mitigar o tempo de falha até a instalação da unidade móvel. Se não houver unidades móveis disponíveis, o sistema ficará em falha até a chegada de uma nova unidade que estava em processo de aquisição.

Ressalta-se que os valores de intervalos de instalação e aquisição são parâmetros de entrada do sistema. Os valores citados nos três parágrafos anteriores são os dados utilizados inicialmente nas simulações, obtidos a partir do comportamento usual de uma concessionária de grande porte.

Será analisado um período de 10 anos, com um coeficiente de variação de 1\%, dispondo de 132 unidades no início do período sendo expandida para 147 no primeiro mês do oitavo ano de simulação. Para fins de simplificação, será adotada a mesma carga para todas as unidades, de 7,295 MW, sendo possível, caso necessário, utilizar cargas diferentes para cada unidade. Não foi utilizado acréscimos de carga no período em análise.

\section{4. Resultados}

Para os testes abaixo, será utilizado o sistema elétrico descrito no item anterior, com 132 unidades iniciais, sendo expandido para 147 da classe $72-25 \mathrm{kV}$, 16 MVA utilizados na MidAmerican [2], com taxa de falha igual para todos os equipamentos de 0,011 falhas por ano. Não será considerado aumento de carga, o tempo de reposição de unidades de estoque está entre 11 e 13 meses, o tempo de instalação de uma unidade móvel entre 1 e 3 dias, a transferência, quando possível, entre 2 e 4 horas. Será analisado um período de 10 anos.

Para simplificar a análise, não serão apresentados todos os índices calculados, contudo, a consolidação dos resultados dos testes está disponível no apêndice ao 
final dessa dissertação, sendo feitas algumas considerações para facilitar seu entendimento.

\subsection{1.}

\section{Caso 1}

Considerando o sistema com o estoque inicial de 5 unidades, a subestação móvel podendo ser utilizada por um período máximo de 180 dias e sem a possibilidade de transferência de carga em nenhuma unidade, será acrescentado unidades móveis visando ilustrar seu impacto no sistema.

Tabela 4-1 - Caso 1: Índices de Confiabilidade

\begin{tabular}{|c|c|c|c|}
\hline $\begin{array}{c}\text { Número de } \\
\text { Unidades Móveis }\end{array}$ & EENS (MWh/p) & $\begin{array}{l}\text { Indisponibilidade } \\
(\mathbf{h} / \mathbf{p})\end{array}$ & $\begin{array}{c}\text { Frequência Média } \\
\text { de Falhas (f/p) }\end{array}$ \\
\hline 0 & $29.571,06$ & $3.908,25$ & 14,4505 \\
\hline 1 & $7.855,19$ & $1.190,98$ & 15,0897 \\
\hline 2 & $6.376,41$ & $1.043,52$ & 15,1153 \\
\hline 3 & $6.263,03$ & $1.029,94$ & 15,2074 \\
\hline 4 & $6.233,11$ & $1.074,01$ & 15,1725 \\
\hline 5 & $6.228,58$ & $1.092,17$ & 15,1842 \\
\hline 6 & $6.228,58$ & $1.092,17$ & 15,1842 \\
\hline
\end{tabular}

O primeiro resultado da Tabela 4-1 ilustra o sistema sem nenhuma unidade móvel, em seguida é inserida a primeira unidade móvel, e assim sucessivamente, uma a uma, até encontrar a saturação; ponto onde não faz diferença inserir mais nenhuma subestação móvel. Isso acontece, pois, a probabilidade de falha no sistema de seis unidades no período de utilização de unidade móvel é muito baixa, não influenciando o resultado.

Destacam-se os valores encontrados para a frequência média de falhas, que mantem o valor em torno do valor inicial, ocorrendo até um pequeno aumento, (dentro da tolerância especificada), visto que a utilização de unidades móveis não visa evitar a falha, e sim minimizar seu impacto para o sistema. As falhas continuaram ocorrendo, entretanto, a utilização de subestações móveis tem o intuito de reduzir a duração das mesmas e, como consequência, seu impacto para o sistema. 
O gráfico da Fig. 4.2 ilustra os resultados acima descritos, mostrando o impacto da primeira unidade inserida no sistema, reduzindo a menos de um terço o valor da indisponibilidade, caindo de $3.908,25$ horas para $1.190,98$ horas no período, com a inclusão da primeira unidade móvel, ilustrando o impacto positivo que a inserção desse equipamento no planejamento de um sistema elétrico pode ter.

A segunda unidade apresenta um impacto menor, e assim por diante, até o momento da saturação em que 5 ou 6 unidades móveis apresentam exatamente o mesmo impacto no sistema. Isso ocorre devido à baixa probabilidade de falhas simultâneas, que seria aonde as subestações móveis apresentariam maior impacto com o seu tempo máximo de utilização limitado a 180 dias, não substituindo assim uma unidade de estoque convencional.

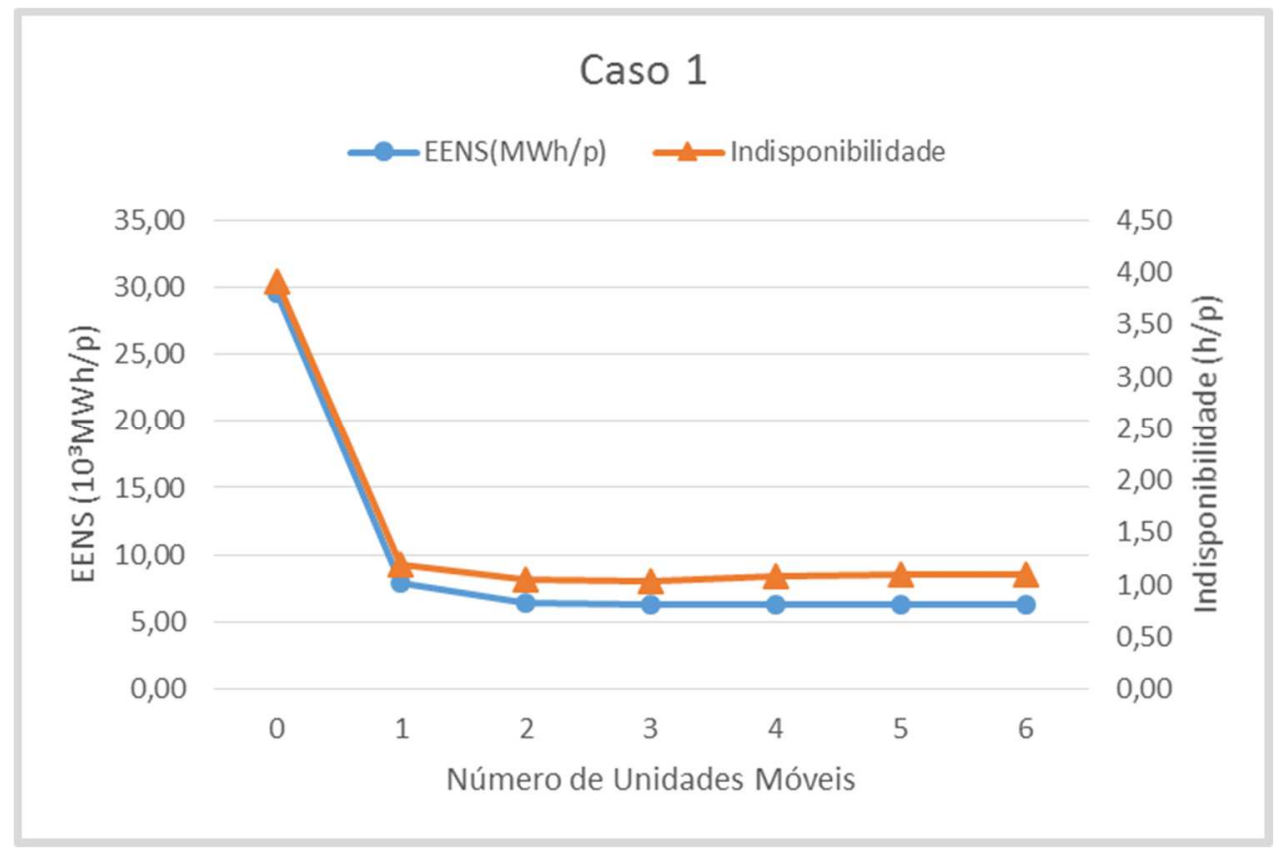

Figura 4.2 - Comportamento EENS (MWh/p) com a inserção de subestações móveis

Destaca-se ainda que a indisponibilidade e a EENS apresentam caraterística semelhante de comportamento, isso se deve ao fato da EENS está diretamente relacionada ao tempo que a carga deixa de ser alimentada.

O objetivo principal deste teste é ilustrar a capacidade de mitigar o tempo de falha até a instalação de uma unidade definitiva. Os resultados ilustram bem o comportamento positivo do sistema com a inserção de unidades móveis. Caso seja necessária uma análise mais detalhada, os outros índices dessa simulação são apresentados no Apêndice dessa dissertação. 


\subsection{2.}

\section{Caso 2}

Considerando o mesmo sistema do Caso 1, foi adotada a possibilidade de transferência de carga em 50\% dos transformadores do sistema. No total, 66 das unidades inicias e 7 unidades da expansão têm a possibilidade de transferir suas cargas para outras unidades ou subestações próximas em caso de falha. Essa transferência é modelada para ocorrer rapidamente, no intervalo de 2 a 4 horas. Contudo, ela tem um período de duração pequeno, sendo assim uma manobra provisória para evitar problemas em outras unidades por sobrecarga. Por esse motivo, só é executada a transferência em caso de existência de unidade de estoque ou unidade móvel para instalação e assim possibilitar o desligamento da transferência em um curto intervalo de tempo.

Tabela 4-2 - Caso 2: Índices de Confiabilidade

\begin{tabular}{|c|c|c|c|}
\hline $\begin{array}{c}\text { Número de } \\
\text { Unidades Móveis }\end{array}$ & EENS $(\mathbf{M W h} / \mathbf{p})$ & $\begin{array}{c}\text { Indisponibilidade } \\
\mathbf{( h / p )}\end{array}$ & $\begin{array}{c}\text { Frequência Média } \\
\text { de Falhas } \mathbf{( f / p )}\end{array}$ \\
\hline 0 & $16.697,49$ & $2.175,92$ & 14,7545 \\
\hline 1 & $4.645,04$ & 681,55 & 15,1745 \\
\hline 2 & $3.835,48$ & 589,24 & 15,2235 \\
\hline 3 & $3.707,37$ & 597,34 & 15,2435 \\
\hline 4 & $3.703,30$ & 600,81 & 15,2366 \\
\hline 5 & $3.698,59$ & 602,26 & 15,2401 \\
\hline 6 & $3.698,59$ & 602,26 & 15,2401 \\
\hline
\end{tabular}

A Tabela 4-2 apresenta os resultados referentes aos índices EENS, indisponibilidade e frequência no período de análise para o sistema com a transferência de carga. A Figura 4.3 ilustra a comparação entre os resultados de EENS dos Casos 1 e 2. Como a EENS e a indisponibilidade apresentam comportamento similar, foi adotada a EENS para fins de comparação por ser o índice utilizado para cálculos de custo de interrupção.

Na Tabela 4-2 pode-se observar novamente o efeito de saturação na inclusão de unidades móveis, fica novamente o ponto de saturação na quinta nova unidade, não fazendo nenhuma diferença a inclusão da sexta unidade. A explicação para esse 
efeito é a mesma do caso anterior, não havendo impacto nos resultados a existência de eventos simultâneos devido à baixíssima probabilidade de ocorrência desses eventos, onde seis ou mais unidades falham simultaneamente. Novamente a frequência de falhas se mantem próxima ao valor inicial, como esperado.

No gráfico da Figura 4.3, o impacto da transferência simples pode ser visualizado, ou seja, no caso onde ainda não existem unidades móveis, pode-se observar que há uma redução significativa da EENS, mais de $40 \%$, em relação ao Caso 1, de 29.571,06 MWh/p para 16.697,49 MWh/p, mostrando a eficácia da transferência de carga em reduzir a duração da falha para o sistema.

O comportamento dos gráficos após a inclusão das unidades móveis, contudo, é bastante similar, mostrando uma acentuada melhora perante a primeira subestação disponível, uma discreta melhora na segunda, e uma saturação nas demais, chegando ao ponto de estagnação na quinta unidade em diante.

É possível concluir então, que apesar de limitado, o uso da transferência onde existe essa possibilidade é uma manobra atraente e de impacto extremamente positivo para a melhora do desempenho do sistema elétrico. Contudo, sempre deve ser levado em consideração suas limitações operativas e custos.

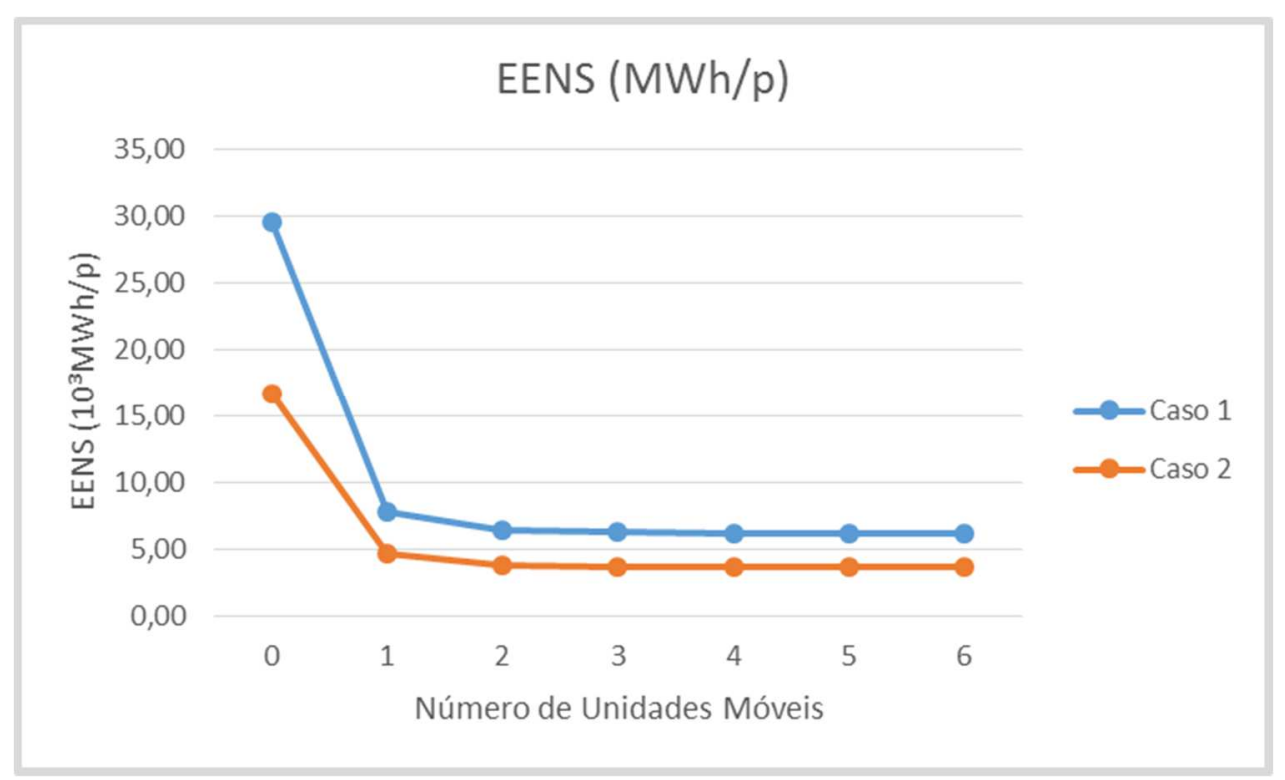

Figura 4.3 - Comparação entre o Caso 1 e 2

Existe uma complementação de operação entre as unidades móveis e a transferência de energia, que apresenta uma melhora global nos resultados do sistema, ficando, em caso de existência de unidade de estoque disponível, as 
unidades móveis empregadas principalmente em locais onde não é possível efetuar a transferência. Os resultados completos deste teste também estão disponíveis no apêndice dessa dissertação.

\subsection{3.}

\section{Caso 3}

Considerando o sistema com 2 unidades de estoque inicial e sem a possibilidade de realizar transferência em nenhuma unidade, colocam-se 3 unidades móveis como padrão e varia-se o tempo de atuação máximo das mesmas, começando com os 180 dias, convencionado como padrão, e aumentando em 9 passos de 360 dias. Com esse caso, é possível comparar a efetividade das unidades móveis em substituir unidades de estoque em uma eventual necessidade.

A Tabela 4-3 apresenta os resultados para a simulação, ficando nítido que quanto maior o tempo de utilização da unidade móvel maior seu impacto no sistema. Neste caso a subestação móvel passa a ser empregada com outra função, a de substituir as unidades de estoque, devido a um dimensionamento propositadamente ruim do estoque inicial, as unidades móveis começam a ser empregadas para substituir as unidades avariadas por um tempo maior do que apenas o de instalação da unidade de estoque, elas passam a alimentar a carga até a chegada de uma nova unidade adquirida

Tabela 4-3 - Caso 3: Índices de Confiabilidade

\begin{tabular}{|c|c|c|c|}
\hline $\begin{array}{c}\text { Período Máximo de } \\
\text { Atuação (Dias) }\end{array}$ & EENS (MWh/p) & $\begin{array}{c}\text { Indisponibilidade } \\
\mathbf{( h / p )}\end{array}$ & $\begin{array}{c}\text { Frequência Média } \\
\text { de Falhas (f/p) }\end{array}$ \\
\hline 180 & $69.692,45$ & $8.286,12$ & 16,8834 \\
\hline 540 & $46.951,04$ & $7.728,08$ & 16,1445 \\
\hline 900 & $33.218,05$ & $5.795,54$ & 16,0024 \\
\hline 1260 & $27.029,48$ & $4.604,94$ & 15,8025 \\
\hline 1620 & $24.136,88$ & $3.827,37$ & 15,6055 \\
\hline 1980 & $22.738,46$ & $3.356,72$ & 15,4945 \\
\hline 2340 & $21.253,27$ & $3.004,34$ & 15,3754 \\
\hline 2700 & $19.463,26$ & $2.663,70$ & 15,2631 \\
\hline 3060 & $17.454,62$ & $2.388,52$ & 15,0319 \\
\hline 3420 & $15.510,51$ & $2.191,05$ & 14,7706 \\
\hline
\end{tabular}


$\mathrm{Na}$ Figura 4.4, observa-se o gráfico do comportamento da EENS com o aumento do número máximo de dias que uma unidade móvel pode alimentar a carga em falha. Como esperado, devido ao número baixo de estoque inicial, a energia que deixa de ser suprida cai com o aumento do número de dias, ficando claro assim a utilização da unidade móvel para suprir a carga por um período longo.

Em tracejado, é apresentado o valor encontrado no Caso 1 para a existência de 5 unidades de estoque e nenhuma unidade móvel, 29.571,06 MWh/p. Destacase que considerando as unidades móveis se comportando como estoque, os resultados teriam de ser similares em algum momento ( 2 unidades de estoque +3 unidades móveis $=5$ unidades totais). Nota-se, no entanto, que rapidamente as unidades móveis ultrapassam o valor de 5 unidades de estoque, isso ocorre por alguns motivos. Primeiramente, o tempo de alocação de uma unidade móvel é muito inferior ao tempo de instalação de uma unidade convencional. Também é preciso levar em conta que a modelagem de uma unidade móvel não contempla falhas no período em que ela será utilizada, considerando para isso que toda unidade móvel estaria com a manutenção e verificações necessárias atualizadas no momento de ligação da mesma ao sistema e seu período de utilização é pequeno se comparado a vida útil de um transformador convencional.

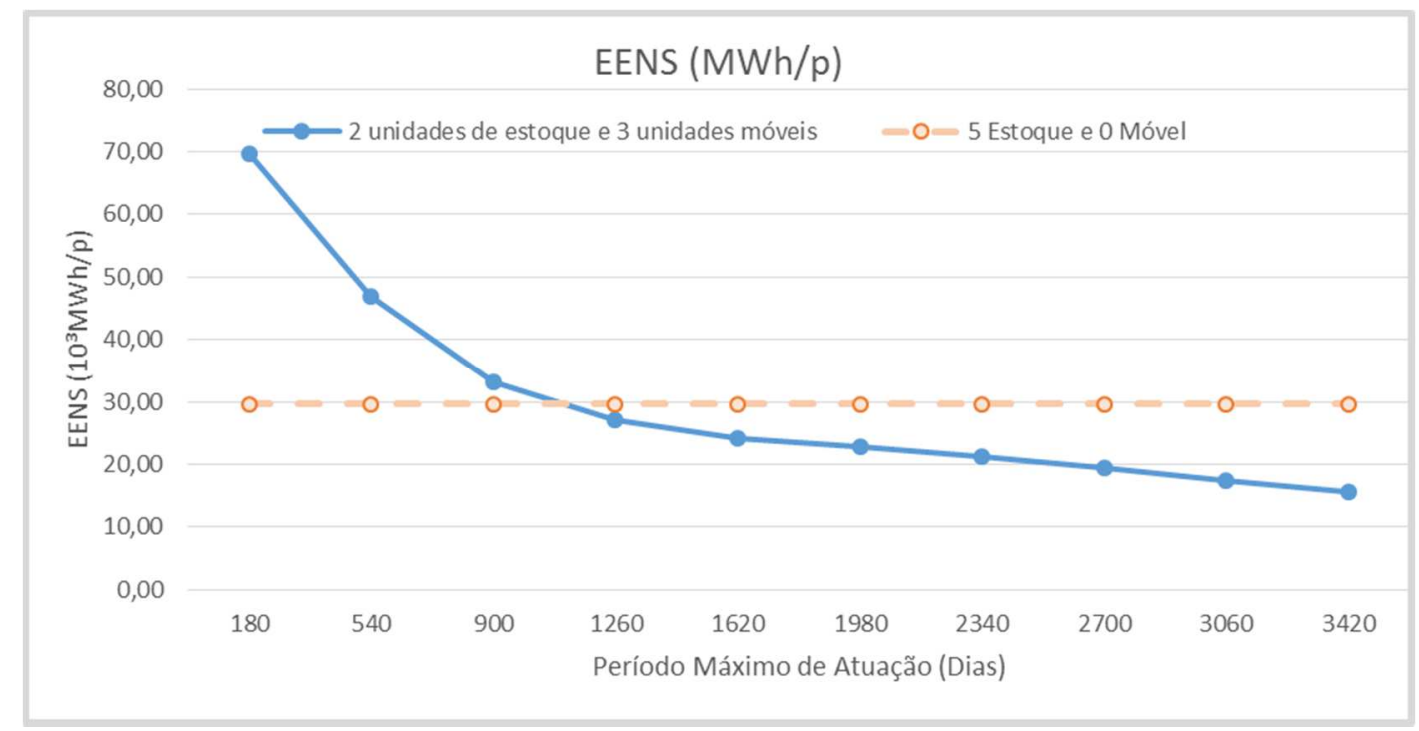

Figura 4.4 - Índice EENS versus tempo máximo de utilização das móveis 
Ressalta-se, entretanto, que não é objetivo principal da utilização da subestação móvel seu emprego como simulado nesse caso. Por ser um equipamento de custo muito superior a unidade de estoque convencional, busca-se com sua utilização aproveitar ao máximo sua flexibilidade de operação, que seria perdida caso a mesma fosse empregada por longos períodos no mesmo local. Outro ponto importante, é que caso seja considerada sua utilização por longos períodos ininterruptos passa a ser necessário considerar sua taxa de falha, que passaria a intervir negativamente em seu desempenho.

O maior objetivo do teste foi alcançado satisfatoriamente, mostrar que as unidades móveis poderiam atuar por longos períodos e se comportariam da forma esperada.

\subsection{4.}

Caso 4

Seguindo as mesmas características do Caso 3, com duas unidades de estoque inicial e três unidades móveis, é inserida a transferência em 66 unidades iniciais e em 7 das previstas para expansão. Do mesmo modo, o tempo de utilização da subestação móvel começa em 180 dias e passa por 9 aumentos de 360 dias.

Tabela 4-4 - Caso 4: Índices de Confiabilidade

\begin{tabular}{|c|c|c|c|}
\hline $\begin{array}{c}\text { Período Máximo de } \\
\text { Atuação (Dias) }\end{array}$ & EENS (MWh/p) & $\begin{array}{c}\text { Indisponibilidade } \\
\mathbf{( h / p )}\end{array}$ & $\begin{array}{c}\text { Frequência Média } \\
\text { de Falhas (f/p) }\end{array}$ \\
\hline 180 & $64.319,17$ & $7.531,31$ & 17,0865 \\
\hline 540 & $38.001,14$ & $5.786,86$ & 16,6454 \\
\hline 900 & $26.748,87$ & $4.236,26$ & 16,3997 \\
\hline 1260 & $22.305,95$ & $3.528,47$ & 16,0924 \\
\hline 1620 & $20.011,55$ & $3.028,38$ & 15,8421 \\
\hline 1980 & $18.842,76$ & $2.680,02$ & 15,7084 \\
\hline 2340 & $17.656,63$ & $2.470,77$ & 15,5685 \\
\hline 2700 & $16.068,93$ & $2.204,59$ & 15,4073 \\
\hline 3060 & $14.358,19$ & $2.011,58$ & 15,1384 \\
\hline 3420 & $12.831,16$ & $1.872,17$ & 14,8289 \\
\hline
\end{tabular}


A Tabela 4-4 mostra um comportamento semelhante aos resultados da Tabela 4-3, onde quanto maior o tempo de permanência das unidades móveis no sistema menor será a indisponibilidade do período analisado e, como esperado, a energia não suprida e os outros índices.

A Figura 4.5 permite uma melhor comparação do comportamento do sistema entre o Caso 3 e 4 . É possível observar que, como esperado, a curva com os resultados do caso atual apresenta valores menores de EENS se comparado ao caso anterior. Destaca-se que o tempo de transferência foi definido entre 2 e 4 horas neste caso, e o tempo de instalação de um transformador, entre 11 e 13 dias, e o de uma unidade móvel, ente 1 e 3 dias, é o mesmo do caso anterior.

Entretanto o impacto da utilização da transferência neste caso é menor se comparado ao impacto que a inclusão do mesmo recurso causou no Caso 2, onde a inclusão da transferência sem unidades móveis causou uma melhora superior a 40\% nos índices de EENS e indisponibilidade. Neste caso, a melhora foi inferior a 10\%, isso se deve ao fato da ocorrência da transferência estar diretamente relacionada a existência de unidade de estoque ou unidade móvel disponível. No caso proposto o sistema apresenta poucas unidades de estoque inicial, logo, a utilização da transferência se reduz.

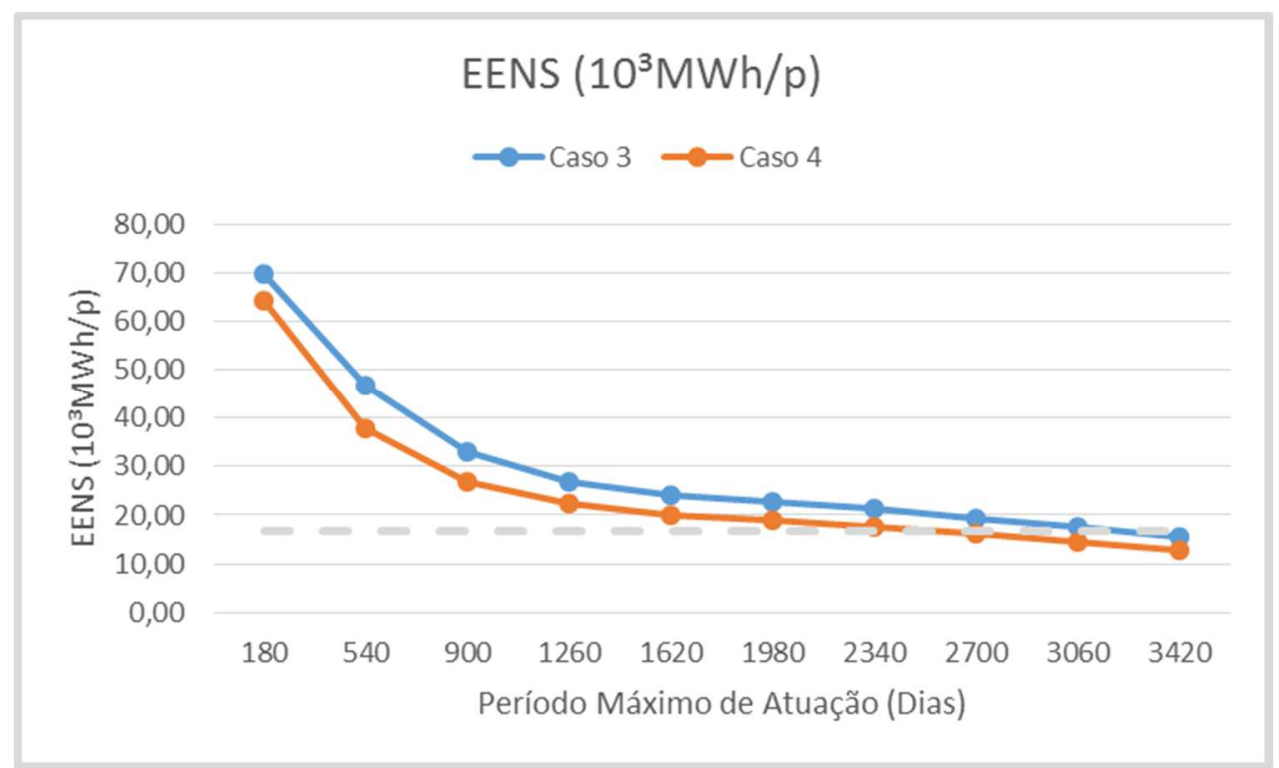

Figura 4.5 - Índice EENS versus tempo máximo de utilização das móveis

Esse caso permite fazer uma importante análise, que é a comparação com o seu equivalente em estoque inicial. O Caso 2 apresenta o equivalente a essa análise, 
onde é simulado um sistema com 5 unidades de estoque inicial, com possibilidade de transferência para as mesmas unidades desse caso e sem nenhuma unidade móvel, esse resultado é representado pela linha tracejada no gráfico da Fig. 4.5.

Neste caso, é possível observar que, apesar de também alcançar os valores do equivalente em unidades de estoque, as unidades móveis necessitariam ficar por um intervalo de tempo maior operando ininterruptamente para alcançar esse desempenho. Neste caso, a diferença de tempo de instalação entre móvel e transformador convencional é atenuada nas unidades onde é possível efetuar a transferência, reduzindo assim a vantagem apresentada pelas unidades móveis no caso anterior, e tornando a comparação mais efetiva, por aproximar o tempo de eliminação da interrupção entre os dois casos possíveis.

Nota-se mais uma vez a importância da transferência quando utilizada dentro de suas especificidades, seu impacto positivo, e sua possibilidade de atuação em cooperação tanto com unidades móveis como com unidades de estoque convencionais.

\subsection{5. Caso 5}

Para o mesmo sistema elétrico proposto inicialmente, os testes serão refeitos dobrando o valor inicial da taxa falha de 0,011 para 0,022 falhas por ano. Serão consideradas ao longo deste caso duas unidades de estoque inicial e um tempo de permanência máximo de unidades móveis de 1095 dias. Os valores foram escolhidos visando ilustrar o impacto maior que as unidades móveis teriam sobre um sistema degradado se comparado ao do Caso 1 . O período de permanência da unidade móvel foi expandido com objetivo de ilustrar uma visão menos conservadora em relação a sua utilização, entretanto, não o suficiente para concorrer com unidades de estoque convencionais, que não é o objetivo deste teste.

A Tabela 4-5 mostra resultados com melhoras nos índices de EENS e indisponibilidade em todas as inclusões de unidades móveis testadas. Neste caso, como a unidade móvel fica em utilização por um período mais longo, um número maior de unidades pode ser de fato utilizado em falhas em diferentes momentos. A probabilidade de ocorrência de falhas múltiplas dentro do tempo de utilização 
máximo proposto neste caso, com o sistema degradado, aumenta se comparado ao período inicial adotado.

Tabela 4-5 - Caso 5: Índices de Confiabilidade

\begin{tabular}{|c|c|c|c|}
\hline $\begin{array}{c}\text { Número de } \\
\text { Unidades Móveis }\end{array}$ & EENS (MWh/p) & $\begin{array}{c}\text { Indisponibilidade } \\
(\mathbf{h} / \mathbf{p})\end{array}$ & $\begin{array}{c}\text { Frequência Média } \\
\text { de Falhas (f/p) }\end{array}$ \\
\hline 0 & $780.762,95$ & $50.128,06$ & 12,7985 \\
\hline 1 & $489.241,30$ & $36.596,06$ & 17,7777 \\
\hline 2 & $302.340,02$ & $26.268,49$ & 22,2262 \\
\hline 3 & $189.676,31$ & $19.342,81$ & 25,4911 \\
\hline 4 & $131.052,35$ & $15.872,93$ & 27,4271 \\
\hline 5 & $101.694,31$ & $13.806,76$ & 28,6376 \\
\hline 6 & $90.252,63$ & $13.209,78$ & 29,0417 \\
\hline
\end{tabular}

No gráfico da Figura 4.6, observa-se que a inclusão de unidades móveis acarreta num impacto relevante no sistema até a quinta unidade, apresentando melhora nos índices de EENS e indisponibilidade, demonstrando, como esperado, que quanto piores forem as condições operativas de um sistema, maior o impacto que a inserção de unidades móveis irá apresentar sobre o mesmo.

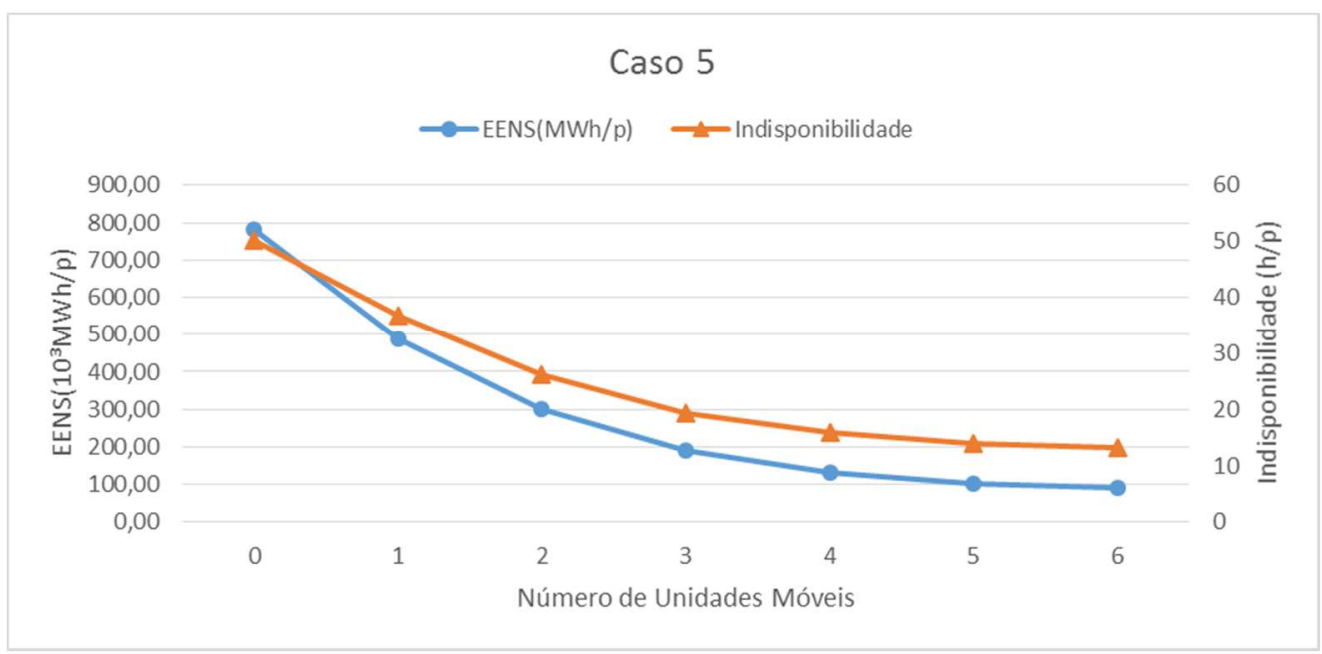

Figura 4.6 - Índice EENS versus unidade móvel em um sistema degradado

Ressalta-se que houve uma grande degradação do sistema elétrico proposto, feita de forma intencional, para mostrar a validade da atuação de mais de uma subestação móvel. Se comparado aos resultados do Caso 1, onde apenas a primeira 
unidade móvel apresenta impacto significativo de melhora no sistema, é visível a grande discrepância de comportamento do sistema nos dois casos. Não é esperado um sistema operando nas condições especificadas nesse caso, ele representa apenas uma finalidade acadêmica para testar o desempenho do modelo proposto.

Em casos de sistemas de maior porte a probabilidade de falhas simultâneas seria consideravelmente maior, descartando a necessidade de degradação do sistema para sua ocorrência.

\subsection{6.}

Caso 6

Neste item, será utilizado o sistema com 5 unidades de estoque inicial, com tempo de instalação entre 9 e 11 dias, e uma unidade móvel disponível no início de sua operação. O objetivo deste caso é mostrar a relação entre o tempo de instalação da unidade móvel e sua eficiência. Portanto, não será considerada a possibilidade de transferência de carga das unidades, pois tal fator mascararia o aumento de tempo de instalação da subestação móvel.

Com o objetivo de avaliar apenas seu poder de mitigar o tempo de falha, será mantido seu tempo máximo de operação em 180 dias. Foram definidos testes com variações de 0,5 dia no tempo de instalação de uma unidade móvel, variando de 0,5 a 9 dias.

Esse teste também mostra a importância da localização estratégica das unidades móveis, visto que grande parte do seu tempo de instalação está atrelado ao seu deslocamento até o local de falha. Por ser equipamento de grande porte e sensível, precisa se deslocar em baixa velocidade e em muitos casos com batedores pelas estradas, sendo a distância até o local da falha fator importante na sua eficiência.

Como esperado, a Tabela 4-6 mostra a relação direta entre o tempo de instalação da móvel e a indisponibilidade do sistema. Observa-se que a unidade móvel perde gradativamente sua eficácia, repetindo o teste para as mesmas especificações, contudo sem unidades móveis e fixando o tempo de instalação da unidade convencional em 9 dias temos o resultado da Tabela 4-7.

Pode-se observar também que o valor para a unidade móvel com 9 dias de instalação e os valores para o mesmo caso sem unidades móveis, porém fixando a 
instalação das unidades convencionais em 9 dias, são muito próximos, havendo uma pequena melhora no caso de 6 unidades de estoque, onde a indisponibilidade é $3.257,98 \mathrm{~h} / \mathrm{p}$, em relação a 5 unidades e 1 móvel com 9 dias de instalação, onde a indisponibilidade é $3.525,28 \mathrm{~h} / \mathrm{p}$.

Tabela 4-6 - Caso 6: Índices de Confiabilidade

\begin{tabular}{|c|c|c|c|}
\hline $\begin{array}{c}\text { Tempo de Instalação } \\
\text { (Dias) }\end{array}$ & EENS (MWh/p) & $\begin{array}{c}\text { Indisponibilidade } \\
(\mathrm{h} / \mathrm{p})\end{array}$ & $\begin{array}{c}\text { Frequência Média } \\
\text { de Falhas (f/p) }\end{array}$ \\
\hline 0,5 & $4.051,40$ & 651,13 & 15,1700 \\
\hline 1 & $5.373,79$ & 835,48 & 15,1412 \\
\hline 1,5 & $6.576,23$ & 998,81 & 15,1019 \\
\hline 2 & $7.887,64$ & $1.181,03$ & 15,0882 \\
\hline 2,5 & $9.120,45$ & $1.363,13$ & 15,0400 \\
\hline 3 & $10.314,58$ & $1.534,41$ & 15,0262 \\
\hline 3,5 & $11.587,60$ & $1.710,83$ & 14,9795 \\
\hline 4 & $12.827,48$ & $1.920,01$ & 14,9259 \\
\hline 4,5 & $14.084,02$ & $2.073,58$ & 14,8884 \\
\hline 5 & $15.299,51$ & $2.213,29$ & 14,8482 \\
\hline 5,5 & $16.463,33$ & $2.413,51$ & 14,7799 \\
\hline 6 & $17.693,82$ & $2.603,80$ & 14,7336 \\
\hline 6,5 & $18.951,63$ & $2.765,04$ & 14,6854 \\
\hline 7 & $20.163,90$ & $2.885,66$ & 14,6538 \\
\hline 7,5 & $21.399,27$ & $3.066,28$ & 14,6175 \\
\hline 8 & $22.595,21$ & $3.224,24$ & 14,5914 \\
\hline 8,5 & $24.041,15$ & $3.405,04$ & 14,6016 \\
\hline 9 & $25.300,46$ & $3.525,28$ & 14,5533 \\
\hline
\end{tabular}

Tabela 4-7 - Caso 6: Índices de Confiabilidade - Sem Unidades Móveis

\begin{tabular}{|c|c|c|c|}
\hline $\begin{array}{c}\text { Unidades em } \\
\text { Estoque }\end{array}$ & EENS (MWh/p) & $\begin{array}{c}\text { Indisponibilidade } \\
\mathbf{( h / p )}\end{array}$ & $\begin{array}{c}\text { Frequência Média } \\
\text { de Falhas (f/p) }\end{array}$ \\
\hline 5 & $26.899,13$ & $3.553,95$ & 14,5201 \\
\hline 6 & $24.143,34$ & $3.257,98$ & 14,4690 \\
\hline
\end{tabular}

No gráfico da Figura 4.7, pode-se visualizar esse efeito, estando o caso inicial com uma unidade móvel em azul, o caso com 5 unidades de estoque inicial com 9 
dias para instalação em pontilhado vermelho, e o de 6 unidades de estoque inicial também com 9 dias de instalação em tracejado verde, sendo os dois últimos casos sem nenhuma unidade móvel disponível.

No caso específico de 9 dias para instalação da unidade móvel, percebe-se um resultado melhor sobre o caso com apenas 5 unidades no estoque. Levando-se em conta que os dois testes apresentam o mesmo tempo de instalação, esse resultado melhor se deve aos casos onde não há unidades de estoque disponíveis, e a unidade móvel será acionada para suprir a carga por um período de 180 dias.

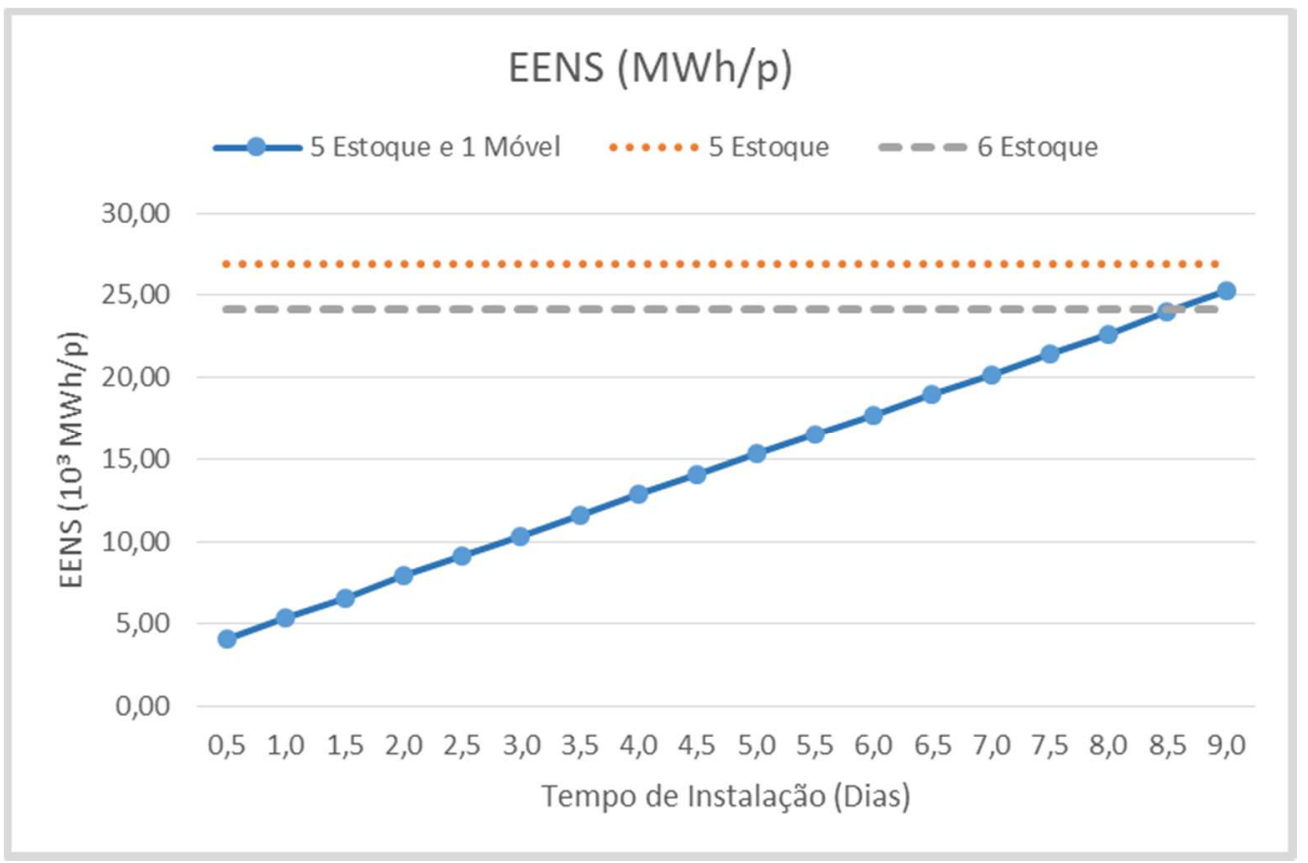

Figura 4.7 - Índice EENS versus tempo de instalação de unidade móvel em um sistema

Na comparação com 6 unidades de estoque inicial, o resultado do caso com 5 unidades e 1 móvel é inferior, pois neste caso, quando acabar as 5 unidades iniciais a sexta unidade convencional poderá ficar por um período muito superior ao da unidade móvel e ambas as unidades terão o mesmo tempo de instalação.

Como se sabe, o valor de uma unidade convencional é consideravelmente menor que o de uma unidade móvel, logo, o caso com 6 unidades apresenta grande vantagem sobre o caso original.

Perante todos os dados, fica claro que se uma unidade móvel não apresentar um tempo de instalação baixo ela perde a atratividade se comparada a uma unidade convencional. No gráfico da Figura 4.7 é possível analisar que até o tempo de 
instalação da unidade móvel se aproximar do tempo de instalação de uma unidade convencional ela mantem resultados melhores, e quanto menor seu tempo de instalação, mais atrativos são os resultados se comparados ao de uma unidade convencional.

Com isso, é possível afirmar que além da disponibilidade da unidade móvel, é de grande importância para o sistema por ela atendido que a unidade móvel esteja em local adequado para atender a mais rápido possível o maior número de localizações de falhas possível.

\subsection{7.}

Caso 7

Este caso explora o impacto do tempo de transferência de carga para sua real efetividade na melhoria do sistema. Para melhor visualização do efeito, foi considerado que todas as unidades possuem a possibilidade de terem suas cargas transferidas em caso de falha. Foi adotado o sistema com 5 unidades de estoque inicial e uma unidade móvel. Foram realizados testes variando o tempo de transferência de 1 a 24 horas, em passos de 1 hora. A Tabela 4-8 mostra os resultados dos índices de confiabilidade neste caso.

Como esperado, os índices de desempenho EENS e indisponibilidade aumentam diretamente proporcionais ao aumento do tempo para execução da transferência, mostrando que sua efetividade está, como no caso das unidades móveis, atrelada ao seu rápido acionamento.

Com finalidade de comparação e verificação de resultados, foi executado um segundo teste considerando que todas as instalações, tanto de unidades móveis como de unidades convencionais seriam executadas em um dia, ou seja, 24 horas, sem o recurso de transferência de carga no sistema.

Nota-se ser necessário atuar nos tempos de instalação, pois a transferência de carga só é executada após a falha preceder a instalação de uma unidade convencional ou móvel. Caso não exista nenhum estoque disponível no momento da falha, a transferência não é executada visando mitigar a mesma, pois diferentemente da unidade móvel que suporta ficar alguns meses em operação, não é possível sustentar a transferência em execução por longos períodos de tempo sem impactar no funcionamento do sistema. 
Tabela 4-8 - Caso 7: Índices de Confiabilidade

\begin{tabular}{|c|c|c|c|}
\hline $\begin{array}{c}\text { Tempo de } \\
\text { Transferência (Horas) }\end{array}$ & EENS (MWh/p) & $\begin{array}{l}\text { Indisponibilidade } \\
(\mathbf{h} / \mathbf{p})\end{array}$ & $\begin{array}{c}\text { Frequência Média } \\
\text { de Falhas ( } \mathbf{f} / \mathbf{p})\end{array}$ \\
\hline 1 & $1.371,72$ & 163,68 & 15,2621 \\
\hline 2 & $1.485,02$ & 179,99 & 15,2633 \\
\hline 3 & $1.595,56$ & 197,10 & 15,2559 \\
\hline 4 & $1.706,81$ & 215,53 & 15,2554 \\
\hline 5 & $1.817,16$ & 233,28 & 15,2542 \\
\hline 6 & $1.933,21$ & 250,81 & 15,2539 \\
\hline 7 & $2.049,27$ & 268,95 & 15,2566 \\
\hline 8 & $2.159,35$ & 285,93 & 15,2518 \\
\hline 9 & $2.276,82$ & 302,79 & 15,2498 \\
\hline 10 & $2.389,61$ & 320,61 & 15,2462 \\
\hline 11 & $2.511,13$ & 337,17 & 15,2479 \\
\hline 12 & $2.617,28$ & 352,77 & 15,2424 \\
\hline 13 & $2.732,49$ & 370,96 & 15,2401 \\
\hline 14 & $2.835,48$ & 386,17 & 15,2338 \\
\hline 15 & $2.953,44$ & 403,47 & 15,2340 \\
\hline 16 & $3.085,87$ & 423,51 & 15,2351 \\
\hline 17 & $3.185,24$ & 437,80 & 15,2304 \\
\hline 18 & $3.306,71$ & 457,49 & 15,2300 \\
\hline 19 & $3.415,67$ & 474,26 & 15,2352 \\
\hline 20 & $3.508,80$ & 486,47 & 15,2220 \\
\hline 21 & $3.628,23$ & 501,42 & 15,2235 \\
\hline 22 & $3.735,08$ & 518,03 & 15,2233 \\
\hline 23 & $3.834,33$ & 531,75 & 15,2206 \\
\hline 24 & $3.951,82$ & 549,50 & 15,2226 \\
\hline
\end{tabular}

A Figura 4.8 apresenta a comparação de resultados, a EENS para o período no segundo teste é de $3822.83 \mathrm{MWh}$, resultado levemente melhor que o da transferência em 24 horas e o tempo de instalação de unidades convencionais entre 11 e 13 dias e de unidades móveis entre 1 e 3 dias. Isso se justifica pela melhora dos tempos de instalação em situações que não ocorrem transferência. Por exemplo, no momento de falha de uma unidade não há transformadores em estoque nem disponibilidade de unidades móveis, assim a transferência não será executada, 
contudo quando chegar uma unidade de estoque ao sistema, a mesma será instalada com um tempo menor do que na primeira simulação, isso justificaria a pequena melhora apresentada entre os dois casos de comparação.

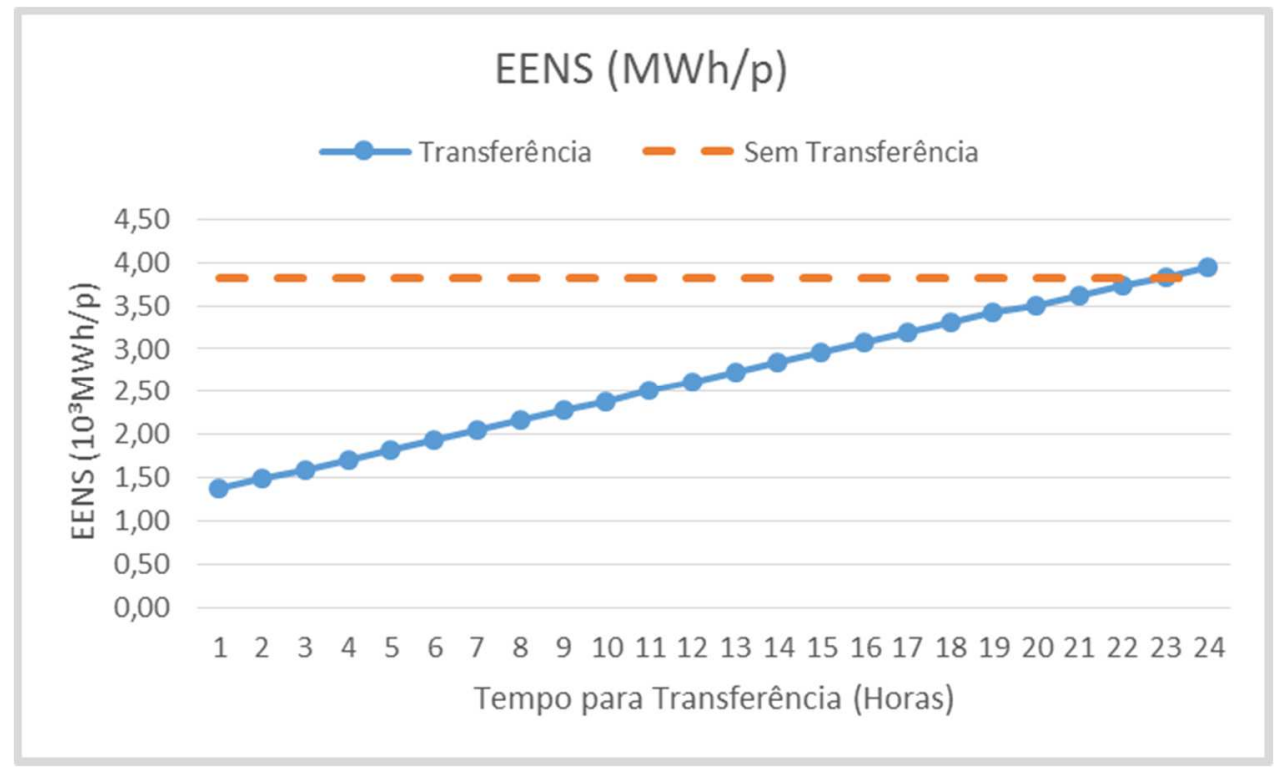

Figura 4.8 - Índice EENS versus tempo de execução de transferência de carga em um sistema

Ressalta-se que a melhora é pequena, pois casos onde a transferência não irá ocorrer na forma em que o sistema foi modelado, com 5 unidades de estoque inicial e uma unidade móvel são raros, isso foi feito propositadamente para a comparação apresentar real valor.

Do mesmo modo que o Caso 6 fica claro que a eficiência da transferência está associada à sua velocidade de execução, caso haja alguma dificuldade de manobra ou impossibilidade de execução momentânea, a mesma fica prejudicada em relação a sua real efetividade.

\subsection{8.}

Caso 8

Com a finalidade de analisar a viabilidade econômica da inclusão de unidades móveis no sistema, esse caso se dedica a analisar diferentes configurações do mesmo e comparar seus custos de investimento e operação. Os valores adotados para essa análise foram: 
- $\quad \mathrm{R} \$ 1.000 .000,00$ para aquisição de uma nova unidade convencional;

- $\quad \mathrm{R} \$ 4.500 .000,00$ para aquisição de uma subestação móvel;

- Amortização em 35 anos com taxa de 12\% por ano;

- $\quad$ Tarifa de energia elétrica de $\mathrm{R} \$ 204,60$ por MW/h;

- Custo por interrupção de 1.500,00 MW/h.

Para o cálculo do Custo de Operação é levado em conta a energia que deixa de ser vendida durante a interrupção mais o custo por interrupção. O Custo de Investimento está atrelado aos equipamentos comprados para melhoria do sistema, ou seja, equipamentos não previstos no dimensionamento inicial. Será utilizado o mesmo sistema base utilizado nos casos anteriores, considerando um estoque inicial com 5 unidades, transferência em metade das unidades e, a princípio, nenhuma unidade móvel disponível.

Inicialmente, será avaliado o impacto da inclusão de unidades convencionais, considerando a inclusão no primeiro ano de simulação. Variando a quantidade de unidades extras de 0 a 4, e analisa-se o impacto na EENS e nos custos.

Tabela 4-9 - Inclusão de Unidades Convencionai
\begin{tabular}{|c|c|}
\hline $\begin{array}{c}\text { Número de Unidades } \\
\text { de Estoque }\end{array}$ & EENS (MWh/p) \\
\hline $5+0=5$ & $16.697,49$ \\
\hline $5+1=6$ & $14.125,68$ \\
\hline $5+2=7$ & $13.643,68$ \\
\hline $5+3=8$ & $13.506,65$ \\
\hline $5+4=9$ & $13.334,55$ \\
\hline
\end{tabular}

A fim de propiciar comparação adequada, foi realizado o teste com as mesmas condições de sistema acima para a inclusão de móveis, retirando as unidades extras de estoques, voltando à configuração de 5 unidades de estoque inicial e metade das unidades executando transferência. Para esse caso, foram simulados os custos para inclusão de 0 a 3 móveis. Nota-se que esse é o mesmo caso utilizado no Item 4.4.2. Sendo assim, os resultados para energia não suprida são os mesmos descritos neste item, repetidos aqui apenas para as unidades de interesse. 
Tabela 4-10 - Análise de Custos anualizados de Inclusão de Unidades Convencionais

\begin{tabular}{|c|c|c|c|c|}
\hline $\begin{array}{l}\text { Número de } \\
\text { Unidades de } \\
\text { Estoque }\end{array}$ & $\begin{array}{l}\text { Investimento } \\
\left(10^{3} \mathrm{R} \$ \text { /ano }\right)\end{array}$ & $\begin{array}{l}\text { Interrupção } \\
\text { (103R \$/ano) }\end{array}$ & $\begin{array}{l}\text { Não Faturamento } \\
\left(10^{3} R \$ / \text { ano }\right)\end{array}$ & $\begin{array}{c}\text { Total } \\
\left(10^{3} R \$ / \text { ano }\right)\end{array}$ \\
\hline $5+0=5$ & 0.00 & $25.046,23$ & $3.416,31$ & $28.462,54$ \\
\hline $5+1=6$ & 691,12 & $21.188,52$ & $2.890,11$ & $24.769,75$ \\
\hline $5+2=7$ & $1.382,23$ & $20.465,52$ & $2.791,50$ & $24.639,25$ \\
\hline $5+3=8$ & $2.073,35$ & $20.259,98$ & $2.763,46$ & $25.096,78$ \\
\hline $5+4=9$ & $2.764,46$ & $20.001,83$ & $2.728,25$ & $25.494,54$ \\
\hline
\end{tabular}

Tabela 4-11 - Inclusão de Unidades Móveis

\begin{tabular}{|c|c|}
\hline $\begin{array}{c}\text { Número de Unidades } \\
\text { Móveis }\end{array}$ & EENS (MWh/p) \\
\hline 0 & $16.697,49$ \\
\hline 1 & $4.645,04$ \\
\hline 2 & $3.835,48$ \\
\hline 3 & $3.707,37$ \\
\hline
\end{tabular}

Tabela 4-12 - Análise de Custos anualizados de Inclusão de Unidades Móveis

\begin{tabular}{|c|c|c|c|c|}
\hline $\begin{array}{c}\text { Número de } \\
\text { Unidades Móveis }\end{array}$ & $\begin{array}{c}\text { Investimento } \\
\text { (103 } \mathrm{R} \$ \text { /ano })\end{array}$ & $\begin{array}{l}\text { Interrupção } \\
\text { (103R } \$ \text { /ano) }\end{array}$ & $\begin{array}{c}\text { Não Faturamento } \\
\left(10^{3} \mathrm{R} \$ / \text { ano }\right)\end{array}$ & $\begin{array}{c}\text { Total } \\
\left(10^{3} \mathrm{R} \$ \text { /ano }\right)\end{array}$ \\
\hline 0 & 0.00 & $25.046,23$ & $3.416,31$ & $28.462,54$ \\
\hline 1 & $3.110,02$ & $6.967,55$ & 950,37 & $11.027,95$ \\
\hline 2 & $6.220,05$ & $5.753,22$ & 784,74 & $12.758,01$ \\
\hline 3 & $9.330,07$ & $5.561,05$ & 758,53 & $15.649,65$ \\
\hline
\end{tabular}

Comparando a Tabela 4-9 com a Tabela 4-11 pode-se observar que o impacto, sobre o sistema em questão, de uma unidade móvel é consideravelmente maior que o de uma unidade convencional ao estoque. Na comparação entre as Tabelas 4-10 e 4-12 pode-se concluir que em relação aos custos a inclusão de uma unidade móvel se torna a melhor alternativa de investimento para o sistema, por apresentar o menor custo total. 
Com esses resultados, a unidade móvel se mostra atrativa tanto operacionalmente, por ser uma ferramenta flexível e reduzir de forma considerável os índices de EENS, como interessante financeiramente. Apesar do alto investimento, o benefício empregado no sistema apresenta retorno financeiro interessante ao longo do período de vida útil, desde que dimensionada de forma correta.

\section{5.}

\section{Tempos de Simulação}

O programa de SMC cronológica foi desenvolvido usando o ambiente MATLAB e executado em um computador com processador Intel® CoreTM i7 4510U / 2,6GHz. Sua execução depende de um arquivo de entrada (leitura de dados) com informações do sistema. Ao final da simulação é impresso um relatório de saída. Para a execução de cada caso, de 1 a 8 anteriormente descrito, foram feitas simulações para todas configurações adotadas no mesmo, variando os dados necessários no arquivo de entrada.

De uma forma geral, foram necessários 20 minutos de CPU, em média, para cada caso simulado. Considerando os sete cenários usados no Caso 1, o tempo total de simulação foi de 7,7 minutos, resultando em média 1,1 minutos para cada cenário. No Caso 2, o tempo total de simulação foi maior, totalizando 25 minutos, com 2,8 minutos em média por cenário. $\mathrm{O}$ aumento do tempo de simulação se justifica pela melhora dos índices, i.e., quanto mais raro o evento de falha, maior o número de simulações necessárias para capturar sua ocorrência. Já o Caso 5 demorou 20,3 minutos e o Caso 8 necessitou de 17,2 minutos para ser executado. O caso 7 apresentou o maior tempo de simulação, totalizando 321,6 minutos, devido ao número elevado de cenários envolvidos, 24 no total, tendo configuração do sistema índices de falha extremamente baixos.

De um modo geral, os tempos de simulação foram satisfatórios e se comportaram dentro do esperado para as diferentes configurações do sisrema. Ressalta-se que como o objetivo do método é o planejamento, os tempos necessários para simulação não são empecilhos para seu emprego. De qualquer 
forma, tais tempos seriam muito menores utilizando-se de linguagens mais apropriadas: e.g., Fortran, $\mathrm{C}++$, etc.

\section{6.}

\section{Conclusão}

Ao longo deste capítulo foi apresentado em maiores detalhes as peculiaridades das unidades móveis, suas principais vantagens e formas de utilização, demonstrando assim a importância de sua modelagem e inserção na análise de sistemas elétricos. Foram apresentados também o processo de simulação e a estratégia operativa, explicando os motivos de escolha do método de simulação Monte Carlo e seu funcionamento básico, além das premissas e hipóteses adotadas no processo de simulação.

O sistema apresentou o comportamento esperado perante a inclusão de unidades móveis, reagindo de forma contundente ao longo dos testes. Da mesma maneira, a opção da transferência foi incluída e pode ser analisada de acordo com o proposto ao longo do capítulo. A operação conjunta entre os dois recursos apresentou resultados dentro do esperado.

Os casos propostos visavam demonstrar não apenas a sensibilidade do algoritmo a variação dos dados de entrada, mas também os impactos causados pelas mudanças de configuração e as melhoras possíveis através das alternativas modeladas. Ao longo dos testes foi visível a influência dos tempos de instalação e de transferência a eficiência dos métodos propostos, evidenciando uma possibilidade de modelagem futura da alocação das unidades reservas e móveis, visando a otimização do sistema pela alocação do estoque.

Além das análises dos índices do sistema, executou-se uma análise de custos que demonstrou a viabilidade econômica do modelo proposto, e seu retorno financeiro ao causar considerável redução dos custos operacionais, mostrando a efetividade da inclusão de unidades móveis em sistemas reais. 


\section{5 \\ Conclusão}

No primeiro capítulo foi apresentado o problema proposto para essa dissertação sendo feito um pequeno histórico de como o problema estava inserido no sistema elétrico, além de apresentar a estrutura desta dissertação. No Capítulo 2 foram apresentados os modelos analíticos mais utilizados até então, mostrando suas vantagens e limitações, justificando o motivo de sua não utilização no desenvolvimento desse estudo.

No terceiro capítulo foi descrito o modelo de Simulação Monte Carlo (SMC), suas formas de utilização e suas principais vantagens perante os métodos discutidos no Capítulo 2. Ilustrou-se a evolução das análises que utilizam esse método e quais aplicações são modeladas através do mesmo, mostrando toda uma gama de recursos que se torna possível modelar através da simulação cronológica, como o envelhecimento das unidades e tempos de instalação distintos.

O Capítulo 4 discutiu detalhadamente a relevância das unidades móveis para os sistemas elétricos, como também o processo de simulação e considerações adotadas para as mesmas. Por fim, foram apresentados os resultados das simulações e feitas as devidas análises. Os casos simulados ao longo do Capítulo 4 ilustram as vantagens da modelagem proposta e sua efetividade, apresentando resultados compatíveis que mostram o desempenho do sistema de acordo com o esperado. A SMC cronológica apresentou um funcionamento adequado e computacionalmente eficiente tendo em vista a complexidade do problema.

A partir dos diversos testes realizados percebe-se que a utilização de unidades móveis e transferência de carga possui impacto positivo no sistema. De uma forma geral, pode-se concluir que há uma saturação na melhora do comportamento do sistema a partir do aumento desnecessário no número de unidades móveis, e que essas são melhor aproveitadas se estiverem localizadas em pontos estratégicos, diminuindo seu tempo de instalação. Destaca-se ainda que a principal vantagem das subestações móveis está em sua flexibilidade operativa, o que é perdido caso seja 
utilizada por longos períodos, como se fossem unidades convencionais. Tais observações somente são possíveis com a utilização da metodologia proposta nesta dissertação, que efetivamente avalia o desempenho de diferentes estratégias operativas (e.g., transferência de carga) e da reserva técnica disponível de transformadores (unidades convencionais e móveis). Obviamente, cada sistema (grupo/classe de transformadores e outros equipamentos) terá suas próprias especificações (e.g., taxas de falha, tempos de instalação, etc.) e, consequentemente, desempenhos específicos a serem avaliados pela metodologia proposta.

O modelo apresentado ao longo desta dissertação mostrou grande flexibilidade em relação aos dados de entrada e análise de diferentes configurações, propiciando resultados com comportamentos adequados às modelagens e próximos da realidade operativa. Uma das principais vantagens apresentadas pelo método SMC cronológico é exatamente sua flexibilidade e capacidade de modelar praticamente quaisquer peculiaridades existentes nos sistemas reais.

Apesar dos custos computacionais um pouco mais elevados, que não apresentaram grandes impactos ao longo das simulações executadas, a capacidade de inserção de diferentes parâmetros e modelagem de diversas peculiaridades torna seu uso extremamente atrativo, pois inclui fatores ignorados por outros modelos, como o tempo de instalação das unidades, que se torna fator importantíssimo na análise aqui proposta.

Ficam como sugestões de trabalhos futuros os seguintes tópicos:

- Generalizar o modelo de transferência de carga permitindo realocações parciais para cada subestação do sistema de distribuição;

- Otimizar o estoque considerando tanto as unidades convencionais como unidades móveis, visando encontrar o dimensionamento com menor custo total e suas inserções temporais no período de estudo;

- Modelar o posicionamento geográfico das unidades em operação e das unidades reservas, visando tornar mais realista o tempo de instalação e otimizar a distribuição espacial das unidades de estoque;

- Expandir o estudo proposto para sistemas elétricos de grande porte, ilustrando o real impacto de unidades móveis em sistemas reais, principalmente 
modelando suas distribuições de vida útil remanescente no início do período de simulação.

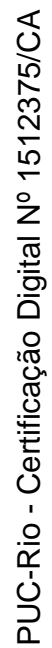


6

\section{Referências bibliográficas}

1 W. LI; E. VAAHEDI e Y. MANSOUR, “Determining Number and Timing of Substation Spare Transformers using a Probabilistic Cost Analysis Approach", IEEE Transactions on Power Delivery, Vol. 14, No 3, July 1999.

2 A.A. CHOWDHURY e D.O. KOVAL, "Development of Probabilistic Models for Computing Optimal Distribution Substation Spare Transformers", Industrial and Commercial Power Systems Technical Conference, IEEE, pp. 204-211, 2005.

3 AGÊNCIA NACIONAL DE ENERGIA ELÉTRICA - ANEEL, Procedimentos de Distribuição de Energia Elétrica no Sistema Elétrico Nacional - PRODIST Módulo 8 - Qualidade da Energia Elétrica, Janeiro 2017.

4 W. LI, "Incorporating Aging Failures in Power System Reliability Evaluation”, IEEE Trans. on Power Systems, Vol. 17, № 3, pp. 918-923, August 2002.

5 W. LI, "Evaluating Mean Life of Power System Equipment with Limited endof-life Failure Data Power Systems", IEEE Transactions on Power Systems, Vol. 19, No 1, pp. 236-242, February 2004.

6 L. CHMURA; P.H.F. MORSHUIS; E. GULSKI; J.J. SMITE e A. JANSSEN, "Statistical Analysis of Subcomponent Failures in Power Transformers", Electrical Insulation Conference, IEEE Conference Publications, 2011.

7 G.A. HAMOUD, “Assessment of Spare Transformer Requirements for Distribution Stations", IEEE Trans. on Power Syst., Vol. 26, № 1, pp. 174180, February 2011. 
8 G.A. HAMOUD, "Assessment of Spare Transformer Requirements for High Voltage Load Stations", Power and Energy Society General Meeting, pp. 1-8, July 2012.

9 J.G.C. COSTA e A.M. LEITE DA SILVA, "Monte Carlo Simulation to Assess the Optimum Number of Distribution Spare Transformers", Proc. 10th Int. Conf. Probability Methods Applied to Power Systems PMAPS, Rincón, PR, USA, May 25-29, 2008.

10 C.M. ADAMS, “Inventory Optimization Techniques, System vs. Item Level Inventory Analysis”, in: Reliab. And Maint. Symp. Proc., pp. 55-60, 2004.

11 A.M. LEITE DA SILVA; J.G.C. COSTA e A.A. CHOWDHURY, "Probabilistic Methodologies for Determining the Optimal Number of Substation Spare Transformers", IEEE Trans. on Power Systems, Vol. 25, No 1, February 2010.

12 A. LAW e D. KELTON, "Simulation Modeling and Analysis", New York, McGraw-Hill, 2000.

13 H. ZHENG; Y. CHENG; B. GOU; D. FRANK; A. BERN e W.E. MUSTON, "Impact of Automatic Switches on Power Distribution System Reliability", Electric Power Systems Research, Vol. 83, Issue 1, pp. 51-57, February 2012.

14 R. BILLINTON e R.N. ALLAN, "Reliability Evaluation of Engineering Systems", New York, Plenum, 1983.

15 A. WOOD, "Availability Calculations with Exhaustible Spares", IEEE Trans. on Reliability, Vol. 38, No 3, pp. 388-391, August 1989.

16 S. YANG e Z. DU, "Criticality Evaluation for Spare Parts Initial Provisioning”, in Reliab. Maint. Symp. Proc., pp. 507-513, 2004.

17 S.M. ROSS, “Introduction to Probability Models”, New York: Academic Press, 1972.

18 W. FELLER, "Introdução a Teoria das Probabilidades e suas Aplicações”. São Paulo: Edgard Blucher, 1976. 
19 F.S. HILLER e G. J. LIEBERMAN, "Introduction to Operations Research", 8ed. Boston: McGraw-Hill, 2005.

20 S.B. RICHMOND, “Operations Research for Management Decisions", New York: Ronald Press, 1968.

21 A. PAPOULIS, "Probability, Random Variables and Stochastic Process", 3ed. New York: McGraw-Hill, 1965.

22 L. CHWIF e A.C. MEDINA, "Modelagem e Simulação de Eventos Discretos, Teoria e Aplicações”, 2ed. São Paulo, 2007.

23 R. BRONSON, “Pesquisa Operacional”. São Paulo: McGraw-Hill, 1985.

24 D. GROSS e C.M. HARRIS, "Fundamentals of Queueing Theory", New York: John Wiley \& Sons, 1974.

25 A.M. LEE, “Applied Queueing Theory”, London/New York: MacMillan/St Matins Press, 1966.

26 J. BANKS, “Discrete-event System Simulation”. 4ed. New Jersey: Pearson Prentice Hall, 2005.

27 D.S. PRADO, "Teoria das Filas e da Simulação", Série Pesquisa Operacional, Vol. 2 INDG Tecnologia e Serviços Ltda., 2006.

28 K.G. MACHADO, "Otimização De Estoques de Transformadores em Sistemas de Potência via Simulação Monte Carlo Cronológica e Técnicas Meta-heurísticas”, UNIFEI 2014.

29 A.M. LEITE DA SILVA; J.G.C. COSTA; R.A.G. FERNÁNDEZ e L.L. SOUZA, "Metodologia Probabilística e Software para o Dimensionamento Ótimo de Reserva Técnica de Equipamentos de Subestação", P\&D ANEEL - CEMIG D-245, Relatórios Técnicos 1 a 12, 2010-2013.

30 N.S. NETO; J.G.C. COSTA; A.M. LEITE DA SILVA e I.M. PUREZA, "Avaliação da Confiabilidade de Parques de Transformação com Reserva Técnica Compartilhada - Aprimoramentos Metodológicos" CBA-2016. 
31 L.L. DE SOUZA, "Metodologia Probabilística para Dimensionamento de Reserva Técnica de Transformadores de Subestações de Distribuição de Energia Elétrica”, UNIFEI 2014.

32 R. KUMAR, "Use of Mobile Unit Substations (MUS's) at Ontario Hydro", pp. 188-194, $\mathbf{8}^{\text {th }}$ International Conference on IEEE 1998.

33 J. LOPEZ-ROLDAN; J. ENNS; P.GUILLAUME e C. DEVRIENDT, "Mobile Substations: Application, Engineering and Structural Dynamics", Transmission and Distribution Conference and Exhibition, 2006 IEEE PES.

34 G. HAMOUD, "Cost/Benefit Analysis for Use of Mobile Unit Substations in Customer Delivery System" Power Engineering Society General Meeting, 2006. IEEE

35 G.A. HAMOUD, "Use of Mobile Unit Transformers in High Voltage Load Stations", Probabilistic Methods Applied to Power Systems, 2008. Proceedings of the $10^{\text {th }}$ International Conference on PMAPS '08.

36 G.A. HAMOUD e C. YIU, "Use of Mobile Substation in Redundant Customer Delivery System”, IEEE Transactions on Power Systems, Vol. 29, no. 3, pp 1403-1409, Maio de 2014.

37 G.A. HAMOUD e C. YIU, "One Markov Model for Spare Analysis of Distribution Power Transformers", IEEE Transactions on Power Systems, Vol. 31, n. 2, pp 1643-1648, Março de 2016.

38 J.C.O. MELLO; M.V.F. PEREIRA e A.M. LEITE da SILVA, “ Evaluation of Reliability Worth in Composite Systems Based on Pseudo-Sequential Monte Carlo Simulation”, IEEE Transactions on Power Systems, Vol. 9, $\mathrm{n}^{\circ} .3$, pp 1318-1326, Agosto de 1994. 


\section{Apêndice}

\section{1.}

\section{Caso 1: Resultados}

A Figura 7.1 apresenta os resultados compilados dos testes executados neste caso.

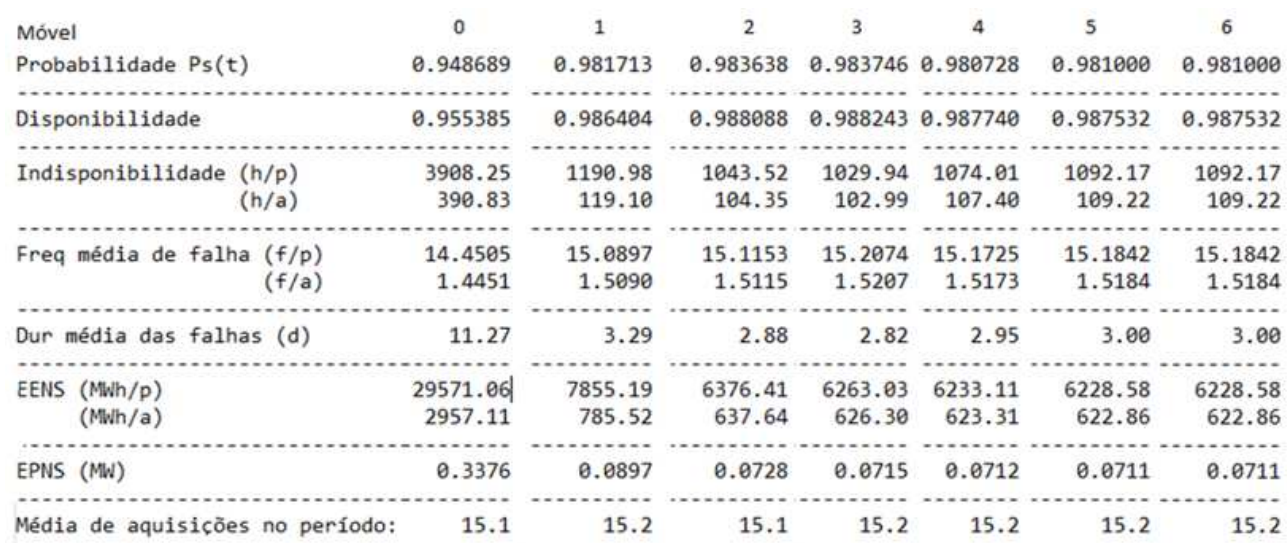

Figura 7.1 - Resultados completos do processo de simulação Caso 1

O programa apresenta como resultado 9 índices:

- Probabilidade Ps(t): A probabilidade do sistema ser encontrado em funcionamento;

- Disponibilidade: A porcentagem de tempo em que o sistema esteve disponível;

- Indisponibilidade: Fornecida em horas por período analisado (h/p) e horas por ano (h/a), fornece o tempo em que o sistema esteve indisponível;

- Frequência Média de Falha: também fornecido por período e por ano, o índice mostra a frequência de ocorrências de falha no sistema;

- Duração Média das Falhas: apresenta a duração média de cada falha em dias;

- EENS: fornecido em MWh por período ou por ano, mostra a expectativa de energia não suprida do sistema;

- $\quad$ EPNS: Fornecido em MW, ilustra a demanda não atendida; 
- Média de aquisições no período: Número médio de equipamentos que entraram em processo de aquisição no período.

Destaca-se nos resultados acima primeiramente que o beta para convergência foi aplicado ao índice EENS, ou seja, a simulação foi repetida até esse índice apresentar variações menores de $1 \%$ entre ciclos de simulações. Outra análise importante a ser feita é que a frequência média de falha não é reduzida com a inclusão de unidades móveis, mantendo assim o número médio de aquisições no período, não é objetivo de inclusão da subestação móvel reduzir o número de falhas no sistema e sim mitigar o impacto da mesma no sistema. Dentro da margem de erro os outros índices se comportaram da maneira esperada.

\section{2 .}

\section{Caso 2: Resultados}

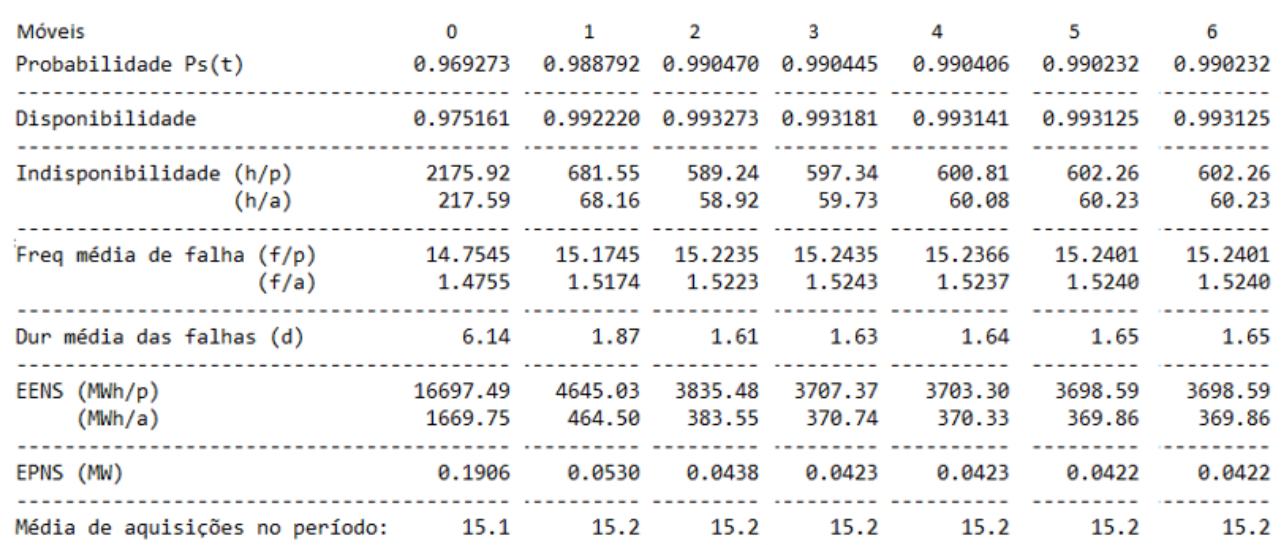

Figura 7.2 - Resultados completos do processo de simulação Caso 2

A Figura 7.2 apresenta os mesmos índices da Figura 7.1, com os resultados seguindo como esperado. Os índices de forma geral apresentam resultados melhores que os da seção anterior, como esperado, pelo fato da transferência ser executada em tempo consideravelmente menor que a instalação, mesmo de uma unidade móvel. Nesse caso foi incluída a possibilidade de executar transferência em metade das unidades, logo os resultados de EENS apresentam valores menores mesmo antes da inclusão de unidades móveis, se comparada ao caso inicial, sem móveis e sem transferência. Os demais índices também apresentam melhoras na combinação de atuação entre unidades móveis e unidades com possibilidade de executar 
transferência. Esse caso retrata um comportamento muito próximo com o da realidade dos sistemas nacionais, onde parte das unidades conseguem efetuar a transferência de sua carga em um momento de falha e parte não apresenta essa possibilidade.

Da mesma forma a frequência média de falhas e a média de aquisições no período permanece praticamente inalterada, mostrando que a transferência, da mesma forma que as unidades móveis visam reduzir o tempo de falha.

\section{3.}

\section{Caso 3: Resultados}

\begin{tabular}{|c|c|c|c|c|c|}
\hline Dias de Utilização & 180 & 540 & 900 & 1260 & 1620 \\
\hline Probabilidade Ps(t) & 0.864921 & 0.847877 & 0.875903 & 0.895292 & 0.921509 \\
\hline Disponibilidade & 0.905410 & 0.911780 & 0.933841 & 0.947432 & 0.956309 \\
\hline $\begin{array}{r}\text { Indisponibilidade (h/p) } \\
\text { (h/a) }\end{array}$ & $\begin{array}{r}8286.12 \\
828.61\end{array}$ & $\begin{array}{r}7728.08 \\
772.81\end{array}$ & $\begin{array}{r}5795.54 \\
579.55\end{array}$ & $\begin{array}{r}4604.94 \\
460.49\end{array}$ & $\begin{array}{r}3827.37 \\
382.74\end{array}$ \\
\hline $\begin{array}{r}\text { Freq média de falha }(\mathrm{f} / \mathrm{p}) \\
(\mathrm{f} / \mathrm{a})\end{array}$ & $\begin{array}{r}16.8834 \\
1.6883\end{array}$ & $\begin{array}{r}16.1445 \\
1.6144\end{array}$ & $\begin{array}{r}16.0024 \\
1.6002\end{array}$ & $\begin{array}{r}15.8025 \\
1.5803\end{array}$ & $\begin{array}{r}15.6055 \\
1.5605\end{array}$ \\
\hline Dur média das falhas (d) & 20.45 & 19.95 & 15.09 & 12.14 & 10.22 \\
\hline $\begin{array}{l}\text { EENS (MWh/p) } \\
\qquad(\text { MWh/a) }\end{array}$ & $\begin{array}{r}69692.45 \\
6969.25\end{array}$ & $\begin{array}{r}46951.04 \\
4695.10\end{array}$ & $\begin{array}{r}33218.05 \\
3321.80\end{array}$ & $\begin{array}{r}27029.48 \\
2702.95\end{array}$ & $\begin{array}{r}24136.88 \\
2413.69\end{array}$ \\
\hline EPNS (MW) & 0.7956 & 0.5360 & 0.3792 & 0.3086 & 0.2755 \\
\hline édia de aquisições no período: & 15.1 & 15.0 & 15.0 & 15.0 & 15.0 \\
\hline
\end{tabular}

Figura 7.3 - Resultados primeira metade do intervalo do Caso 3

\begin{tabular}{|c|c|c|c|c|c|}
\hline Dias de Utilização & 1980 & 2340 & 2700 & 3060 & 3420 \\
\hline Probabilidade Ps(t) & 0.927494 & 0.931525 & 0.932757 & 0.933498 & 0.957532 \\
\hline Disponibilidade & 0.961681 & 0.965704 & 0.969592 & 0.972734 & 0.974988 \\
\hline $\begin{array}{r}\text { Indisponibilidade }(h / p) \\
(h / a)\end{array}$ & $\begin{array}{r}3356.72 \\
335.67\end{array}$ & $\begin{array}{r}3004.34 \\
300.43\end{array}$ & $\begin{array}{r}2663.70 \\
266.37\end{array}$ & $\begin{array}{r}2388.52 \\
238.85\end{array}$ & $\begin{array}{r}2191.05 \\
219.10\end{array}$ \\
\hline $\begin{array}{r}\text { Freq média de falha }(f / p) \\
(f / a)\end{array}$ & $\begin{array}{r}15.4945 \\
1.5495\end{array}$ & $\begin{array}{r}15.3754 \\
1.5375\end{array}$ & $\begin{array}{r}15.2631 \\
1.5263\end{array}$ & $\begin{array}{r}15.0319 \\
1.5032\end{array}$ & $\begin{array}{r}14.7706 \\
1.4771\end{array}$ \\
\hline Dur média das falhas ( $\mathrm{d}$ & 9.03 & 8.14 & 7.27 & 6.62 & 6.18 \\
\hline $\begin{array}{r}\text { EENS }(\text { MWh } / p) \\
(M W h / a)\end{array}$ & $\begin{array}{r}22738.46 \\
2273.85\end{array}$ & $\begin{array}{r}21253.27 \\
2125.33\end{array}$ & $\begin{array}{r}19463.26 \\
1946.33\end{array}$ & $\begin{array}{r}17454.62 \\
1745.46\end{array}$ & $\begin{array}{r}15510.51 \\
1551.05\end{array}$ \\
\hline EPNS (MW) & 0.2596 & 0.2426 & 0.2222 & 0.1993 & 0.1771 \\
\hline édia de & 15.0 & 15.0 & 15.1 & 15.0 & 15.1 \\
\hline
\end{tabular}

Figura 7.4 - Resultados segunda metade do intervalo do Caso 3 
As Figuras 7.3 e 7.4 mostram os resultados para as simulações de aumento de tempo da utilização da unidade móvel, visando aproximar seus resultados do caso inicial, onde seriam 5 unidades de estoque, contra 2 unidades de estoque inicial e 3 móveis com tempo de utilização majorados. $\mathrm{O}$ aumento progressivo nos índices é visível, se aproximando dos valores esperados e até os superando.

Fica visível ao analisar esses resultados que o comportamento dos índices segue o esperado para a análise proposta nesse caso. Destaca-se que a Duração Média das Falhas não é tão baixa como nos casos anteriores com 3 unidades móveis, isso se deve ao fato da unidade móvel não se comportar do modo convencional neste caso. Ao ter seu estoque inicial desfalcado, o sistema quando entra em falha encontra disponível uma unidade móvel que no início das simulações, com o tempo de 180 dias, não consegue extinguir a interrupção por longos períodos, e caso não chegue uma unidade convencional em 180 dias o sistema retorna para estado de falha. Ao final da simulação, com períodos de tempo longos, a unidade móvel passa a ser usada de forma fixa em um local de falha, dessa forma ela perde a capacidade de mitigar o tempo das próximas interrupções do sistema.

As simulações neste caso demonstram que em casos extremos é possível que uma unidade móvel funcione como uma unidade de estoque convencional.

\section{4. \\ Caso 4: Resultados}

Os resultados mostrados nas Figuras 7.5 e 7.6 ilustram uma pequena melhora em relação ao caso anterior. O sistema se comporta dentro do esperado para as considerações feitas para esse teste.

Destaca-se aqui que a possibilidade de transferência não apresenta impacto tão grande nesse teste, algo esperado, pela própria limitação da execução da transferência. Se no momento da falha na unidade que tem possibilidade de ter sua carga transferida para outra subestação não houver unidade de estoque ou unidade móvel disponível a mesma não será executada. Como nesse caso houve uma redução considerável do estoque inicial, a transferência em muitas situações de falha ao longo dos testes não pode ser executada. Mantendo assim, valores que geralmente são reduzidos com a possibilidade de transferência, com valores mais elevados, dentre eles a Duração Média das Falhas. 


\begin{tabular}{|c|c|c|c|c|c|}
\hline Dias de Utilização & 180 & 540 & 900 & 1260 & 1620 \\
\hline Probabilidade Ps $(t)$ & 0.879731 & 0.894859 & 0.916444 & 0.926994 & 0.939783 \\
\hline Disponibilidade & 0.914026 & 0.933940 & 0.951641 & 0.959721 & 0.965429 \\
\hline $\begin{array}{r}\text { Indisponibilidade }(\mathrm{h} / \mathrm{p}) \\
(\mathrm{h} / \mathrm{a})\end{array}$ & $\begin{array}{r}7531.31 \\
753.13\end{array}$ & $\begin{array}{r}5786.86 \\
578.69\end{array}$ & $\begin{array}{r}4236.26 \\
423.63\end{array}$ & $\begin{array}{r}3528.47 \\
352.85\end{array}$ & $\begin{array}{r}3028.38 \\
302.84\end{array}$ \\
\hline $\begin{array}{r}\text { Freq média de falha }(f / p) \\
\qquad(f / a)\end{array}$ & $\begin{array}{r}17.0865 \\
1.7087\end{array}$ & $\begin{array}{r}16.6454 \\
1.6645\end{array}$ & $\begin{array}{r}16.3997 \\
1.6400\end{array}$ & $\begin{array}{r}16.0924 \\
1.6092\end{array}$ & $\begin{array}{r}15.8421 \\
1.5842\end{array}$ \\
\hline Dur média das falhas (d) & 18.37 & 14.49 & 10.76 & 9.14 & 7.97 \\
\hline $\begin{array}{r}\text { EENS }(\text { MWh } / p) \\
(\text { MWh/a) }\end{array}$ & $\begin{array}{r}64319.17 \\
6431.92\end{array}$ & $\begin{array}{r}38001.14 \\
3800.11\end{array}$ & $\begin{array}{r}26748.87 \\
2674.89\end{array}$ & $\begin{array}{r}22305.95 \\
2230.59\end{array}$ & $\begin{array}{r}20011.55 \\
2001.15\end{array}$ \\
\hline EPNS (MW) & 0.7342 & 0.4338 & 0.3054 & 0.2546 & 0.2284 \\
\hline Média de aquisições no período: & 15.1 & 15.0 & 15.0 & 15.0 & 15.0 \\
\hline
\end{tabular}

Figura 7.5 - Resultados primeira metade do intervalo do Caso 4

\begin{tabular}{|c|c|c|c|c|c|}
\hline Dias de Utilização & 1980 & 2340 & 2700 & 3060 & 3420 \\
\hline Probabilidade Ps $(t)$ & 0.941944 & 0.943658 & 0.943611 & 0.944766 & 0.963987 \\
\hline Disponibilidade & 0.969406 & 0.971795 & 0.974833 & 0.977037 & 0.978628 \\
\hline $\begin{array}{r}\text { Indisponibilidade }(\mathrm{h} / \mathrm{p}) \\
\qquad(\mathrm{h} / \mathrm{a})\end{array}$ & $\begin{array}{r}2680.02 \\
268.00\end{array}$ & $\begin{array}{r}2470.77 \\
247.08\end{array}$ & $\begin{array}{r}2204.59 \\
220.46\end{array}$ & $\begin{array}{r}2011.58 \\
201.16\end{array}$ & $\begin{array}{r}1872.17 \\
187.22\end{array}$ \\
\hline $\begin{array}{r}\text { Freq média de falha }(\mathrm{f} / \mathrm{p}) \\
(\mathrm{f} / \mathrm{a})\end{array}$ & $\begin{array}{r}15.7084 \\
1.5708\end{array}$ & $\begin{array}{r}15.5685 \\
1.5569\end{array}$ & $\begin{array}{r}15.4073 \\
1.5407\end{array}$ & $\begin{array}{r}15.1384 \\
1.5138\end{array}$ & $\begin{array}{r}14.8289 \\
1.4829\end{array}$ \\
\hline Dur média das falhas (d) & 7.11 & 6.61 & 5.96 & 5.54 & 5.26 \\
\hline $\begin{array}{r}\text { EENS }(\text { MWh/p) } \\
(\text { MWh/a) }\end{array}$ & $\begin{array}{r}18842.76 \\
1884.28\end{array}$ & $\begin{array}{r}17656.63 \\
1765.66\end{array}$ & $\begin{array}{r}16068.93 \\
1606.89\end{array}$ & $\begin{array}{r}14358.19 \\
1435.82\end{array}$ & $\begin{array}{r}12831.16 \\
1283.12\end{array}$ \\
\hline EPNS (MW) & 0.2151 & 0.2016 & 0.1834 & 0.1639 & 0.1465 \\
\hline Média de aquisições no período: & 15.0 & 15.0 & 15.1 & 15.0 & 15.0 \\
\hline
\end{tabular}

Figura 7.6 - Resultados segunda metade do intervalo do Caso 4 


\section{5.}

\section{Caso 5: Resultados}

\begin{tabular}{|c|c|c|c|c|c|c|c|}
\hline Móveis & 0 & 1 & 2 & 3 & 4 & 5 & 6 \\
\hline Probabilidade Ps(t) & 0.348500 & 0.507380 & 0.615362 & 0.684752 & 0.722401 & 0.732311 & 0.731410 \\
\hline 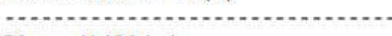 & & & - & 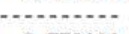 & (n) & (2) & \\
\hline Disponibilidade & 0.427762 & 0.582237 & 0.700131 & 0.779192 & 0.818802 & 0.842389 & 0.849203 \\
\hline Then & 501709 & 3650606 & 56268 & (1) & 1587703 & & \\
\hline $\begin{array}{r}\text { Indisponibilidade }(h / p) \\
(h / a)\end{array}$ & $\begin{array}{r}50128.06 \\
5012.81\end{array}$ & $\begin{array}{r}36596.06 \\
3659.61\end{array}$ & $\begin{array}{r}26268.49 \\
2626.85\end{array}$ & $\begin{array}{r}19342.81 \\
1934.28\end{array}$ & $\begin{array}{r}15872.93 \\
1587.29\end{array}$ & $\begin{array}{r}13806.76 \\
1380.68\end{array}$ & $\begin{array}{r}13209.78 \\
1320.98\end{array}$ \\
\hline $\begin{array}{r}\text { Freq média de falha }(\mathrm{f} / \mathrm{p}) \\
\qquad(\mathrm{f} / \mathrm{a})\end{array}$ & $\begin{array}{r}12.7985 \\
1.2799\end{array}$ & $\begin{array}{r}17.7777 \\
1.7778\end{array}$ & $\begin{array}{r}22.2262 \\
2.2226\end{array}$ & $\begin{array}{r}25.4911 \\
2.5491\end{array}$ & $\begin{array}{r}27.4271 \\
2.7427\end{array}$ & $\begin{array}{r}28.6376 \\
2.8638\end{array}$ & $\begin{array}{r}29.0417 \\
2.9042\end{array}$ \\
\hline Dur média das falhas (d) & 163.20 & 85.77 & 49.24 & 31.62 & 24.11 & 20.09 & 18.95 \\
\hline $\begin{array}{l}\text { EENS }(M N h / p) \\
(M N h / a)\end{array}$ & $\begin{array}{r}780762.95 \\
78076.30\end{array}$ & $\begin{array}{r}489241.30 \\
48924.13\end{array}$ & $\begin{array}{r}302340.02 \\
30234.00\end{array}$ & $\begin{array}{r}189676.31 \\
18967.63\end{array}$ & $\begin{array}{r}131052.35 \\
13105.24\end{array}$ & $\begin{array}{r}101694.31 \\
10169.43\end{array}$ & $\begin{array}{r}90252.63 \\
9025.26\end{array}$ \\
\hline EPNS (MW) & 8.9128 & 5.5849 & 3.4514 & 2.1653 & 1.4960 & 1.1609 & 1.0303 \\
\hline Média de aquisições no período: & 29.9 & 29.7 & 29.9 & 29.8 & 29.7 & 29.6 & 29.6 \\
\hline
\end{tabular}

Figura 7.7 - Resultados do Caso 5

O objetivo deste caso era conseguir demonstrar maior efetividade de mais de uma unidade móvel no sistema, para isso a taxa de falha foi aumentada, provocando um número maior de falhas no sistema.

Dessa maneira, os índices apresentam resultados consideravelmente piores quando comparados aos casos anteriores, contudo, a segunda e terceira unidade móvel conseguem produzir efeito de melhora no sistema, o que não é alcançado anteriormente.

Um índice que precisa de maior atenção nessa análise é o de frequência de falha, que aumenta de acordo com o aumento do número de unidades móveis apesar da melhora do sistema. O que ocorre, é que com o baixo número de estoque e grande número de falhas, as unidades móveis são utilizadas para sanar a interrupção que foi contabilizada, contudo não existe unidade de estoque disponível para a retirada da unidade móvel. Quando o tempo máximo de utilização da unidade móvel é alcançado, a mesma é retirada do sistema e a unidade volta ao estado de falha, contabilizando assim outra falha, aumentando como consequência, a frequência média de falhas.

De maneira geral, os resultados seguiram o comportamento esperado, para estudos futuros, a análise do impacto de mais de uma unidade poderá ser efetuada em sistemas de grande porte. 
7.6.

\section{Caso 6: Resultados}

\begin{tabular}{|c|c|c|c|c|c|c|c|c|c|}
\hline Dias para Instalaçäo & 0.5 & 1.0 & 1.5 & 2.0 & 2.5 & 3.0 & 3.5 & 4.0 & 4.5 \\
\hline Probabilidade Ps(t) & 0.987582 & 0.985290 & 0.984395 & 0.982132 & 0.980348 & 0.975472 & 0.972868 & 0.968771 & 0.967438 \\
\hline Disponibilidade & 0.992567 & 0.990463 & 0.988598 & 0.986518 & 0.984439 & 0.982484 & 0.980470 & 0.978082 & 0.976329 \\
\hline $\begin{array}{r}\text { Indisponibilidade }(\mathrm{h} / \mathrm{p}) \\
(\mathrm{h} / \mathrm{a})\end{array}$ & $\begin{array}{r}651.13 \\
65.11\end{array}$ & $\begin{array}{r}835.48 \\
83.55\end{array}$ & $\begin{array}{r}998.81 \\
99.88\end{array}$ & $\begin{array}{r}1181.03 \\
118.10\end{array}$ & $\begin{array}{r}1363.13 \\
136.31\end{array}$ & $\begin{array}{r}1534.41 \\
153.44\end{array}$ & $\begin{array}{r}1710.83 \\
171.08\end{array}$ & $\begin{array}{r}1920.01 \\
192.00\end{array}$ & $\begin{array}{r}2073.58 \\
207.36\end{array}$ \\
\hline $\begin{array}{r}\text { Freq média de falha }(f / p) \\
\qquad(f / a)\end{array}$ & $\begin{array}{r}15.1700 \\
1.5170\end{array}$ & $\begin{array}{r}15.1412 \\
1.5141\end{array}$ & $\begin{array}{r}15.1019 \\
1.5102\end{array}$ & $\begin{array}{r}15.0882 \\
1.5088\end{array}$ & $\begin{array}{r}15.0400 \\
1.5040\end{array}$ & $\begin{array}{r}15.0262 \\
1.5026\end{array}$ & $\begin{array}{r}14.9795 \\
1.4980\end{array}$ & $\begin{array}{r}14.9259 \\
1.4926\end{array}$ & $\begin{array}{r}14.8884 \\
1.4888\end{array}$ \\
\hline Dur média das falhas (d) & 1.79 & 2.30 & 2.76 & 3.26 & 3.78 & 4.25 & 4.76 & 5.36 & 5.80 \\
\hline $\begin{array}{r}\text { EENS }(\text { Wh } / p) \\
(\text { Wh } / a)\end{array}$ & $\begin{array}{r}4051.40 \\
405.14\end{array}$ & $\begin{array}{r}5373.79 \\
537.38\end{array}$ & $\begin{array}{r}6576.23 \\
657.62\end{array}$ & $\begin{array}{r}7887.64 \\
788.76\end{array}$ & $\begin{array}{r}9120.45 \\
912.04\end{array}$ & $\begin{array}{r}10314.58 \\
1031.46\end{array}$ & $\begin{array}{r}11587.60 \\
1158.76\end{array}$ & $\begin{array}{r}12827.48 \\
1282.75\end{array}$ & $\begin{array}{r}14084.02 \\
1408.40\end{array}$ \\
\hline EPNS (MW) & 0.0462 & 0.0613 & 0.0751 & 0.0900 & 0.1041 & 0.1177 & 0.1323 & 0.1464 & 0.1608 \\
\hline Média de aquisições & 15.2 & 15.2 & 15.2 & 15.2 & 15.2 & 15.2 & 15.2 & 15.2 & 15.1 \\
\hline
\end{tabular}

Figura 7.8 - Resultados da primeira metade das simulações do Caso 6

\begin{tabular}{|c|c|c|c|c|c|c|c|c|c|}
\hline Dias para Instalaçåo & 5.0 & 5.5 & 6.0 & 6.5 & 7.0 & 7.5 & 8.0 & 8.5 & 9.0 \\
\hline Probabilidade Ps $(t)$ & 0.968324 & 0.966233 & 0.963701 & 0.960607 & 0.960809 & 0.958649 & 0.953085 & 0.952271 & 0.952229 \\
\hline Disponibilidade & 0.974734 & 0.972448 & 0.970276 & 0.968436 & 0.967059 & 0.964997 & 0.963194 & 0.961130 & 0.959754 \\
\hline $\begin{array}{r}\text { Indisponibilidade }(h / p) \\
\qquad(h / a)\end{array}$ & $\begin{array}{r}2213.29 \\
221.33\end{array}$ & $\begin{array}{r}2413.51 \\
241.35\end{array}$ & $\begin{array}{r}2603.80 \\
260.38\end{array}$ & $\begin{array}{r}2765.04 \\
276.50\end{array}$ & $\begin{array}{r}2885.66 \\
288.57\end{array}$ & $\begin{array}{r}3066.28 \\
306.63\end{array}$ & $\begin{array}{r}3224.24 \\
322.42\end{array}$ & $\begin{array}{r}3405.04 \\
340.50\end{array}$ & $\begin{array}{r}3525.58 \\
352.56\end{array}$ \\
\hline $\begin{array}{r}\text { Freq média de falha }(f / p) \\
(f / a)\end{array}$ & $\begin{array}{r}14.8482 \\
1.4848\end{array}$ & $\begin{array}{r}14.7799 \\
1.4780\end{array}$ & $\begin{array}{r}14.7336 \\
1.4734\end{array}$ & $\begin{array}{r}14.6854 \\
1.4685\end{array}$ & $\begin{array}{r}14.6538 \\
1.4654\end{array}$ & $\begin{array}{r}14.6175 \\
1.4618\end{array}$ & $\begin{array}{r}14.5914 \\
1.4591\end{array}$ & $\begin{array}{r}14.6016 \\
1.4602\end{array}$ & $\begin{array}{r}14.5533 \\
1.4553\end{array}$ \\
\hline Dur média das falhas (d) & 6.21 & 6.80 & 7.36 & 7.85 & 8.21 & 8.74 & 9.21 & 9.72 & 10.09 \\
\hline $\begin{array}{r}\text { EENS }(\text { MWh } / p) \\
(\text { MWh/a) }\end{array}$ & $\begin{array}{r}15299.51 \\
1529.95\end{array}$ & $\begin{array}{r}16463.33 \\
1646.33\end{array}$ & $\begin{array}{r}17693.82 \\
1769.38\end{array}$ & $\begin{array}{r}18951.63 \\
1895.16\end{array}$ & $\begin{array}{r}20163.90 \\
2016.39\end{array}$ & $\begin{array}{r}21399.27 \\
2139.93\end{array}$ & $\begin{array}{r}22595.21 \\
2259.52\end{array}$ & $\begin{array}{r}24041.15 \\
2404.12\end{array}$ & $\begin{array}{r}25300.46 \\
2530.05\end{array}$ \\
\hline EPNS (MW) & 0.1747 & 0.1879 & 0.2020 & 0.2163 & 0.2302 & 0.2443 & 0.2579 & 0.2744 & 0.2888 \\
\hline lédia de aquisições & 15.1 & 15.1 & 15.1 & 15.1 & 15.1 & 15.1 & 15.1 & 15.1 & 15.1 \\
\hline
\end{tabular}

Figura 7.9 - Resultados da segunda metade das simulações do Caso 6

As Figuras 7.8 e 7.9 representam os resultados alcançados no Caso 6. Degradando o tempo de instalação das unidades móveis, como esperado, há uma piora gradual dos índices do sistema, mostrando que a efetividade do efeito da unidade móvel está diretamente relacionado ao tempo de instalação da mesma.

Foi escolhido variar o tempo de instalação até o período de 9 dias visando igualar ao tempo mínimo de instalação de unidades convencionais. 


\begin{tabular}{|c|c|c|}
\hline Unidades de Estoque & 5 & 6 \\
\hline Probabilidade Ps $(t)$ & 0.955016 & 0.968000 \\
\hline Disponibilidade & 0.959430 & 0.962808 \\
\hline $\begin{array}{r}\text { Indisponibilidade }(h / p) \\
(h / a)\end{array}$ & $\begin{array}{r}3553.95 \\
355.40\end{array}$ & $\begin{array}{r}3257.98 \\
325.80\end{array}$ \\
\hline $\begin{array}{r}\text { Freq média de falha }(\mathrm{f} / \mathrm{p}) \\
\qquad(\mathrm{f} / \mathrm{a})\end{array}$ & $\begin{array}{r}14.5201 \\
1.4520\end{array}$ & $\begin{array}{r}14.4690 \\
1.4469\end{array}$ \\
\hline Dur média das falhas (d) & 10.20 & 9.38 \\
\hline $\begin{array}{r}\text { EENS }(\text { MWh } / p) \\
(M W h / a)\end{array}$ & $\begin{array}{r}26899.13 \\
2689.91\end{array}$ & $\begin{array}{r}24143.34 \\
2414.33\end{array}$ \\
\hline EPNS (MW) & 0.3071 & 0.2756 \\
\hline Média de aquis: & 15.1 & 15.0 \\
\hline
\end{tabular}

Figura 7.10 - Resultados das simulações do Caso 6 sem unidades móveis

A Figura 7.10 ilustra as simulações feitas para fim de comparação, onde foi definido o tempo de instalação de unidades convencionais em 9 dias e mostrado que apesar de ter uma unidade móvel, o sistema com 5 unidades de estoque do início da simulação apresenta pouca melhora em relação ao sistema com apenas as 5 unidades de estoque iniciais quando o tempo de utilização da unidade móvel chega aos 9 dias. E para fim de comparação, nessa situação a inclusão de uma unidade de estoque convencional, com preço inferior ao de uma unidade móvel, apresenta resultados melhores.

Assim fica evidenciada a necessidade de rapidez na instalação das unidades móveis para aumentar sua eficiência, e abre, portanto, um campo de análise para futuros estudos sobre a melhor forma de posicionar as unidades estratégicas, levando em consideração a localização das unidades no campo.

\section{7.}

\section{Caso 7: Resultados}

\begin{tabular}{|c|c|c|c|c|c|c|c|c|c|c|c|c|}
\hline Horas para Transferência & 1 & 2 & 3 & 4 & 5 & 6 & 7 & 8 & 9 & 10 & 11 & 12 \\
\hline Probabilidade Ps(t) & 0.997049 & 0.996804 & 0.996464 & 0.996349 & 0.996027 & 0.995826 & 0.995519 & 0.995232 & 0.994873 & 0.994728 & 0.994444 & 0.994127 \\
\hline sponibilidade & 998132 & 0.997945 & 0.997750 & 0.997540 & 0.997337 & 0.997137 & 0.996930 & 0.996736 & 0.996543 & 0.996340 & 0.996151 & 0.995973 \\
\hline $\begin{aligned} \text { Indisponibilidade } & (\mathrm{h} / \mathrm{p}) \\
& (\mathrm{h} / \mathrm{a})\end{aligned}$ & $\begin{array}{r}163.68 \\
16.37\end{array}$ & $\begin{array}{r}179.99 \\
18.00\end{array}$ & $\begin{array}{r}197.10 \\
19.71\end{array}$ & $\begin{array}{r}215.53 \\
21.55\end{array}$ & $\begin{array}{r}233.28 \\
23.33\end{array}$ & $\begin{array}{r}250.81 \\
25.08\end{array}$ & $\begin{array}{r}268.95 \\
26.90\end{array}$ & $\begin{array}{r}285.93 \\
28.59\end{array}$ & $\begin{array}{r}302.79 \\
30.28\end{array}$ & $\begin{array}{r}320.61 \\
32.06\end{array}$ & $\begin{array}{r}337.17 \\
33.72\end{array}$ & $\begin{array}{r}352.77 \\
35.28\end{array}$ \\
\hline $\begin{array}{r}\text { Freq média de falha }(f / p) \\
(f / a)\end{array}$ & $\begin{array}{r}15.2621 \\
1.5262\end{array}$ & $\begin{array}{r}15.2633 \\
1.5263\end{array}$ & $\begin{array}{r}15.2559 \\
1.5256\end{array}$ & $\begin{array}{r}15.2554 \\
1.5255\end{array}$ & $\begin{array}{r}15.2542 \\
1.5254\end{array}$ & $\begin{array}{r}15.2539 \\
1.5254\end{array}$ & $\begin{array}{r}15.2566 \\
1.5257\end{array}$ & $\begin{array}{r}15.2518 \\
1.5252\end{array}$ & $\begin{array}{r}15.2498 \\
1.5250\end{array}$ & $\begin{array}{r}15.2462 \\
1.5246\end{array}$ & $\begin{array}{r}15.2479 \\
1.5248\end{array}$ & $\begin{array}{r}15.2424 \\
1.5242\end{array}$ \\
\hline Dur média das falhas (d) & 0.45 & 0.49 & 0.54 & 0.59 & 0.64 & 0.69 & 0.73 & 0.78 & 0.83 & 0.88 & 0.92 & 0.96 \\
\hline $\begin{aligned} & \text { EENS }(\text { MWh/p) } \\
&(\text { MWh/a) }\end{aligned}$ & $\begin{array}{r}1371.72 \\
137.17\end{array}$ & $\begin{array}{r}1485.02 \\
148.50\end{array}$ & $\begin{array}{r}1595.56 \\
159.56\end{array}$ & $\begin{array}{r}1706.81 \\
170.68\end{array}$ & $\begin{array}{r}1817.16 \\
181.72\end{array}$ & $\begin{array}{r}1933.21 \\
193.32\end{array}$ & $\begin{array}{r}2049.27 \\
204.93\end{array}$ & $\begin{array}{r}2159.35 \\
215.94\end{array}$ & $\begin{array}{r}2276.82 \\
227.68\end{array}$ & $\begin{array}{r}2389.61 \\
238.96\end{array}$ & $\begin{array}{r}2511.13 \\
251.11\end{array}$ & $\begin{array}{r}2617.28 \\
261.73\end{array}$ \\
\hline EPNS (MW) & 0.0157 & 0.0170 & 0.0182 & 0.0195 & 0.0207 & 0.0221 & 0.0234 & 0.0247 & 0.0260 & 0.0273 & 0.0287 & 0.0299 \\
\hline dia de aquisições no $p$ & 15.2 & 15.2 & 15.2 & 15.2 & 15.2 & 15.2 & 15.2 & 15.2 & 15.2 & 15.2 & 15.2 & 15.2 \\
\hline
\end{tabular}

Figura 7.11 - Resultados da primeira metade das simulações do Caso 7 


\begin{tabular}{|c|c|c|c|c|c|c|c|c|c|c|c|c|}
\hline Horas para Transferência & 13 & 14 & 15 & 16 & 17 & 18 & 19 & 20 & 21 & 22 & 23 & 24 \\
\hline Probabilidade Ps $(t)$ & 0.993869 & 0.993693 & 0.993322 & 0.992998 & 0.992744 & 0.992335 & 0.992003 & 0.991825 & 0.991758 & 0.991376 & 0.991394 & 0.991215 \\
\hline Disponibilidade & .995765 & 0.995592 & 0.995394 & 0.995165 & 0.995002 & 0.994777 & 0.994586 & 0.994447 & 0.994276 & 0.994086 & 0.993930 & 0.993727 \\
\hline $\begin{array}{r}\text { Indisponibilidade }\left(\begin{array}{r}(\mathrm{h} / \mathrm{p}) \\
(\mathrm{h} / \mathrm{a})\end{array}\right.\end{array}$ & $\begin{array}{r}370.96 \\
37.10\end{array}$ & $\begin{array}{r}386.17 \\
38.62\end{array}$ & $\begin{array}{r}403.47 \\
40.35\end{array}$ & $\begin{array}{r}423.51 \\
42.35\end{array}$ & $\begin{array}{r}437.80 \\
43.78\end{array}$ & $\begin{array}{r}457.49 \\
45.75\end{array}$ & $\begin{array}{r}474.26 \\
47.43\end{array}$ & $\begin{array}{r}486.47 \\
48.65\end{array}$ & $\begin{array}{r}501.42 \\
50.14\end{array}$ & $\begin{array}{r}518.03 \\
51.80\end{array}$ & $\begin{array}{r}531.75 \\
53.18\end{array}$ & $\begin{array}{r}549.50 \\
54.95\end{array}$ \\
\hline $\begin{array}{r}\text { Freq média de falha }(\mathrm{f} / \mathrm{p}) \\
(\mathrm{f} / \mathrm{a})\end{array}$ & $\begin{array}{r}15.2401 \\
1.5240\end{array}$ & $\begin{array}{r}15.2338 \\
1.5234\end{array}$ & $\begin{array}{r}15.2340 \\
1.5234\end{array}$ & $\begin{array}{r}15.2351 \\
1.5235\end{array}$ & $\begin{array}{r}15.2304 \\
1.5230\end{array}$ & $\begin{array}{r}15.2300 \\
1.5230\end{array}$ & $\begin{array}{r}15.2352 \\
1.5235\end{array}$ & $\begin{array}{r}15.2220 \\
1.5222\end{array}$ & $\begin{array}{r}15.2235 \\
1.5224\end{array}$ & $\begin{array}{r}15.2233 \\
1.5223\end{array}$ & $\begin{array}{r}15.2206 \\
1.5221\end{array}$ & $\begin{array}{r}15.2226 \\
1.5223\end{array}$ \\
\hline Dur média das falhas (d) & 1.01 & 1.06 & 1.10 & 1.16 & 1.20 & 1.25 & 1.30 & 1.33 & 1.37 & 1.42 & 1.46 & 1.50 \\
\hline $\begin{aligned} & \text { EENS }(\text { MWh/p) } \\
&(\text { MWh/a) }\end{aligned}$ & $\begin{array}{r}2732.49 \\
273.25\end{array}$ & $\begin{array}{r}2835.48 \\
283.55\end{array}$ & $\begin{array}{r}2953.44 \\
295.34\end{array}$ & $\begin{array}{r}3085.87 \\
308.59\end{array}$ & $\begin{array}{r}3185.24 \\
318.52\end{array}$ & $\begin{array}{r}3306.71 \\
330.67\end{array}$ & $\begin{array}{r}3415.67 \\
341.57\end{array}$ & $\begin{array}{r}3508.80 \\
350.88\end{array}$ & $\begin{array}{r}3628.23 \\
362.82\end{array}$ & $\begin{array}{r}3735.08 \\
373.51\end{array}$ & $\begin{array}{r}3834.33 \\
383.43\end{array}$ & $\begin{array}{r}3951.82 \\
395.18\end{array}$ \\
\hline EPNS (MW) & 0.0312 & 0.0324 & 0.0337 & 0.0352 & 0.0364 & 0.0377 & 0.0390 & 0.0401 & 0.0414 & 0.0426 & 0.0438 & 0.0451 \\
\hline Média de aquisições no período: & 15.2 & 15.2 & 15.2 & 15.2 & 15.2 & 15.2 & 15.2 & 15.2 & 15.2 & 15.2 & 15.2 & 15.2 \\
\hline
\end{tabular}

Figura 7.12 - Resultados da segunda metade das simulações do Caso 7

\begin{tabular}{|c|c|}
\hline Probabilidade Ps(t) & 0.992071 \\
\hline Disponibilidade & 0.993853 \\
\hline $\begin{array}{r}\text { Indisponibilidade }(\mathrm{h} / \mathrm{p}) \\
\qquad(\mathrm{h} / \mathrm{a})\end{array}$ & $\begin{array}{r}538.44 \\
53.84\end{array}$ \\
\hline $\begin{array}{r}\text { Freq média de falha }(f / p) \\
\qquad(f / a)\end{array}$ & $\begin{array}{r}15.2238 \\
1.5224\end{array}$ \\
\hline Dur média das falhas (d) & 1.47 \\
\hline $\begin{array}{r}\text { EENS }(\text { MWh/p) } \\
(\text { MWh/a) }\end{array}$ & $\begin{array}{r}3822.83 \\
382.28\end{array}$ \\
\hline EPNS（MW） & 0.0436 \\
\hline
\end{tabular}

Figura 7.13 - Resultados do segundo teste do Caso 7

Os resultados do Caso 7 visam, como no caso anterior, mostrar a importância do tempo de execução de uma transferência para sua efetiva utilidade.

Como recurso de manobra de sistema, a transferência apresenta algumas limitações de execução, e não faria sentido utilizar uma manobra que poderia impactar mais unidades se ela não apresentasse ganho real a operação do sistema.

Nas Figuras 7.11 e 7.12 progressivas, porém pequenas, pioras do sistema são observadas, ao aumentarmos o tempo para execução da transferência. As alterações são sutis pela escala da alteração da transferência ser realizada em horas, o que para a visão macro do sistema ainda é um intervalo pequeno. Contudo a variação da primeira configuração simulada, onde a transferência é executada em 1 hora, para a última, onde a mesma é executada em 24 horas, consegue mostrar as alterações sofridas pelo sistema em sua decorrência.

Sabendo que a transferência é executada apenas na existência de uma unidade que a substituirá em curto prazo, foi reduzido os tempos de instalação, tanto de 
unidades móveis como de unidades convencionais, com ambos em 1 dia, e sem a possibilidade de utilização da unidade móvel. Assim foi possível comparar o desempenho do sistema com essa nova configuração, o resultado está na Figura 7.13.

A configuração do segundo teste apresenta resultados melhores, pois nos momentos em que a transferência não será executada no momento da falha, por motivo de não ter unidade de reposição disponível, quando essa unidade estiver disponível seu tempo de instalação estará reduzido, causando assim melhoras nos índices.

De um modo geral os índices se comportaram dentro do esperado nos dois testes executados nesse caso.

\section{8.}

\section{Caso 8: Resultados}

\begin{tabular}{|c|c|c|c|c|c|}
\hline Unidades de Estoque Extra & 0 & 1 & 2 & 3 & 4 \\
\hline Probabilidade Ps(t) & 0.969273 & 0.976444 & 0.977803 & 0.975681 & 0.976500 \\
\hline Disponibilidade & 0.975161 & 0.978349 & 0.978903 & 0.979015 & 0.979205 \\
\hline $\begin{aligned} \text { Indisponibilidade } & (\mathrm{h} / \mathrm{p}) \\
& (\mathrm{h} / \mathrm{a})\end{aligned}$ & $\begin{array}{r}2175.92 \\
217.59\end{array}$ & $\begin{array}{r}1896.64 \\
189.66\end{array}$ & $\begin{array}{r}1848.12 \\
184.81\end{array}$ & $\begin{array}{r}1838.28 \\
183.83\end{array}$ & $\begin{array}{r}1821.60 \\
182.16\end{array}$ \\
\hline $\begin{array}{r}\text { Freq média de falha }(\mathrm{f} / \mathrm{p}) \\
\qquad(\mathrm{f} / \mathrm{a})\end{array}$ & $\begin{array}{r}14.7545 \\
1.4755\end{array}$ & $\begin{array}{r}14.7985 \\
1.4798\end{array}$ & $\begin{array}{r}14.8435 \\
1.4843\end{array}$ & $\begin{array}{r}14.7954 \\
1.4795\end{array}$ & $\begin{array}{r}14.7350 \\
1.4735\end{array}$ \\
\hline Dur média das falhas (d) & 6.14 & 5.34 & 5.19 & 5.18 & 5.15 \\
\hline $\begin{aligned} \text { EENS }(\text { MWh/p) } \\
(\text { MWh/a) }\end{aligned}$ & $\begin{array}{r}16697.49 \\
1669.75\end{array}$ & $\begin{array}{r}14125.68 \\
1412.57\end{array}$ & $\begin{array}{r}13643.68 \\
1364.37\end{array}$ & $\begin{array}{r}13506.65 \\
1350.67\end{array}$ & $\begin{array}{r}13334.55 \\
1333.46\end{array}$ \\
\hline EPNS (MW) & 0.1906 & 0.1613 & 0.1557 & 0.1542 & 0.1522 \\
\hline ́dia de aquisições no per & 15.1 & 15.1 & 15.2 & 15.1 & 15.0 \\
\hline
\end{tabular}

Figura 7.14 - Resultados do Caso 8

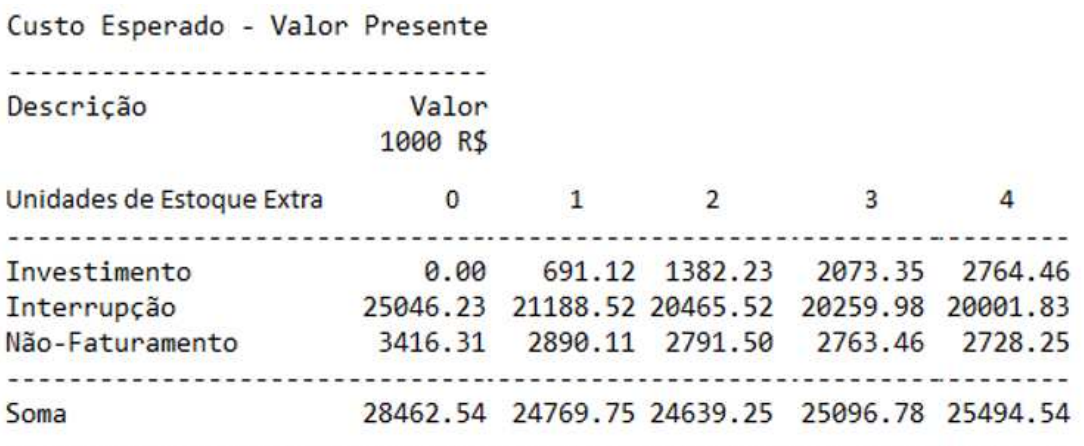

Figura 7.15 - Resultados do Caso 8 


\begin{tabular}{|c|c|c|c|c|}
\hline Descrição & $\begin{array}{r}\text { Valor } \\
1000 \mathrm{R} \$\end{array}$ & & & \\
\hline Unidades Móveis. & 0 & 1 & 2 & 3 \\
\hline Investimento & 0.00 & 3110.02 & 6220.05 & 9330.07 \\
\hline Interrupção & 25046.23 & 6967.55 & 5753.22 & 5561.05 \\
\hline Não-Faturamento & 3416.31 & 950.37 & 784.74 & 758.53 \\
\hline Soma & 28462.54 & 11027.95 & 12758.01 & 15649.65 \\
\hline
\end{tabular}

Figura 7.16 - Resultados do Caso 8

As Figuras 7.14 e 7.15 retratam os impactos pelo aumento das unidades de estoque de 5 a 9, a primeira mostra os impactos nos índices do sistema e a segunda mostra o impacto nos custos de operação e investimento. Nota-se que para esse caso são considerados acréscimos no número de estoque, e apenas os acréscimos ao caso base, com 5 unidades de estoque, são considerados investimentos.

A Figura 7.16 apresenta os resultados para os custos envolvidos na inclusão de unidades móveis, sem alteração no estoque inicial previsto. Neste caso é necessário a apresentação dos índices do sistema por se tratar do mesmo caso base do Caso 2, onde já foram apresentados os índices para a configuração com 1, 2 e 3 unidades móveis.

Em uma análise global de resultados é possível concluir que a melhor alternativa de investimento para o caso proposto é a aquisição de uma unidade móvel, que apresenta o menor custo total para o período analisado.

Este teste torna possível visualizar a viabilidade econômica da inclusão de unidades móveis na operação de sistemas elétricos reais. 